\title{
Canada Science and Technology Museum \\ Architecture as a link between Technology and \\ Natural Environment,
}

\author{
By
}

\section{Adel Mohamed Maher, Bsc.}

\author{
A thesis submitted to \\ The Faculty of Graduate Studies and Research \\ In partial fulfillment of the requirements for the degree of
}

Master of Architecture

Carleton University

Ottawa, Ontario

October 14, 2004

(C) Copyright

2004, Adel Mohamed Maher 


\begin{abstract}
I have chosen the redesign of CSTM to explore how a new facility on a new site might allow the Museum to raise awareness, develop understanding, and foster new interpretations of technology. As designer, this project allowed me to explore the dynamic relationship between architecture, site, and program. The choice of site, namely Chaudiere and Amelia islands in the Ottawa River, presented a particularly rich opportunity to explore a mutually beneficial relationship between architecture, existing industrial infrastructure, and the natural environment.

This thesis is divided into two complementary parts: 1) a brief exploration of the relation between technology and culture in the last two centuries, and 2) the design of the new museum. The site selection and design portion of the thesis is undertaken as a means of exploring potential synergies between the program and the site. In this regard, the proposed facility's relationship to its site is understood as a metaphor for the relationship between the built and natural environments.
\end{abstract}




\section{Acknowledgements}

I would like to express my sincere appreciation to my supervisor Prof. Benjamin Gianni how has guided me through this study. I would also like to extend my special thanks to my committee members, Dr. Stephen Fai, Prof. Lucie Fontein, Dr. Paul Donahue and Prof. Yves Gosselin and from the school of Architecture Dr. Greg Andonian and Prof. Ozayr Saloojee.

I want to thank the officials of Canada Science and Technology Museum and their entire staff for their input during the process and for their generosity in providing me with all the information that I needed. Similarly, I would like to thank the National Capital Commission and particularly Lori Thornton in letting me use their valuable documents for this study.

I would also like to thank Mr. Robert Vaillancourt from the City of Ottawa, Sheila Sturk-Green and Marybelle Mitchell from the Inuit Art Foundation in their support at various stages of this study.

And finally, I want to thank my Parents far away in Libya, my children and the one person who was most supportive and patient during this process, my wife Eman. 


\section{Table of Contents}

List of Illustrations. vii

List of Drawing Panels.................................................viii

List of Tables...............................................................

List of Appendices.......................................................viii

Introduction.......................................................... 1

1. Exploration of technology .......................................... 6

1-1. Technology and Canada ............................... 7

1-2. Definition of Technology ................................. 10

1-3. Evolution of thinking with respect to technology ... 12

1-4. Architecture and Technology ........................... 16

1-5. Sustainability .......................................... 19

1-6. LEED ......................................................... 22

1-6-1. Definition of LEED ............................... 22

1-6-2. Benefits and Results ............................ 23

2. The project....................................................... 27

2-1. Existing CSTM ........................................ 28

2-1-1. Building Facilities ............................ 28

2-1-2. Observations .................................. 30

2-1-3. A New vision .................................... 31

2-2. Precedents ................................................. 33

2-2-1. Definition of Museum ........................ 34

2-2-2. Ontario Science Centre .......................... 36

2-2-3. Design ........................................ 38

2-2-4. Observations ................................... 40

2-2-5. Objectives of the New CSTM................... 41

2-3. The New Location ...................................... 43

2-3-1. Confederation Boulevard ..................... 44

2-3-2. Site selection ................................. 47

2-3-3. History of the site ............................. 56 
2-3-4. Early studies for the site ....................... 61

2-3-5. Site Heritage Survey ............................. 63

2-4. Site planning ............................................. 67

2-5. The Building Program..................................... 76

2-5-1. Main building ................................. 76

2-5-2. Library building ................................... 76

2-5-3. Collection Storage and Corporate Offices... 77

2-5-4. Corporate Storage ............................... 77

2-5-5. List of Long-Term Exhibitions Areas......... 77

2-6. The New Museum Building ............................. 81

2-6-1. New program ..................................... 81

2-6-2. Entrance Pavilion .............................. 85

2-6-3. Planetarium .................................... 86

2-6-4. The Exhibition Area ........................... 87

2-6-5. The Research Facilities ....................... 88

2-6-6.The Archive .................................... 89

2-7. The site as a successful urban community .......... 91

2-8. Design Concept .......................................... 93

3. Conclusion .......................................................... 113

Bibliography …................................................ 121

Appendices ........................................................... 125 


\section{List of Illustrations}

Fig. 1. The Existing CSTM with other Institutions in the Capital City ............................................. 29

Fig. 2. Ontario Science Centre ................................ 37

Fig. 3.1. Location of the New CSTM with the National

Capital's Urban Core................................... 46

Fig. 3.2. Location of the New CSTM with other

Institutions in the Confederation Boulevard .... 46

Fig. 4. Potential Sites ............................................. 48

Fig. 4.1. Scott Paper site ....................................... 49

Fig. 4.2. Bayview Site .......................................... 50

Fig. 4.3. Chaudiere and Amelia Site .......................... 51

Fig. 5. Historical Image of the Site ............................ 60

Fig. 6. Existing Buildings on the Site ....................... 65

Fig. 7. Views from the Site ................................. 68

Fig. 8. New Site within its Urban Fabric .................... 75

Fig. 9. Site Layout ............................................. 99

Fig. 10. Ground Floor Plan ................................... 100

Fig. 11. First Floor Plan ......................................... 101

Fig. 12. Basement Layout ........................................ 102

Fig. 13.1. West Elevation from Booth Street ............... 103

Fig. 13.2. Section through the Great Hall.................. 103

Fig. 14. Entrance Pavilion Layout ........................... 104

Fig. 15. Entrance Pavilion upper levels .................... 105

Fig. 16. View of Museum toward the East ................. 106

Fig. 17. View of Museum toward the North ................ 107

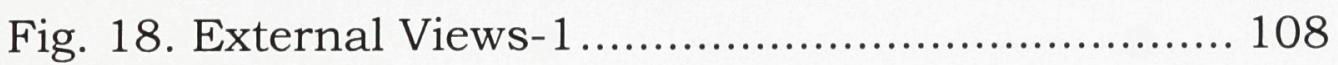

Fig. 19. External Views-2 ...................................... 109

Fig. 20. Inside the Great Hall-1 ............................. 110

Fig. 21. Inside the Great Hall-2 ............................. 111

Fig. 22. Inside the River Hall................................. 112 


\section{List of Drawing Panels}

Drawing Panel No. 1 ............................................. 116

Drawing Panel No. 2 …....................................... 117

Drawing Panel No. 3 ............................................. 118

Drawing Panel No. 4 ............................................... 119

Drawing Panel No. 5 .......................................... 120

\section{List of Tables}

Table 1. Detailed area requirement ......................... 83

\section{List of Appendices}

Appendix A: Leed project checklist........................ 125

Appendix B: History of the Ottawa-Hull Chaudiere

Industrial District ............................. 129 
Introduction

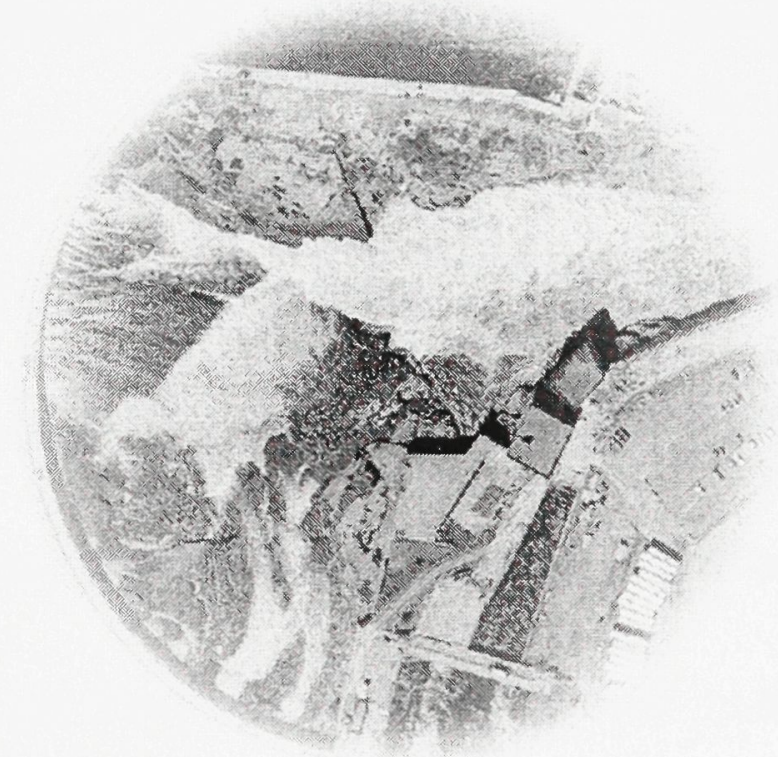


Technology has been a persistent and significant force in the progress of civilization and the fulfillment of human needs. In particular, science and technology have contributed immeasurably to the making of Canada as a country and are integral to its current economic prosperity.

If appropriately sited and designed, a new facility for the Canada Science and Technology Museum (CSTM) will reinforce Canada's strong scientific and technological legacy, will enhance the museum's potential as a leading cultural institution, and will help the museum to more effectively fulfill its mandate. Moreover, relocating the museum to a site on Confederation Boulevard will link it to key landmarks and related institutions including the new Canadian War Museum, the Canadian Museum of Civilization, and the National Gallery. In undertaking the redesign for the museum I see not only the potential to promote interaction and synergy between related national institutions, but the opportunity to develop underutilized portions of Confederation Boulevard - making spectacular views and key elements of Canada's industrial history accessible to the public. 
This thesis is divided into two complementary parts: 1) a brief exploration of the relation between technology and culture in the last two centuries, and 2) the design of the new national museum of science and technology. The site selection and design portion of the thesis is undertaken as a means of exploring potential synergies between program and site. In this regard, the building's relationship to its site is understood as a metaphor for the relationship between the built and natural environments.

I begin the written portion of this thesis by defining modern technology and observing its impact on architecture and the built environment. In the design portion of this thesis, I explore the potential for the Museum's new facilities to become a source of inspiration -- to elicit an emotional response from its visitors while promoting new attitudes toward technology and the environment. I see the museum as a vehicle for raising awareness of the promises, potentials and pitfalls of science and technology in our quest to ensure a better future both for Canadians and for humankind as a whole.

The selection and manipulation of the site was the key element in 
setting the design concept. The island site I chose for the Museum presents a collision of geologic and aquatic landscapes and presents a perfect laboratory to explore the use and conservation of natural resources. The site also possesses significant historical industrial artifacts. Together, these features will help the Museum to showcase the role of the natural environment and of our industrial culture in relation to science and technology.

From an urban perspective, the location of the new museum will contribute to the ongoing re-vitalization of the National Capital's urban Core. Situated as it is on both sides of the Ottawa River, the ceremonial route of the National Capital Region engages natural landscapes and culture in a rich dialogue. The new CMST - both as a building and as an institution -- can promote, strengthen and embody this dialogue.

Where precedents are concerned, I found inspiration in the Ontario Science Centre in Toronto - especially with regard to its use of a "difficult" site. It provided a benchmark example of a successful interaction of a building, program and site, and supported the proposition that the natural environment could be exploited to create a powerful work of architecture. 
The main contribution of this work is an exploration of how the appropriate building on the appropriate site might demonstrate how science and technology might be reconciled with environmental ethics and cultural values to deepen our understanding of technology. By examining the design of the CMST, the thesis attempts to suggest solutions, or more accurately, present positive responses to the dilemmas posed by technology. 
1. Exploration of technology

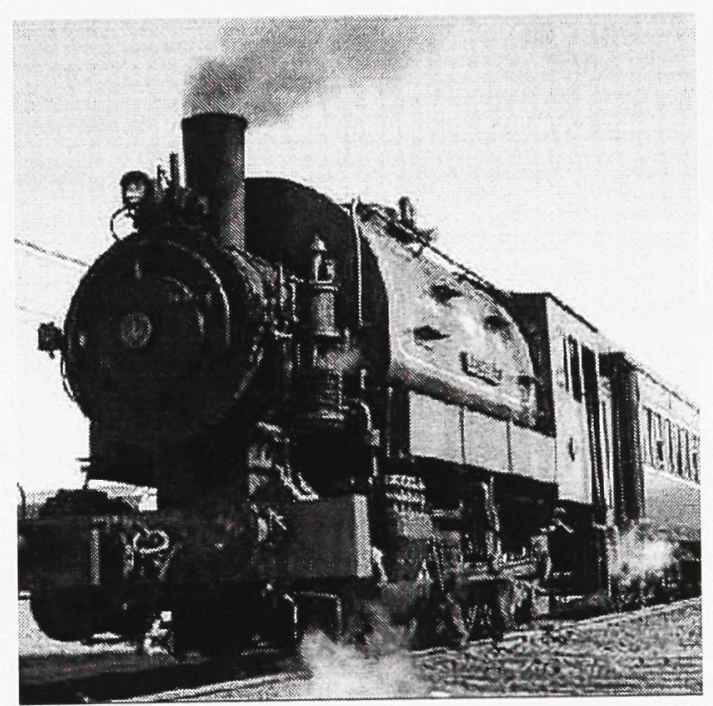




\section{1-1. Technology and Canada}

Modern technology has played a key role in the formation of Canada

-- a nation with a harsh and vast geography, a cold climate and limited manpower. From the time of the early explorers, modern technology was inextricably bound up with life in Canada. It has contributed to the models, norms, and ideas that affect the way Canadians view the world.

Technology has had far-reaching consequences in the shaping of cultural and social structures in Canada. It has helped to bridge gaps between cultures, promoted economic development, and increased productivity. Transportation and telecommunications have played a particularly important role in nation building - helping Canada to bridge the vast distances between the east, west and north. Transportation and telecommunications technologies were not only integral to the emergence of Canada as a country, but continue to keep it together and maintain it as its present level of economic prosperity.

Transportation: As a nation Canada faces the challenge of a relatively small population distributed across a diverse and often 
inhospitable landscape. The railway played a unique role in the birth of Canada - tying together the country and opening up vast tracts of land west of the Great Lakes. Trains transported troops, settlers and materials westward. Rail lines made accessible the huge stretches of forests, prairies, and mountainous terrain of Canada, which, in earlier times, would have been impossible to connect.

The growing number of snowmobiles in the arctic region of Canada provides us with a particularly poignant example of rapid change in the way of life. ${ }^{1}$ The move from traditional dog and reindeer sleds to mechanized means of transportation in order to cross the snowfields of the Canadian arctic has had far reaching consequences on the range of social contact and other life-preserving actions such as emergency medical services. New transportation technologies have also contributed to the number of economic choices for aboriginal people.

Telecommunications: Telecommunications have also helped the nation to overcome the obstacles of distance, permitting remote

1 Bernard, H. Russell, and Pelto Pertti. Technology and Social Change. Prospect Heights, Ill.: Waveland Press, 1987. 
communities to access services taken for granted in large urban centers. Telecommunications has become and integral part of economic and political infrastructure of Canada. ${ }^{2}$

Although, Canada's economy has its roots in colonialism, relying heavily on the export of its wealth of natural resources, the 20th century transportation and communications technologies have helped to transform the nation from a largely rural economy into a modern and technologically-advanced society. ${ }^{3}$

Given the role of science and technology in the making of Canada, the Canada Science and Technology Museum has the potential to become the premiere museum for the interpretation of modern Canadian history.

2 Goyder, John. Technology and Society: A Canadian Perspective. Peterborough, Ont.: Broadview Press, 1997.

3 The Wikimedia Foundation Inc. Encyclopedia. Canada. 10 Aug. 2004 <http://www.campusprogram.com/reference/en/wikipedia/c/ca/canada.html> 


\section{1-2. Definition of Technology}

[Greek] tekhnologia systematic treatment, from tekne art, craft (1) the branch of knowledge that deals with the mechanical arts or applied sciences; a discourse or treatise on (one off these subjects, on an art or arts. The terminology of a particular subject, technical nomenclature. (2) The mechanical arts or applied sciences collectively; the application of (any of) these. A particular mechanical art or applied science (3) A discourse or treatise on an art or arts', the scientific study of the practical or industrial arts. A description of Arts, especially the mechanical (4) Transfer Practical arts collectively (5) A particular practical or industrial art (6) ${ }^{4}$

The term "technology" is derived from the Greek words tekhnē, which refers to an art or craft, and logia, meaning an area of study. Thus, technology means, literally, the study or science of making. Modern historians and social scientists define it more simply as the application of power machinery to production, locating its beginnings in 18 th century England. ${ }^{5}$ But the meaning is not limited to machinery or techniques; it ranges from craft to concept and, at the limit, is a term for knowing in the widest sense.

4 The Oxford English Reference Dictionary. Oxford: Oxford University Press, 2002.

5 Grant, George. Technology and Justice. Toronto: House of Anansi Press, 1986. 
Technology is inextricably linked to human activity; it is a key agent of social development. Technology creates a relationship between the means and ends, between the utilization of tools and the needs and ends they serve. ${ }^{6}$ It can also privilege the product over the means of production - to the detriment of the individuals who make and use the products produced. Both tools and people are integral to the production process and, as such, are subject to the effects of technology.

Technology has provided us with the intellectual and physical capacity to effect dramatic changes and has powered the development in all fields. Technology must now be directed toward solving social and ecological problems (some of which it has created) rather than be treated as neutral and/or an end in itself.

We ask the question concerning technology when we ask what it is. Everyone knows the two statements that answer our question. One says: Technology is a means to an end. The other says: technology is a human activity. The two definitions of technology belong together. For to posit ends and procure and utilize the means to them is a human activity. The manufacture and utilization of equipment, tools, and machines, the manufacture and' used things themselves, and the needs and ends that they serve, all belong to what technology is. The whole complex of these

6 Heidegger, Martin. The Question Concerning Technology and Other Essays. Trans. William Lovitt. New York; London: Harper and Row, 1977. 
contrivances is technology. Technology itself is a contrivance - in latin, an instrumentum. The current conception of technology, according to which it is a means and a human activity, can therefore be called the instrumental and anthropological definition of technology. ${ }^{7}$

\section{1-3. Evolution of thinking with respect to technology}

Technology is closely linked to culture and includes peoples' attitudes towards it. Attitudes, in turn, reflect changing scientific understanding, changing knowledge about the world, and evolving ideas about technology itself. While technology has been present in human experience and has been a fundamental agent of social development, it has only recently entered popular consciousness and debate.

Humankind has undergone several major transformations related to technology. Before the rise of agriculture most people lived in tribes and small groups dependant upon hunting, fishing, and herding. Early civilizations grew up around agricultural work which spread slowly, depending upon the availability of water. During this era, human societies

7 Ibid. 
harnessed energy from other humans (slaves), animals, and by cutting forests to provide fuel for cooking and heating.

The relationship between humanity and nature in the pre-industrial period was one of opposition and conquest, in which human beings sought to subjugate nature. ${ }^{8}$

Religion factored significantly in the way in which people viewed nature. Humans were able to claim dominion over nature to the extent that they understood the nature of other creatures, knew God and were able to attain divine love. This view promoted the existence of human beings as the ultimate possessors of the globe and viewed nature as a place to fulfill and support human activities. It has, over time, led to the degradation of nature and the devaluation of other creatures.

Secularism, from the Renaissance through the Industrial Revolution, paved the way for progress in science and technology, and gave rise to the view that nature operates according to a number of almost ungraspable complex interrelated systems in which human being are

8 Kurokawa, Kisho. Each One a Hero: The Philosophy of Symbiosis. Trans. Jeffrey Hunter. Tokyo; New York: Kodansha International, 1997. 
included. 9

Modern technology has greatly accelerated the rate of progress and changes in lifestyle over the last two centuries. Providing the world with convenience, comfort and speed, technology has altered our interests, the things we think about, the character of our symbols and the nature of our communities.

During this same period, however, technology has led to several critical setbacks in our pursuit of civilization. Human activity has been responsible for global environmental crises that have compromised our relationship to nature. While the age of industrialization revolutionized life in a very short time, it draws its energy from the earth's reserves including coal, gas, and oil based on the assumption that cheap fossil fuels will be endlessly available and that the extraction of these resources will have an insignificant effect on humankind and on the environment.

We have lived for some time now secure in the assumption that we are entitled to all the benefits of technology as long as someone less powerful puts up with the costs. This creates a strange schizophrenia in which our

9 Hagan, Susannah. Taking Shape: A New Contract Between Architecture and Nature. Oxford; Boston: Architectural Press, 2001. 
ideal is to consume sanitized versions of both nature and technology. That is indeed what the richer folk and nations get: a false and incomplete experience of both nature and technology while others suffer the consequences. ${ }^{10}$

10 Van Der Ryn, Sim and Cowan, Stuart. Ecological Design. Washington, D.C.: Island Press, 1995. 


\section{1-4. Architecture and Technology}

Modern architecture and technology are interconnected and reflect contemporary culture. The International Style which became, for a time, synonymous with modern architecture, was an expression of modern technology and norms of the industrial revolution. ${ }^{11}$ The ideology of the industrial revolution was simplicity, function and economy. It has led to economic development and increased productivity.

Architecture was influenced by rapid and drastic economic, social and cultural changes that took place in the west during the Industrial Revolution. Adopting innovative mass production techniques resulted in the rapid growth of cities and in economic prosperity in the 19th century. New means of transportation and large-scale infrastructure projects were launched to meet this expansion and the increasing demands of the public. ${ }^{12}$

11 Kurokawa, Kisho. Each One a Hero: The Philosophy of Symbiosis. Trans. Jeffrey Hunter. Tokyo; New York: Kodansha International, 1997.

12 Ibid 
The Twentieth Century witnessed the elaboration of construction systems and the development of new building materials. The use of reinforced concrete and steel frame construction together with air-conditioning and elevators meant buildings rose higher and had larger floor plates. Generally this form of architecture (especially the sprawl encouraged by widespread road infrastructure) took little notice of the environment or the need for conservation and sustainability.

In the late twentieth century, there is a deep desire to regain a balance between culture and nature, to put certain pernicious technologies back in the bottle, and to question every aspect of the contemporary landscape. We cannot do this without making bridges to the ecological wisdom inherent in the practices of traditional cultures.

Nature is not a model for designs that are then kept rigidly apart in a purely cultural realm. Nature is a matrix within which designs find an identity and a coherence that contribute to the health of the hole. Ecological designs are articulated within an ecosystem or bioregion in the way veins are articulated within a leaf. They fill out an existing structure in a way that enhances the life, the flows, and the processes within it. ${ }^{13}$

At the threshold of the 21 st century, an accumulation of knowledge and experience has helped to transform our understanding. Our vision

13 Van Der Ryn, Sim and Cowan, Stuart. Ecological Design. Washington, D.C.: Island Press, 1995. 
now embraces a concern for the natural environment and an interest in developing better ways to sustain its vitality and conditions. 


\section{1-5. Sustainability}

Sustainable development is defined by the World Commission on Environment and Development in 1987 as meeting "the [human] needs of the present without compromising the ability of future generations to meet their own needs."

A sustainable society is a society that can persist over generations, and act responsibly towards its physical context and its systems social of support. ${ }^{14}$

Sustainability concerns the present and the future. A sustainable architecture supports the existence of humanity without destroying its environmental or compromising the cultural context.

As an approach towards the environment, sustainability considers both the natural and the built environments. The natural environment has suffered greatly from the industrial and waste management practices.

The contemporary built environment is, in large part, a result of the

14 United Nations Economic Commission for Europe. Guidelines on Sustainable Human Settlements Planning and Management. New York and Geneva: United Nations Publications, 1996. 
industrial revolution and reflects the progress of technology. The built environment includes all levels of urban and architectural design and should be sustained by practices that do not advocate a return to primitive life conditions. Sustainability is about understanding our conditions, and developing as communities in ways that make sense -- ecologically and economically.

The concept of sustainability considers a totality of inter-related issues and phenomena - including social and cultural characteristics of humankind. Totality emphasizes relationships rather than pieces in the connections between natural environments, human communities, and the cultures and contexts in which that relationship is articulated. ${ }^{15}$

The meaning of the environment, part of our social and cultural background, is an important aspect of our perception and experience of the environment. As a philosophy, sustainability implies an acknowledgement that we are part of a larger living system that comprehends both the built and natural environment. Our architecture

15 Mahgoub, Yasser. Planning for Sustainable Development. International Conference on Urbanization and Housing, 1997. 
reflects the philosophy of our time and the way we think about society. It is, therefore, not just a question of leveraging innovative technologies for heating and cooling, and/or the use of "environmentally appropriate" materials. The way we think about and approach the design of our communities must be rehabilitated.

If the techniques and technologies associated with industrialization were unsustainable, a new generation of scientists, politicians and philosophers can redefine technology. In its rehabilitated form, technology would promote better ways of living, new values, and a heightened awareness of our communities, our environment and the planet at large. 


\section{1-6. LEED}

While a variety of mechanisms (including building codes and thermal performance standards) have been used to regulate and mitigate the environmental impact of buildings, a new comprehensive rating system has emerged in the last decade (in the U.S.). The LEED ("Leadership in Energy and Environmental Design") system attempts to look at buildings as networks of interrelated environmental impacts and rates them according to a Green Building rating system. The program realizes that decisions made in the design phase of a building will affect its performance and impact on the environment over its entire life span. ${ }^{16}$

\section{1-6-1. Definition of LEED}

As a voluntary rating program, LEED represents the U.S. Green Building Council's effort to develop a national standard for what constitutes a "green building." The goal is to improve environmental

16 U.S. Green Building Council. LEED Reference Guide Version 2.1. Washington, DC: U.S. Green Building Council, 2002. 
performance and long-term economic returns of buildings using both established and innovative practices, standards and technologies. ${ }^{17}$

\section{1-6-2. Benefits and Results}

Sustainable building design provides environmental and economic benefits; it also protects the health and well being of building residents. Studies have shown that sustainable design actually improves productivity in the workplace. LEED addresses climate change directly by rewarding and encouraging energy efficiency. It also addresses climate change indirectly by encouraging material choices and construction practices that minimize the consumption of resources and energy. ${ }^{18}$

LEED is a credit-based system. Its sixty-nine credit points are divided among six environmental impact areas as follows:

17 Ibid

18 The Green Engineer. Christopher, Schaffner. 9 Sept. 2004. <http://www.greenengineer.com/Leed.htm> 
1. Sustainable Sites

2. Water Efficiency

3. Energy and Atmosphere

4. Materials and Resources

5. Indoor Environmental Quality

6. Innovation and Design Process

In order to earn a LEED certification a minimum of 26 points must be achieved. A Silver rating requires between 33 and 38 points, Gold between 39-51, and Platinum between 52 and 69 points.

As a standard, LEED addresses the many environmental impacts associated with buildings - and, by extension, with the building industry. LEED criteria are, however, often independent of each other (some mutually exclusive) and may result in poorly integrated solutions. Also the standards may not reflect environmental impacts consistently - potentially challenging the vision of sustainability as a holistic and integrated approach to design. While the LEED rating system encourages the use of technologies and strategies that improve energy efficiency and reduce environmental impacts, they make no allowance for aesthetic and 
functional considerations that affect the user's experience of the building.

In this sense, while sustainability as a paradigm is comprehensive and attempts to balance all aspects of decision-making, LEED privileges the technical over the aesthetic.

I do not believe that the Museum's desire to attain a platinum LEED certification for the new facility will necessarily compromise the architectural integrity of the design, but, the building's ability to engage the diverse natural environments on its site transcends what can be described by LEED. Sustainability cannot be reduced to a collection of best practices that reduce environmental offenses - although a list of measurable standards can be helpful.

I believe that the Museum of Science and Technology has an important role to play in promoting new values, attitudes, and sustainable approaches to the way we think about our environment. As a major federal institution, it has the potential to "institutionalize" a new vision of technology and promote a better understanding of man's relationship to the environment. Given the appropriate site and facility to complement its collection, the museum can be a vehicle to foster awareness of the 
relationship between technology and contemporary social issues.

In the following part, through the design of a new museum of science and technology for Canada, this thesis will explore and analyze the potential of the architecture of the museum to evoke new interpretations of technology and to promote environmental responsibility. 
2. The project

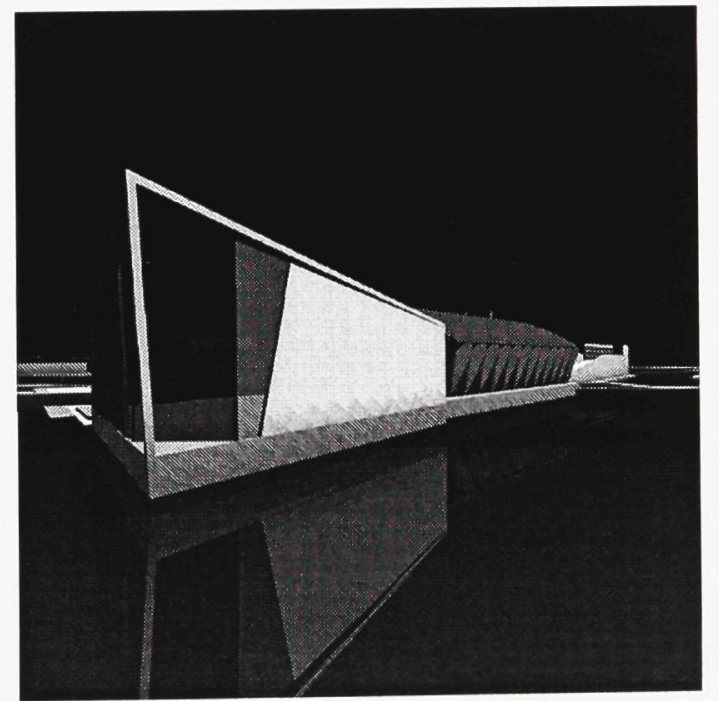




\section{2-1. Existing Canada Science and Technology Museum}

\section{2-1-1. Building Facilities}

Location: St. Laurent Boulevard, Ottawa, Ontario

Site area: 24.6 acres

Total floor area: $34,500 \mathrm{~m}^{2}$

The building occupied by the existing Canada Science and

Technology Museum was built as a distribution centre for Morrison Lamothe Bakery Limited, although it was never actually used as such. The facility was leased to the Federal Government in 1967 and converted to its current use. An addition was constructed on the north side circa 1967 for the locomotive display area. The Crown purchased the facility in the early 1990s and the Museum Corporation obtained custody in 1993.19

19 Provencher Roy + Associés Architects. The Arcop Group. Feasibility and Functional Studies. Canada Science and Technology Museum, 2003. 


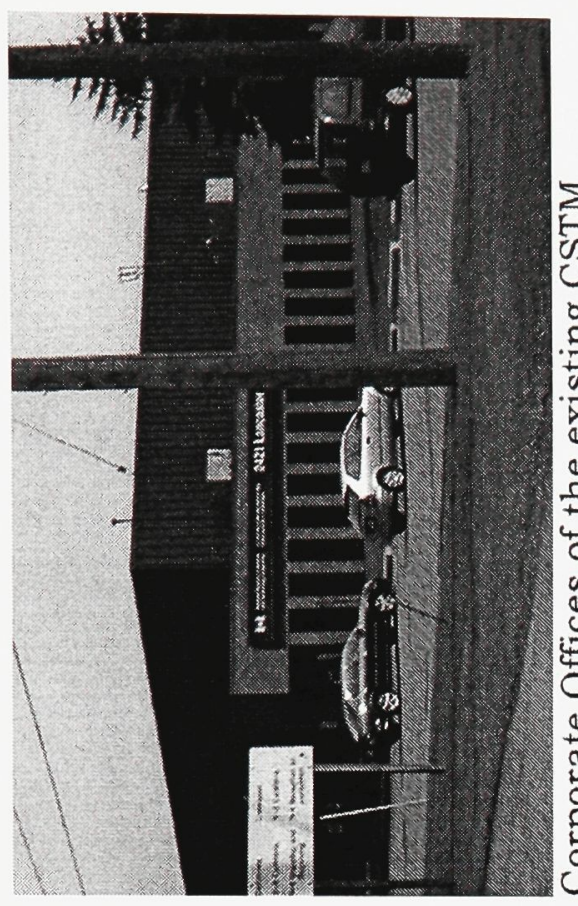

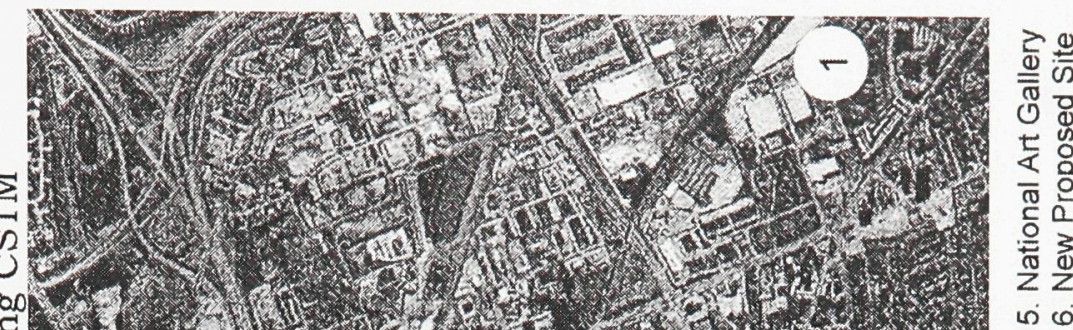

F.

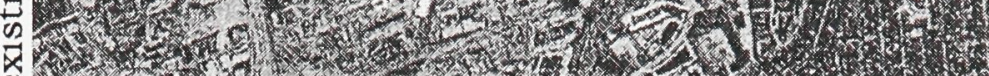

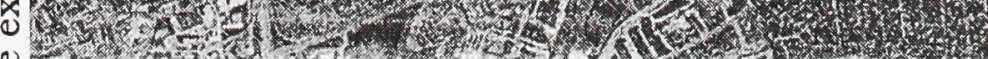

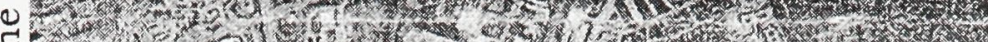

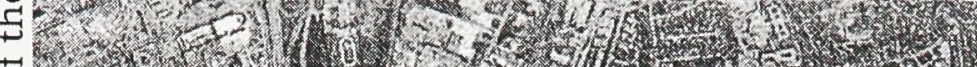
o.t.

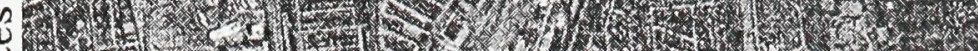

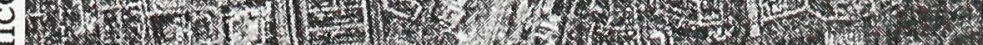
(1)

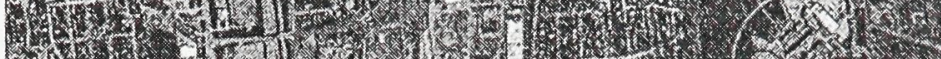

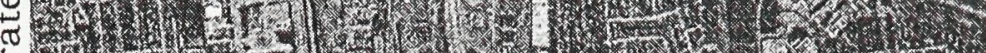

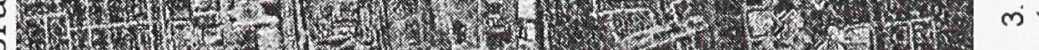

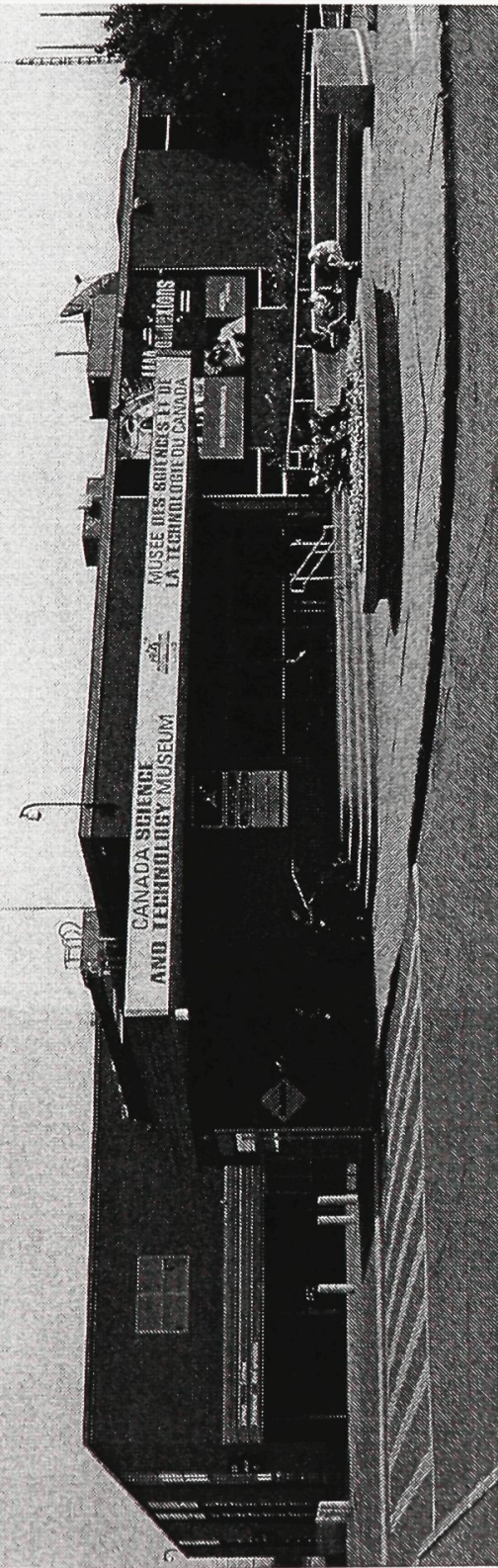

ô. 2.

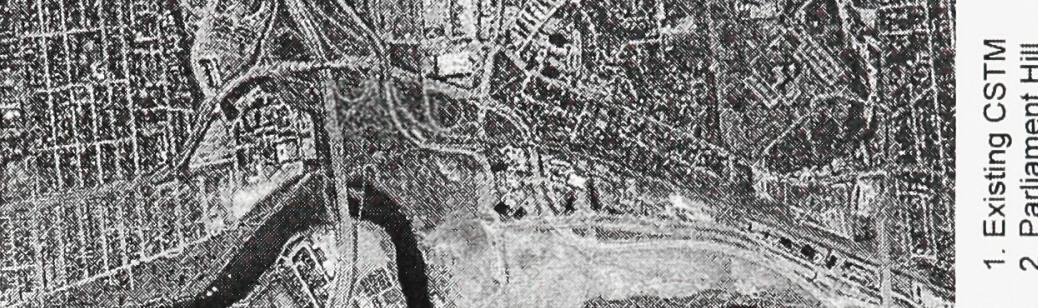

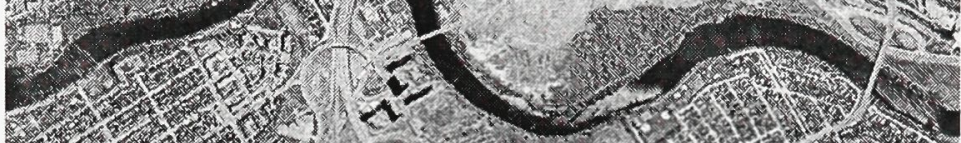
2.7.

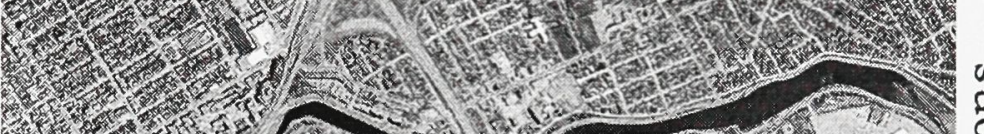
1.7.

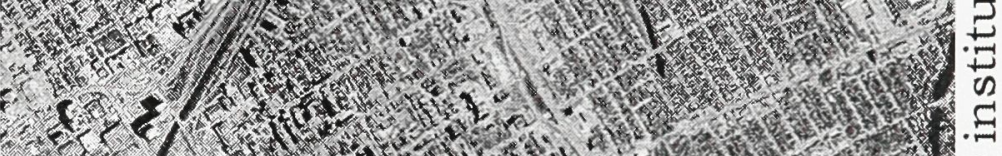
E.

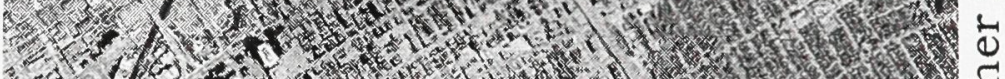

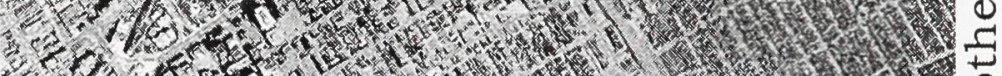

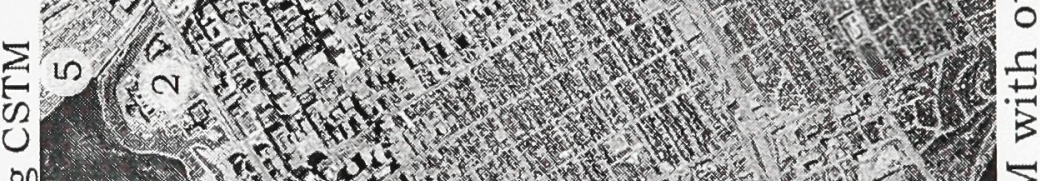

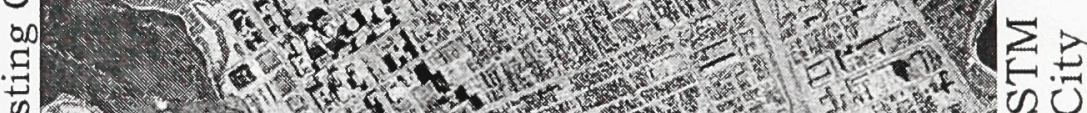

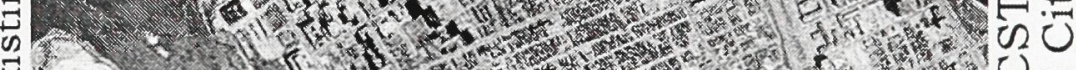

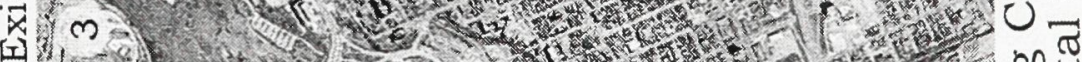

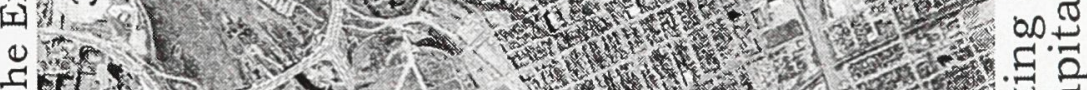

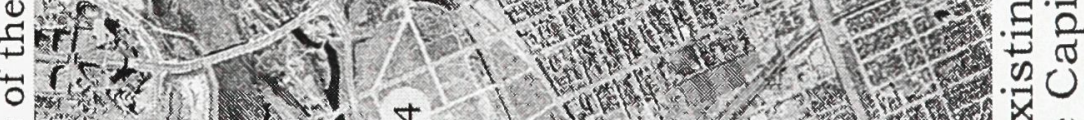
o.k.

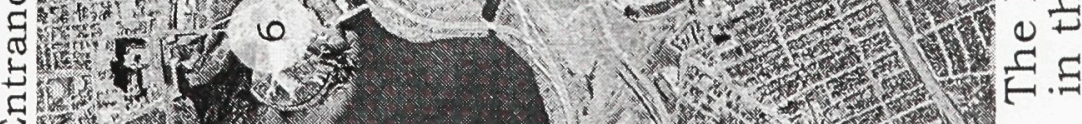

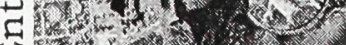
[工凡 


\section{2-1-2. Observations}

The present location and facilities of Canada Science and Technology Museum (CSTM) does not help it meet its potential as a leading cultural institution, nor does it help the museum effectively fulfill its mandate.

Its location far from Confederation Boulevard and other, related museums, institutions and tourist attractions constitutes a major disadvantage. Neither the external image nor the interior spaces of the facility help the institution meet its architectural and environmental potential. The architecture of the facilities neither links to the theme of science and technology nor provides a landmark commensurate with the profile of a National Museum of Science and Technology.

\section{2-1-3. A New vision}

A feasibility study was undertaken for a new Canada Science and Technology Museum by "The Arcop Group" in 2003 with the purpose of defining a vision to guide the museum's development. The Feasibility and 
Functional Study evaluated the existing facilities of the CSTM, identified the future orientation, developed an optimal functional program and budget model, and recommended a new site for which it outlined a master plan for the new CSTM. ${ }^{20}$

The findings and recommendations of this study reinforced the following points:

1. The existing CSTM cannot meet the functional and operational standards appropriate to the national science and technology museum.

2. The "Phased Vision Model" is the appropriate way to proceed, beginning with a Phase I project for a facility of $90,000 \mathrm{~m}^{2}$.

3. Phase I will be able to handle projected artifacts storage for approximately 15 years, while Phase 2 will bring storage capacity to a 25 years horizon.

4. It is recommended that the new CSTM be built on the extended Bayview Site, spanning the existing CP Railway line. 
5. Assuming the immediate start (2003) of the negotiations for funding and land acquisition, the projected completion date for the new CSTM would be 2008/2009.

In addition, the Arcop report reinforced the objective of attaining a LEED (“Leadership in Energy and Environmental Design”) platinum rating for the new facility. The LEED rating system has been gaining acceptance recently as a measuring tool for sustainable building. As mentioned in the first part of this study, it identifies objectives that address energy efficiency and reduce the impact of the building on the environment.

I believe that the Science and Technology Museum has an important role to play in promoting sustainability (by example) and that the architecture's ability to engage this issue should not be limited to LEED. 


\section{2-2. Precedents}

Canada enjoys a number of excellent Science and Technology centers. In addition to the CSTM in Ottawa, facilities can be found in Calgary, Vancouver, Nova Scotia, Toronto, Saskatchewan and Sudbury. The CSTM is, unfortunately, the least distinguished of all these centers from an architectural point of view because neither the site nor the design of the facilities reinforces the themes of science and technology. Landmark architecture, in conjunction with a new location (in proximity to other national museums in Ottawa), would raise the profile and enhance the potential of the CSTM. Despite this fact, the CSTM is the largest of its kind in Canada, with its ongoing collection over 1,000,000 items, and is highly valued for its comprehensive depiction of Canadian achievements and innovations in Science and Technology. ${ }^{21}$

21 Provencher Roy + Associés Architects. The Arcop Group. Feasibility and Functional Studies. Canada Science and Technology Museum, 2003. 


\section{2-2-1. Definition of Museum}

According to the Museum Association (UK) 1984, the typical definition of the museum is an institution with a public objective, which collects, documents, preserve, exhibits and interprets material evidence and associated information for the public benefit. ${ }^{22}$

Science Centers are not classed as museums, as they do not have historical collections. Their role is to present science to the general public in an informative and enjoyable manner. They are environments for informal learning, striking a balance between education and entertainment.

The number of science centers and museums in North America has grown significantly in the past two decades. While many of these centers focus on a specific area, such as geology or ecology, others, like the Ontario Science Center, address science broadly. Few of these institutions are categorized as museums and/or are combined museums and science centers like the CSTM. One such example is the Science Minnesota

22 Matthews, Geoff. Museums and Art Galleries: A Design and Development Guide. Oxford; Boston: Butterworth Architecture, 1991. 
Museum, which is both a museum of natural history and interactive science center. While there are strong similarities between most science and technology centers across North America (they are all committed to fostering scientific and technological literacy through their exhibition programs), what distinguishes the CMST in Ottawa is its focus on Canada and its extensive collection of artifacts - including a rich collection of large-scale locomotives.

Although, I did not have the opportunity to visit many of the numerous science and technology centers in Canada and the US, I have explored most of them through images and written materials. The project that inspired me the most (and which I did manage to visit) was the Ontario Science Centre in Toronto. I examined this project as a case study because, among other reasons, the design of the museum exploits its site in a compelling and successful manner. The architect capitalized on the characteristics of the site to express the role of architecture in linking the natural environment positively with science and technology. Indeed it is the potential to do just this that provided the motivation for my thesis. 


\section{2-2-2. Ontario Science Centre}

Raymond Moriyama was awarded the design of the Science Centre in 1964. ${ }^{23}$ The site, selected prior to the commissioning, is at the geographic centre of Metro Toronto -- about ten minutes by car from downtown Toronto and easily accessible from main highways and arterial roads. It is part of the 180 acre Don River conservation area, which is in the process of being developed into Ernest Thompson Seton Park. Of the 180 acres, only about ten acres are flat; the remainder if the site is either on the valley floor or on the slopes. The difference in elevation between the top of the site and the valley floor was $27 \mathrm{~m}$. In the event of a storm equal to Hurricane Hazel, the valley floor would be completely flooded.

Despite these difficulties, the designer considered the site to be beautiful and to offer significant potential.

23 The Ontario Science Centre. First Ten Years: A History of It's Founding. The Ontario Science Centre, 1979. 


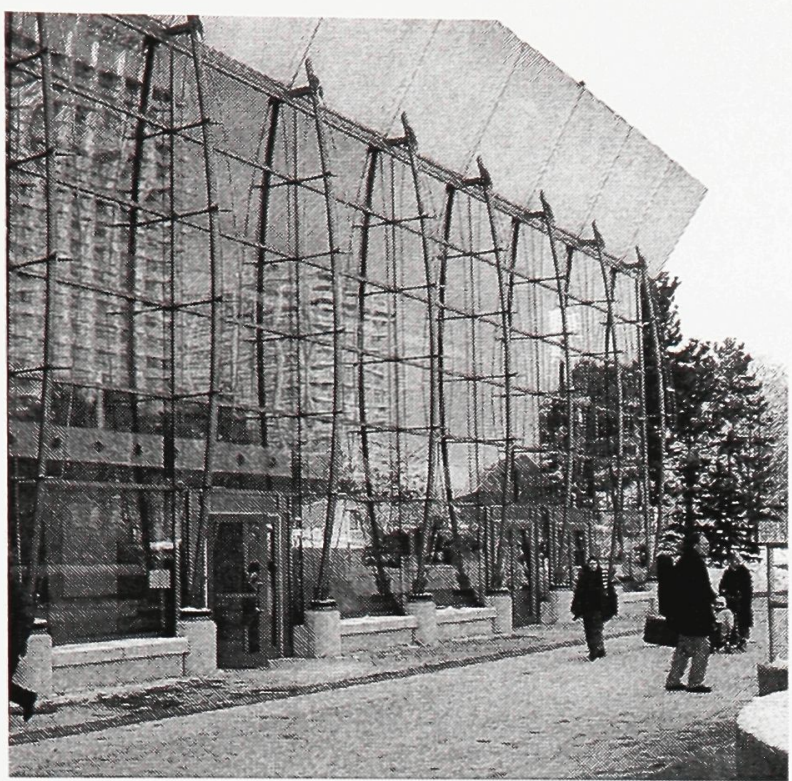

The rectangular Reception Building
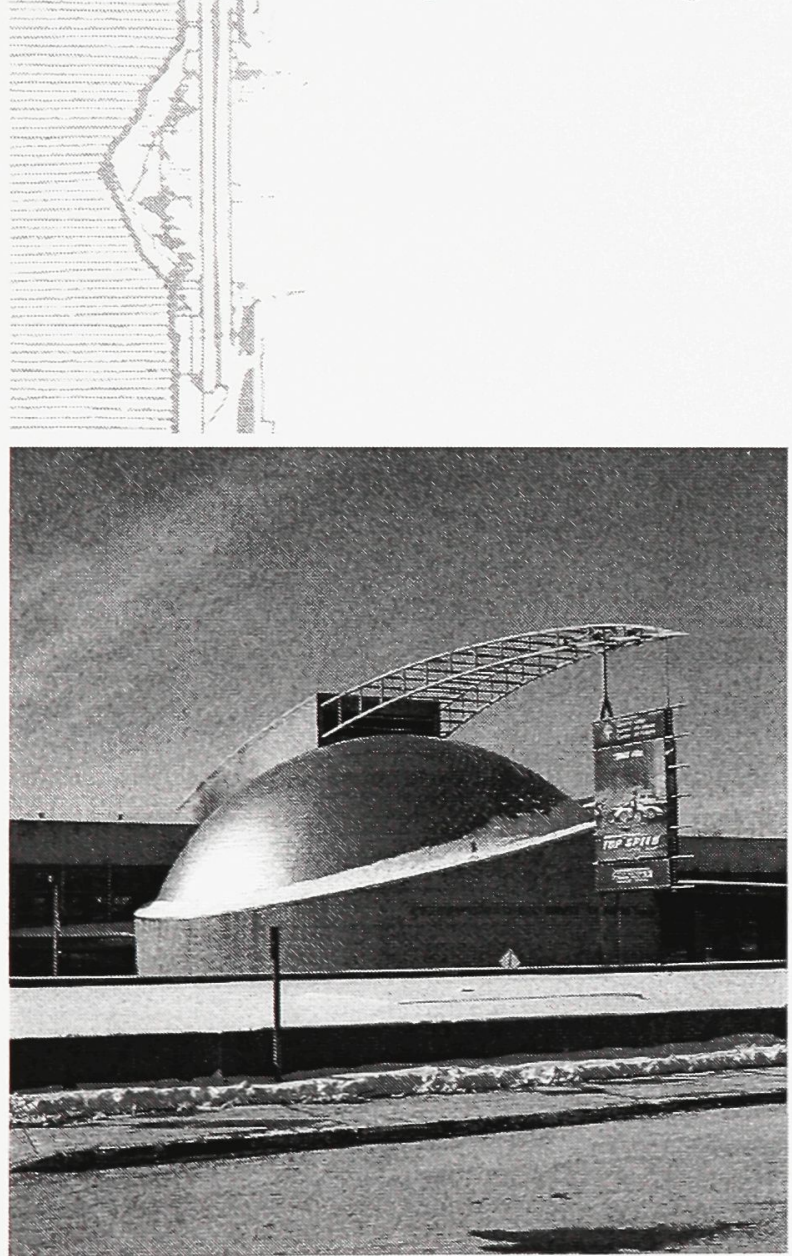

The Planetarium, accommodated by the Reception Builsing

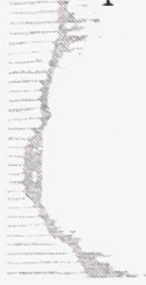

Fig. 2 Ontario Science Centre

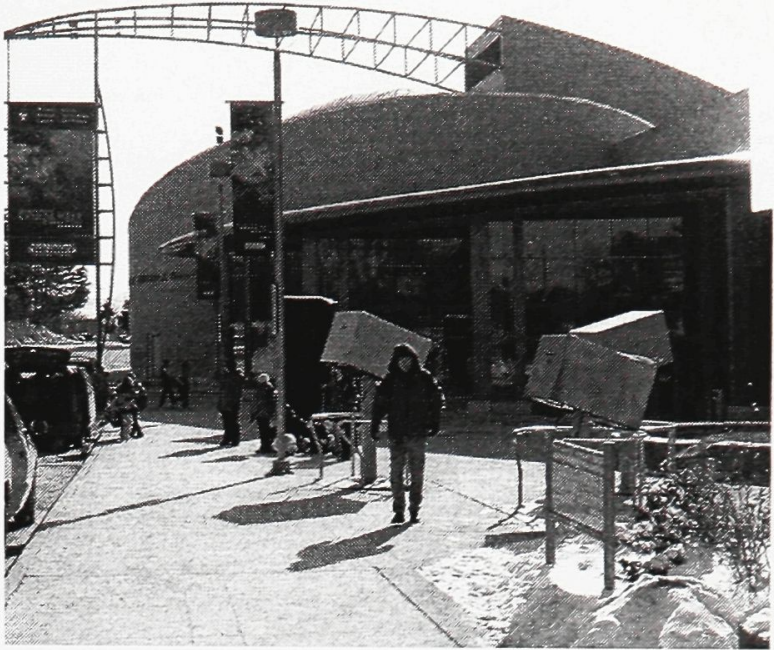

Main Entrance placed on a ridge, at the top of the site

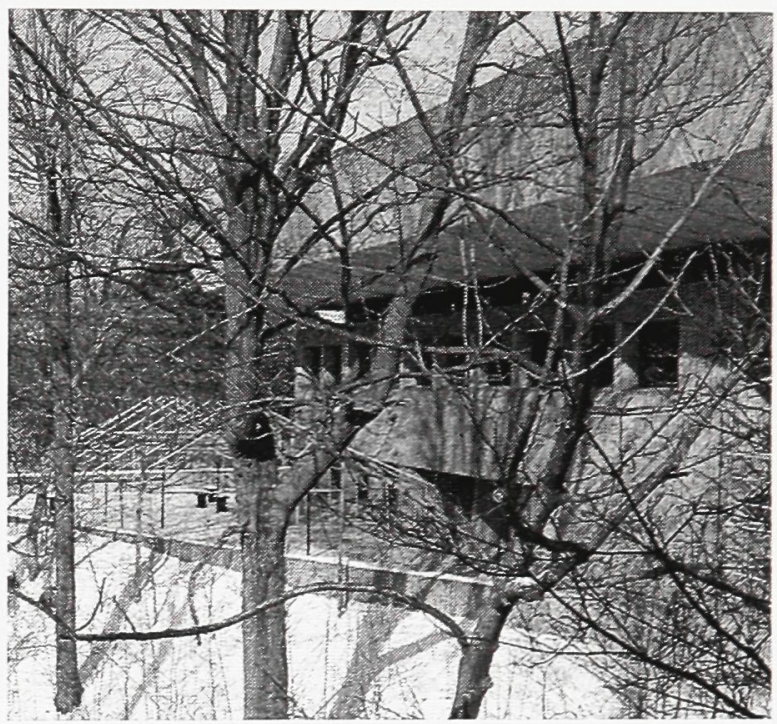

Back of the Reception Building sits on a natural plateau

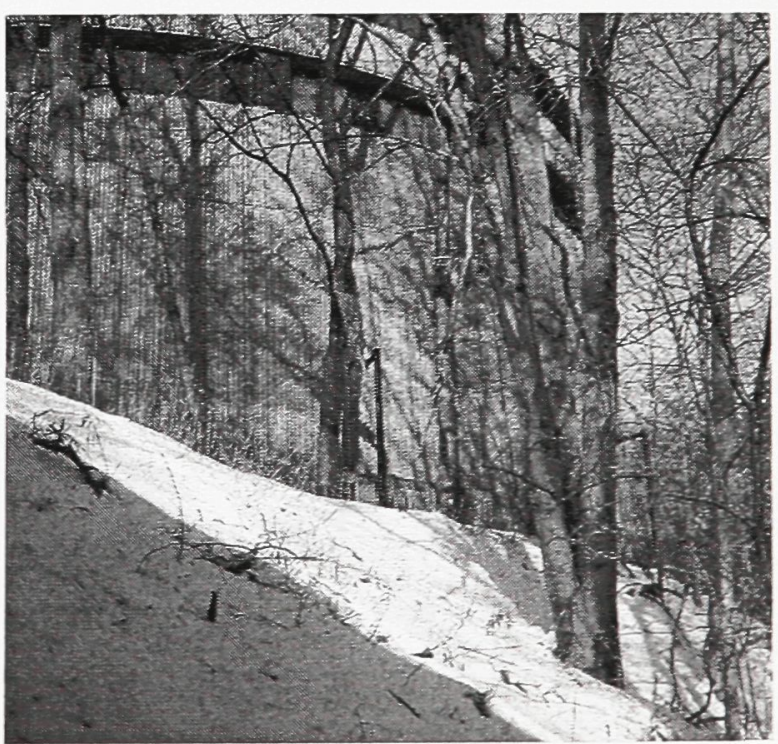

Tower Building, sits at the top of the valley 


\section{2-2-3. Design}

Moriyama's design distributes the various components of the facility down the hillside and into the valley, placing the entrance on a ridge, at the top of the site. His approach to landscaping was simple: "Touch the least; enhance whatever is there." The design concept is based on the Japanese character for the heart, which forms the essence of the design of most Japanese gardens. ${ }^{24}$

The Ontario Science Centre is planned as a complex of three buildings organized on three levels. Textured concrete walls give the exterior facades an impression of rugged strength. The rectangular Reception Building sits on a natural plateau, fronted by a $120 \mathrm{~m}$ ornamental pool whose one-hundred jets not only symbolize Canada's Centennial but serve a practical purpose as part of the air-conditioning system. From the Reception Building, visitors cross a bridge that offers a tree-top view of the wooded gully below. The bridge symbolizes a passageway "from the mundane to the marvelous," and leads to the 
triangular Tower Building, which sits atop the only knoll in the valley. The high ceiling and glass walls evoke a sense of openness and offer panoramic views of the Don Valley.

Moriyama wrote "Symbolically, our ideal can be represented by three interlocking circles - man, science, and nature - as natural as water, land, and air. The fact that it resembles a trillium, the logo for the province, is interesting and a definite plus". ${ }^{25}$

The Valley Building is located $27 \mathrm{~m}$ below the entrance, on the valley floor. It was designed with huge halls for exhibits, workshops for constructing exhibits, and laboratories for scientific research and education programs.

Moriyama was especially concerned about meeting the needs of the public. From his discussions with psychologists, he concluded that, "an average man can absorb only about 900 square meters of detailed man-made exhibits before his mind refuses, to function." The exhibit areas were therefore broken up his into blocks of this size, and separated 
by places where visitors could collect their thoughts, orient themselves, or simply relax. ${ }^{26}$

\section{2-2-4. Observations}

The Science Centre is a conceptually outstanding piece of work which incorporates the interpretation of the site as a key part of its program. It is apparent that the designer took advantage of the steeply sloped, forested and rocky site to create interesting exterior and interior spaces. I was fascinated by the unique architectonics of the place. The complex provided a paragon of the lessons of working in tandem with landscape to create architecture. My study and subsequent visit to the Science Centre reinforced the role of the natural environment in the human realm of science and technology. It heightened my awareness of the potential of what might be considered "difficult" sites to create a dialogue between the natural and the man-made worlds.

For my own design proposal I found that the natural characteristics

26 Ibid 
of the site can be leveraged to augment the program of the museum.

\section{2-2-5. Objectives of the New Canada Science and Technology Museum}

I met with the staff of the CSTM to better understand their goals and aspirations for a new facility. Like most museums, the CSTM has a mandate to collect, document, preserve, exhibit and interpret material artifacts and associated information for the public benefit. Beyond this, however, staff described their vision of the museum as a place to impart knowledge, encourage curiosity, contribute to learning, raise consciousness, and to evoke less tangible experiences such as of the joy of discovering new things with others. The goal is to arouse curiosity, to infuse the visitor with ideas through active participation, and to combine emotional experience with intellectual satisfaction.

The generous input and information provided by staff at the CSTM reinforced that the architecture of the new museum should be an integral part of the institution and its mandate. More broadly, the architecture should help visitors both to interpret the past and to envision a better, 
more responsible future. The new facility should promote a balanced relationship between the environment and culture rather than being overly institutional or monumental. 


\section{2-3. The New Location}

As noted, the site of the new Science and Technology Museum has the potential to play a major role in its overall success. Re-locating the CSTM to the core of the National Capital Region would greatly increase its visibility/profile, help it to better meet its mandates, increase attendance, and more effectively represent Canada's strong scientific and technological legacy.

The Smithsonian complex in Washington D. C. provides an example of how national science and cultural institutions can be connected together in the ceremonial core of a nation's capital. The Smithsonian is the largest institution of its kind in the world, consisting of 16 museums and galleries, the National Zoo, and several scientific research facilities. The majority of these institutions are located on the National Mall between the U.S. Capitol building and the Washington Monument. The Smithsonian museums share their collections with the public through exhibitions, lectures, symposia, school programs, concerts, festivals, and publications. They also serve the scholarly and scientific communities through programs, and 
publications. ${ }^{27}$

\section{2-3-1. Confederation Boulevard}

The National Capital Region straddles the provinces of Quebec and

Ontario. While Ottawa was made capital of the British colonial Province of Canada in 1857, both the National Capital Region and the Federal Precinct at its core now span the Ottawa River to include key portions of the city of Gatineau. ${ }^{28}$

More recently Confederation Boulevard has been developed by the National Capital Commission as a ceremonial route to connect key federal institutions on both sides of the river. These include the Houses of Parliament, National Library/Archives, the Supreme Court, the National Gallery, the Museum of Civilization, the Mint, the War Museum (both the new and old facilities), and a new Portrait Gallery. Organized around the

27 The Wikimedia Foundation Inc. Encyclopedia. The Smithsonian Institution. 15 Sept. 2004 <http://en.wikipedia.org/wiki/Smithsonian_Institution>

28 National Capital commission. Core Area: Concept of Canada's Capital. 1998. 
river, this area enjoys a combination of natural landscape and urban interventions which contribute to a unique and identifiable sense of place.

Currently the core area is in the process of a sector plan project consisting three major phases including vision, planning and development. The project focuses on expressing the vitality of the area and reinforcing the exchange between the federal and local aspects of the core area on both sides of the Ottawa River. 


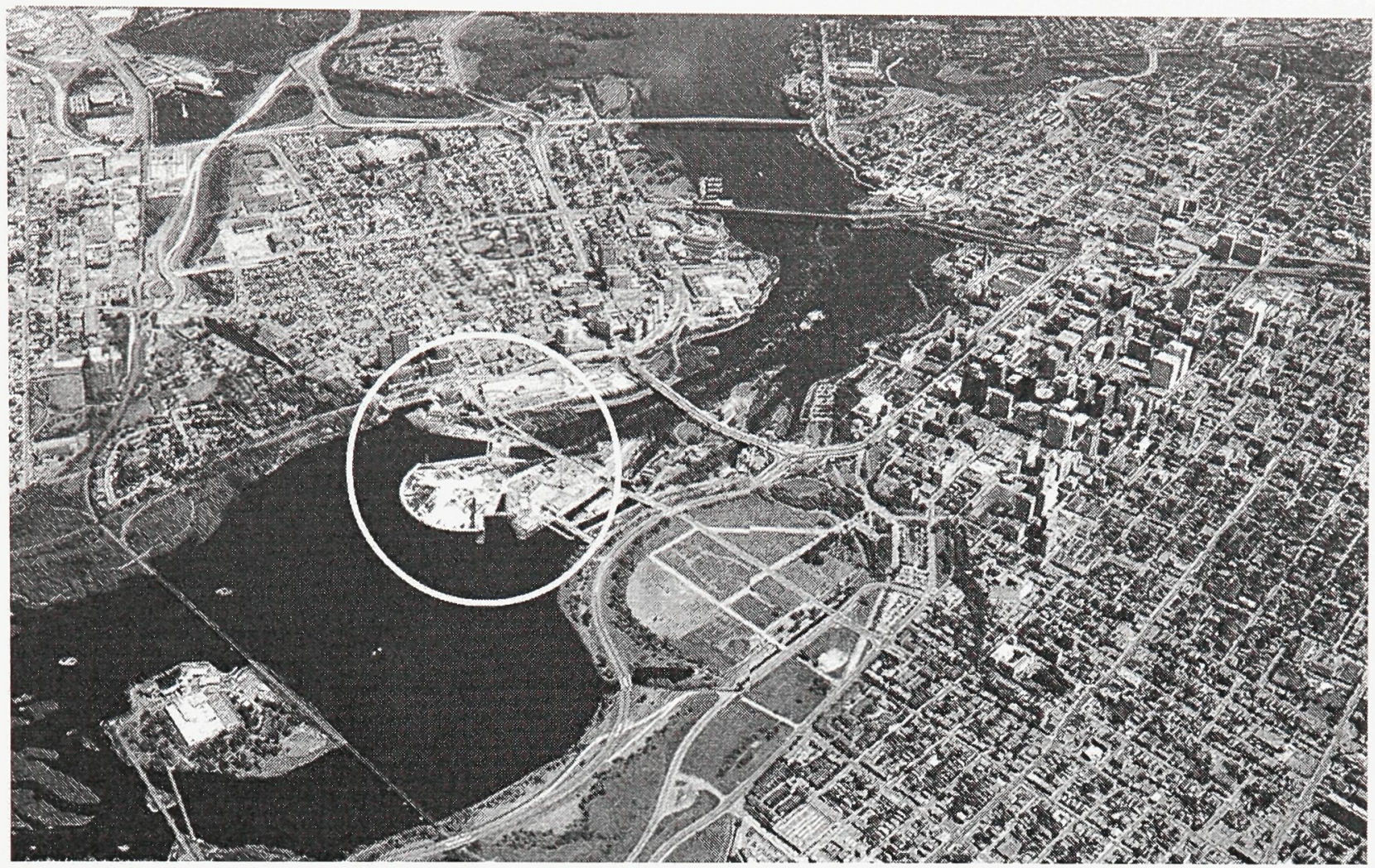

Fig. 3.1 Location of the New CSTM with the National Capital's Urban Core

Source: National Capital Commission. Core Area: Concept of Canada's Capital

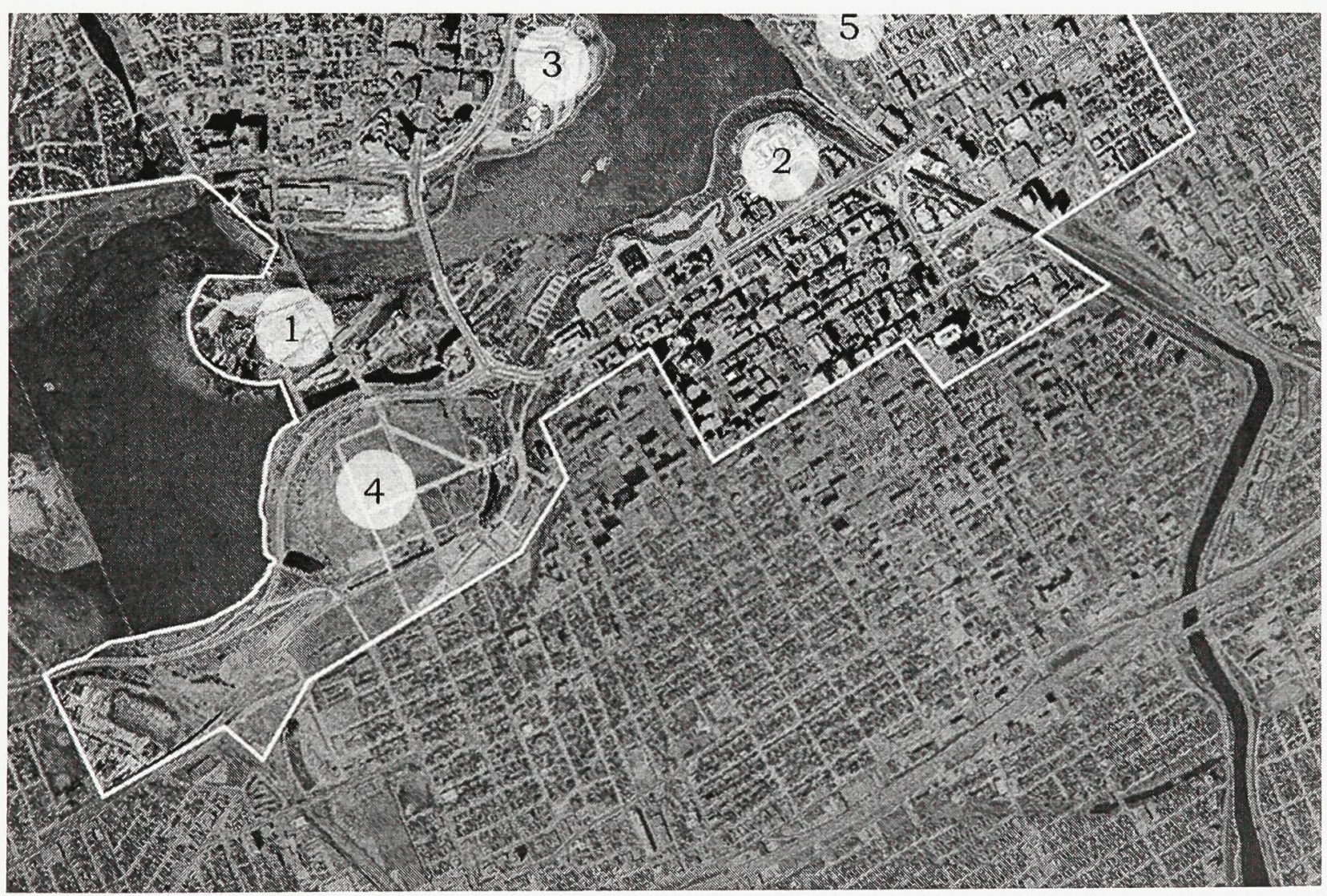

1. Project Site

2. Parliament Hill
3. Museum of Civilization

4. New War Museum
5. National Gallery

Fig. 3.2 Location of the New CSTM with other Institutions in the Confederation Boulevard 


\section{2-3-2. Site selection}

Finding a site to match the mandate of the Museum of Science and Technology and also, to express its role in linking the technology with environment (my thesis) proved to be a challenging process. A survey was made based on a set of basic requirements including factors such as location relative to urban surroundings, size to accommodate the project program, and accessibility. The survey led me to identify three sites on or near Confederation Boulevard for further study. Each of them was assessed for their potential to accommodate the new facilities. The results are summarized as follows: 


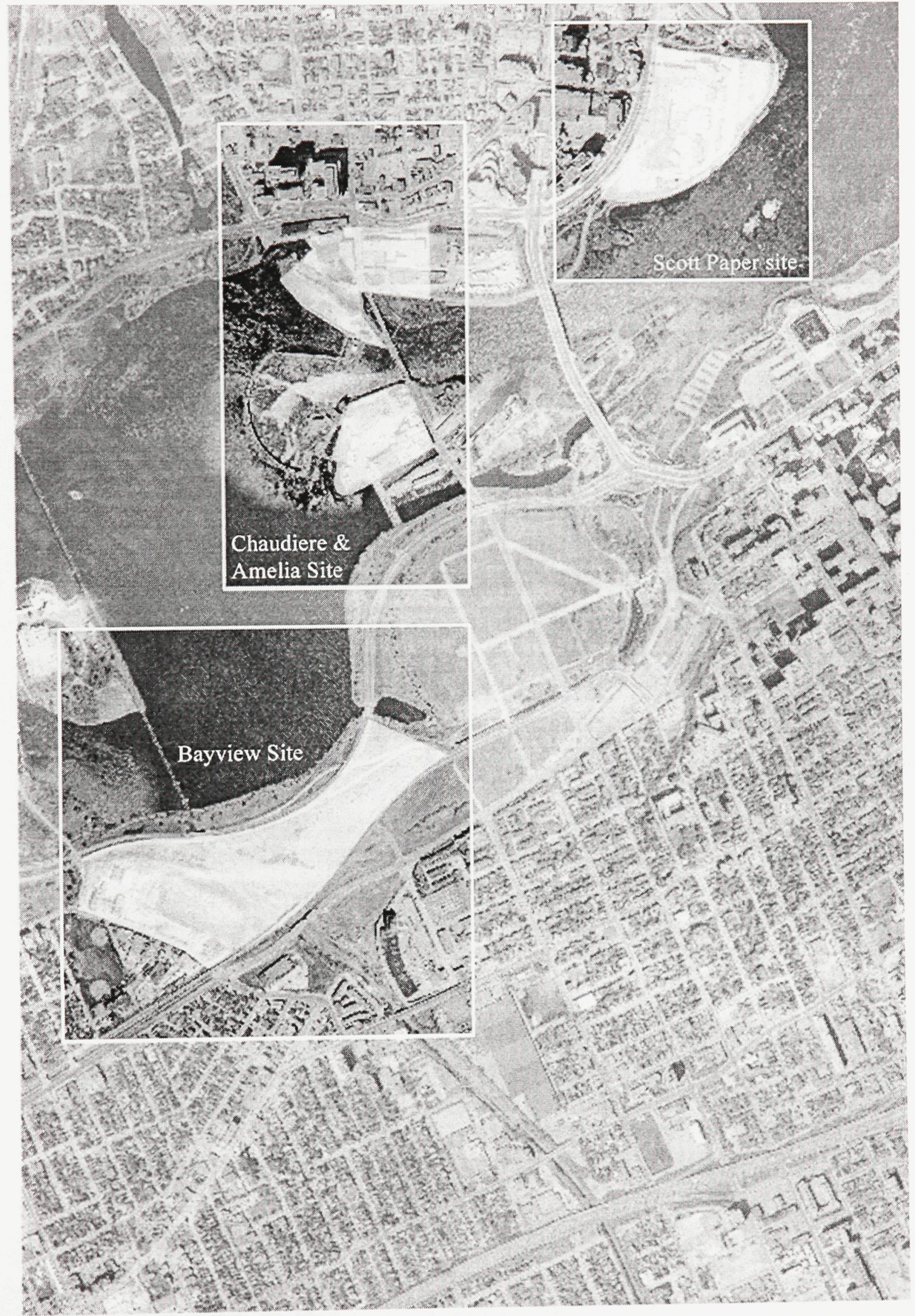

Fig. 4. Potential Sites 
Scott Paper site (32 acres)

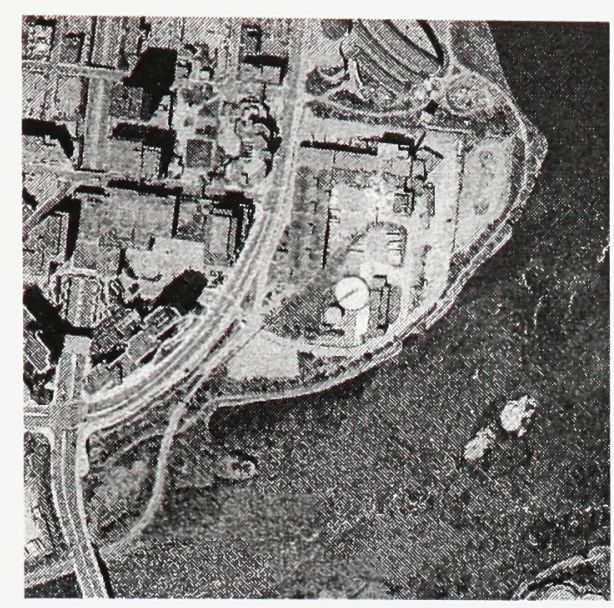

Fig. 4.1. Scott Paper site

Pros:

- Opposite to Parliament and adjacent to the Museum of Civilization.

- Potential for rail access.

- Site reflects past and present industrial use with potential program links with adjacent heritage structures.

- Good access for buses, pedestrians and cyclists.

Cons:

- The setback requirements from the Ottawa River reduce the efficient use of the land.

- Is privately owned and leased recently to another company for 25 years. This makes a reasonable date for site acquisition difficult 
and expensive.

- View protection line to the Parliament Building "by the Confederation Boulevard" applies to the site.

Bayview Site (58 acres)

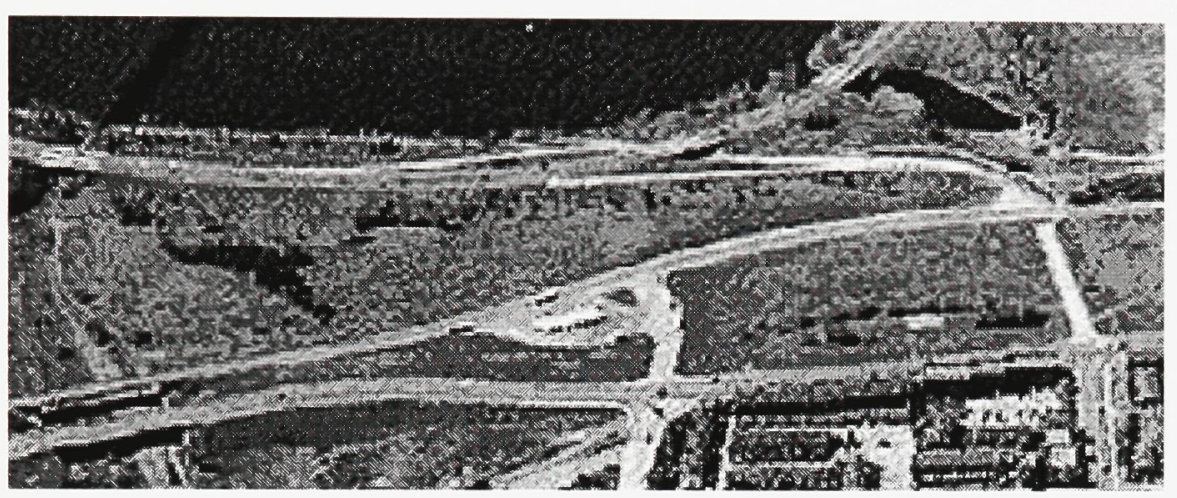

Fig. 4.2. Bayview Site

Pros:

- The site is large enough to accommodate the new facilities and the future expansion.

- Close to the New War Museum.

- Availability of rail access that can be used to run locomotives for demonstration purpose.

- Site topography will provide an interesting planning solution.

- Vehicular access, pedestrian and cycle connections. 
Cons:

- The site is slightly far from the downtown core and not visible from Confederation Blvd.

- Considerable contamination of various types exists on site. The cost of remediation is unknown.

- Nearly half of the site is currently under the city plan with possibility to be reserved for the development of Le-Bretton Flats residential and commercial projects.

- Re-zoning of the south-east and part of the site is required for partial relocation of the bus Transit way.

Chaudiere and Amelia Site (28 acres)

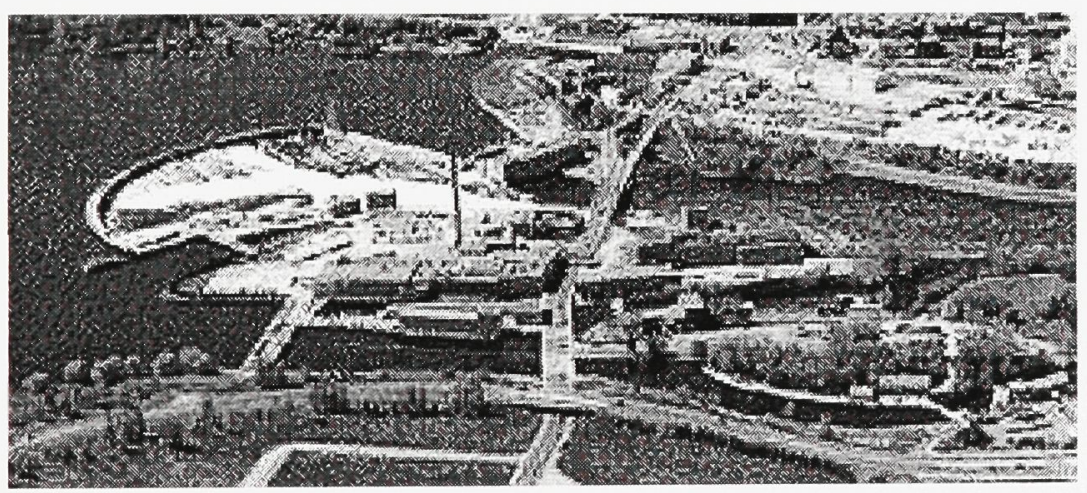

Fig. 4.3. Chaudiere and Amelia Site

Pros:

- Highly visible site. 
- Being on an island provides a very rich and pleasant marine environment and excellent opportunity for exterior facilities.

- Close to the New War Museum.

- The presence of existing heritage industrial buildings including a functioning hydro-electrical plant.

- Served by an existing rail line on the north side of the river.

Cons:

- The setback requirements from the Ottawa River reduce the efficient use of the land. The site is divided into several parcels which would necessitate separating the program into discrete components.

- The site is currently an industrial facility and privately owned by Domtar. Purchase cost for the site includes the cost of a replacement facility for Domtar and is estimated to be over $\$ 100$ million CND.

During the first term of this design thesis I focused on the Bayview site - as this was the site chosen by Arcop. Being adjacent to the river it benefits from a variety of landscape conditions and is capable of 
accommodating the new facilities with its large demanding program. It also provides the recommended rail accessibility to run locomotives.

After several schematic design studies, however, I became increasingly convinced of the potential of Chaudiere Island as a site. Although the island is too small to accommodate the entire program, the adjacent island, Amelia Island, is also available - as are portions of the north shore of the river (Victoria Island, also in the immediate vicinity, would not be used for the CSTM). Together this mini archipelago offers tremendous potential for exploring the role of the natural environment in relation to science and technology.

The redevelopment of these islands as an oasis in the heart of the National Capita is a vital part of the National Capital Commission's plans for the ceremonial core. Several studies, including the Thomson Brandt study, have proposed public facilities for the site. ${ }^{29}$ Therefore, the cost of purchasing the land and relocating the Domtar operation should be assessed as part of any redevelopment plan and should not be borne totally by the CSTM.

29 National Capital Commission. Thomson Brandt Study. 1992. 
The Ottawa River and the Chaudiere Falls together with the three islands present a variety of natural landscapes and an assortment of ways to organize programmatic components -- the cumulative effect of which would be to produce multiple, memorable experiences. The potential exists to enhance the museum's collection and extend its exhibition program by incorporating a number of the historical buildings on the site which, in turn, could be developed as an interpretive center for Canadian industry. The Museum's collection, in turn, will enhance the sensual experiences and history of the site to reinforce the objectives of the museum.

Moreover, the selection of Chaudiere Island as a site would reinforce one of the key objectives of Confederation Boulevard, namely, to strengthen the symbolic link between Ontario and Quebec. It would open a dramatic but inaccessible location to visitors, encourage public access and pedestrian movement to the River (and to and from other cultural establishments, such as the New War Museum), and open new views to the downtown and Parliament Hill.

Unlike the Bayview site, Chaudiere and Amelia islands are home to a number of historically-significant industrial buildings -- relics of an 
important era in Canadian industrial heritage. In addition to interpretative potential with respect to its historical, political and industrial infrastructure, Chaudiere Island embodies the evolving use of water as a power resource for industrial purposes. Together the site and the collection of industrial artifacts are thematically consistent with the CSTM. Indeed the museum and the site have tremendous potential to reinforce each other. 


\section{2-3-3. History of the site 30}

Located near the city's central business district, Chaudiere and Amelia islands are two of three islands that block the Ottawa River -dividing the river into four channels. Historically, the Algonquin Indians considered Chaudiere Falls to be a place of spiritual significance. It was also, however, a place of danger, as it was frequently chosen by enemies for surprise attacks.

European explorers, missionaries and traders began arriving at the Chaudiere in the late1700s. In 1791, Alexander Mackenzie identified a water route to the Pacific Ocean, permitting travel by canoe from sea to sea. Being a "natural obstacle," the Chaudière Falls were a key stopping point along the first Trans-Canada Highway. ${ }^{31}$ The Falls represent the farthest navigable point in the Ottawa River in the trek westward from its mouth at the St. Laurence. The falls, in tandem with the meeting of the

30 National Capital Commission. Chaudiere Historical Documentation. 1982.

31 The www Virtual Library. History of Canada's Capital Region. 15 Sept.2004. <http:/ / www.canadascapital.gc.ca/about_canadas/ncr/history/history2_e.ht ml\#Highway> 
Gatineau and Rideau rivers about a mile east of the falls, were also a key factor in the location and growth of Ottawa as a city. Until the appearance of railways and roads, the Ottawa River was used intensively as a transportation route between the east and the interior of the continent.

By the beginning of the 1800 s, mechanically-minded entrepreneurs had recognized and utilized the massive power potential in the ten meter drop of the falls. The development of the timber resources of the Ottawa River beginning in the early 1800s placed even greater importance on this potential year-round power source. By the 1860 s, it was utilized as one of the largest sawmilling complex in North America.

During the American Civil War, the Ottawa River was used as an emergency route from Kingston to Montreal to avoid stretches of the St. Lawrence River that were more vulnerable to attack. The expanding infrastructure of bridges, roads, wharves, railways and residential districts in the second half of the nineteenth century attracted a wide range of industries to the Chaudiere. The island was used as a stepping stone with bridges to move construction materials from the Quebec side to Ontario for the construction of the Rideau Canal. 
In addition to sawmills, several industries, such as forges, light manufacturing plants, furniture mills, a brewery, a rail depot, warehouses and other small businesses aggregated on the island. The Chaudiere became a centre of active industrial invention. Numerous patents were awarded to Ottawa residents for machines or processes and several breakthroughs of international interest were recorded. Among these, the early development of the sulphite pulping process and the application of the newly-developed technology of hydro-electric power generation for city lighting, industrial electrolysis and electrified city transportation figured prominently.

The Chaudiere continued to be an important industrial centre into the early decades of the twentieth century. Wood industries remained important and hydro-electric generation became an increasingly active enterprise. The hydro-electric plant and another generating station on Amelia Island are still in operation, forming part of the Ottawa hydro-electric system.

The industrial heritage of the site, coupled with its value in the history of Canada in general and Ottawa in particular makes it a showcase 
of the evolving use of technology to utilize natural resources to produce power. Together, these features provide a thematic core for my design thesis and lend validity to the choice of Chaudiere Island as a location.

The opportunity to move the CSTM to this site is an opportunity to transform the existing industrial infrastructure into a living museum, and to exploit the numerous riparian microclimates of the island as a laboratory to explore the relationship between technology and the natural environment. 


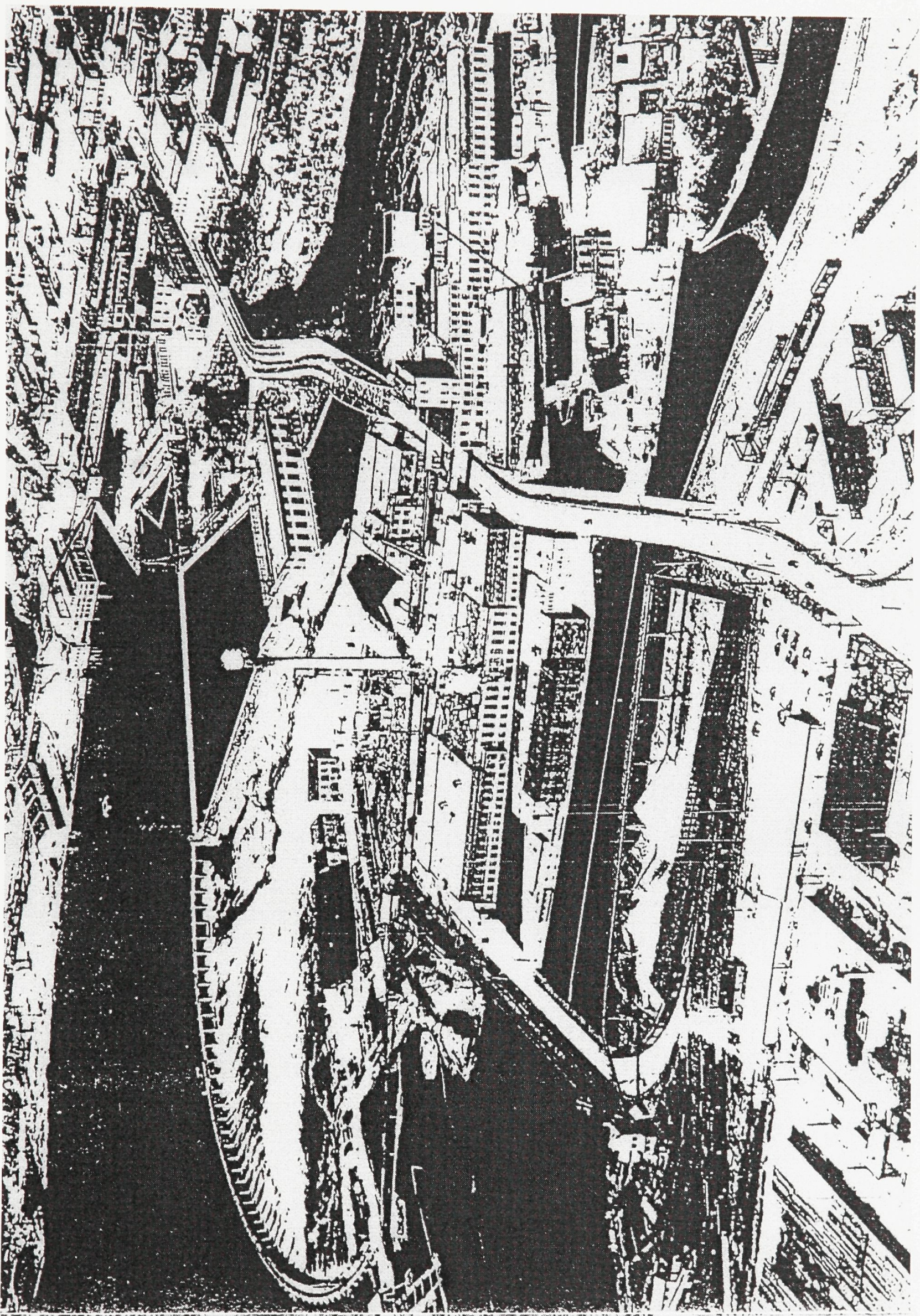

Fig. 5. Historical Image of the Site, indicating its industrial heritage

Source: National Capital Commission. Chaudiere Historical Documentation 


\section{2-3-4. Early studies for the site}

A number of studies of the Ottawa River Islands (Chaudiere, Ameila, Victoria, etc.) have been undertaken by the NCC and others.

An early study carried out by Ray Affleck (1980) included a recommendation that the National Museum of Science and Technology be relocated to the core of the National Capital. The study identified four potential sites as follows:

Site A: The land around Chaudiere Falls and extending northward into Gatineau.

Site B: The land around Chaudiere Falls and extending southward to include Victoria Island and Richmond Landing.

Site C: The parcel of land just north of the Chaudiere Falls in Gatineau.

Site D: In Jacques Cartier Park, northeast of the Museum of Civilization.

The criteria for site selection were based on:

- An appropriate image and presence.

- Utilization of federally owned land. 
- The reuse of existing structures, and finally.

- The enhancement of the built form character and historical appeal of the area.

The conclusion of the study was that aspects of sites A and B offered greater potential than site C. Site D was rejected because of other plans for the area (the report wasn't specific).

The study focused exclusively on federally-owned land and excluded large portions of Chaudiere Island and areas on the north shore of the river owned by the E. B. Eddy Company. As a result the proposal could not take full advantage of views of the Falls from the west end of Chaudiere Island nor could it effectively link the relocated CSTM with other national cultural institutions proposed for the south shore of the river.

In 1992 Thomson Brandt Architects were asked to provide professional urban design services to help establish a development framework for Chaudiere and Victoria. The study's redevelopment plan included general mixed use facilities without dictating an exact program. Suggestions for appropriate facilities ranged from an Arts, Culture and Education Centre, and an Information and Communication Technologies 
Centre, to an Environmental Technologies and Sustainable Industry

Centre. In addition there were a number of community, recreational and service facilities identified for the site.

Unlike the Ray Affleck study, the Thomson Brandt study did not limit itself to federally-owned lands, but looked comprehensively at the creation of unique, sustainable urban oasis in the heart of the National Capital.

\section{2-3-5. Site Heritage Survey}

As part of this thesis I looked carefully at each of the buildings currently on Chaudiere and Amelia islands - drawing heavily on the survey undertaken by Thomson Brandt Architects. The survey identified twenty-six items -- buildings, fragments of buildings, infrastructure, and significant microclimates -- on Victoria, Chaudiere and Amelia Islands. The following list identifies the sixteen items that fell into my proposed redevelopment area. Adjacent to each item is a note indicating whether or not it will be removed or remain as part of my proposed scheme for the new 
CSTM (see also fig. 6):

Buildings

1. Ottawa Electric Railway Steam Plant. (1914)

2. J.R. Booth Power House (1909) - proposed for removal

3. J.R. Booth No. 1 Power House (1880)

4. E.B. Eddy Box Shop (1880)

5. Hydro-Quebec Power House (1912)

6. E.B. Eddy Mill $(1869,1892)$

7. Eddy Paper Machine Building (1890)

8. Booth Board Mill Complex (1912) - proposed for partial removal

9. Booth Groundwork Pulp Mill (1900-1904)

10. Eddy Steam Plant and Stock (1906) - proposed for removal

11. South Chaudiere Paper Machines (1900) - proposed for removal

12. Eddy Hull Powerhouse (1913) - partial

13. Booth Buildings on Albert Island (1900)

Fragments and Sites

14. Site of original Union Bridge (1828)

15. Ring Dam construction and Falls site (1910) 
16. Devil's Hole site

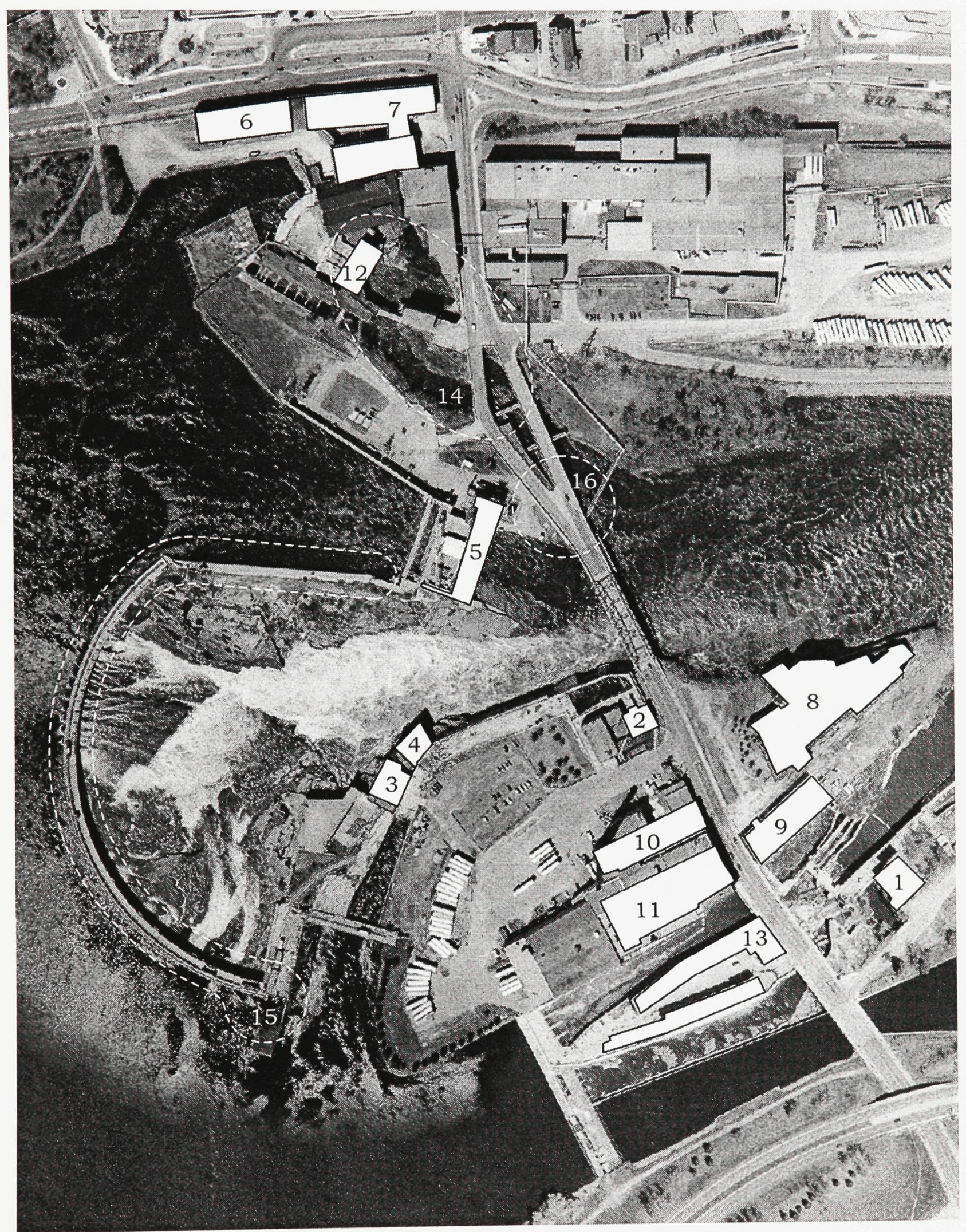

Fig. 6 Existing Buildings on the Site

Source: National Capital Commission. Thomson Brandt Study 
As noted, the industrial heritage of the site was a key consideration in the choice of Chaudiere and Amelia Islands as the location for the new CSTM. As such, an effort was made to preserve and incorporate artifacts that are historically or architecturally significant. My proposal recommends that three of these sixteen buildings be removed and that a fourth be reduced to a single story. All four of these structures have been substantially deformed over time and compromised by their current industrial use. In addition, the position of these buildings prevents the effective use of the site to accommodate new facilities. It should be noted that the remaining twelve buildings/sites will require significant refurbishment to remove asbestos and other contaminants. 


\section{2-4. Site planning}

The selection and characteristics of the site were key elements in formulating a design concept and supplied the most important source of inspiration for the proposed design. While the site imposed limits, these limits provided a rich context for programmatic decisions. Indeed, the desire to take full advantage of the site became an integral part of the program. Wherever possible, I attempted to pull the site into the museum and extend the program of the museum out and across the site. Together with the architecture of the building, the site was planned so as to provide a wide contrast of rich atmospheric experiences, and a continuity of internal and external spaces that are harmonious and unique. It is difficult to separate the design of the building from the disposition of the programmatic pieces across the site.

The following features were seen as assets to be leveraged in expressing the role of science and technology in man's relationship to the natural environment: 


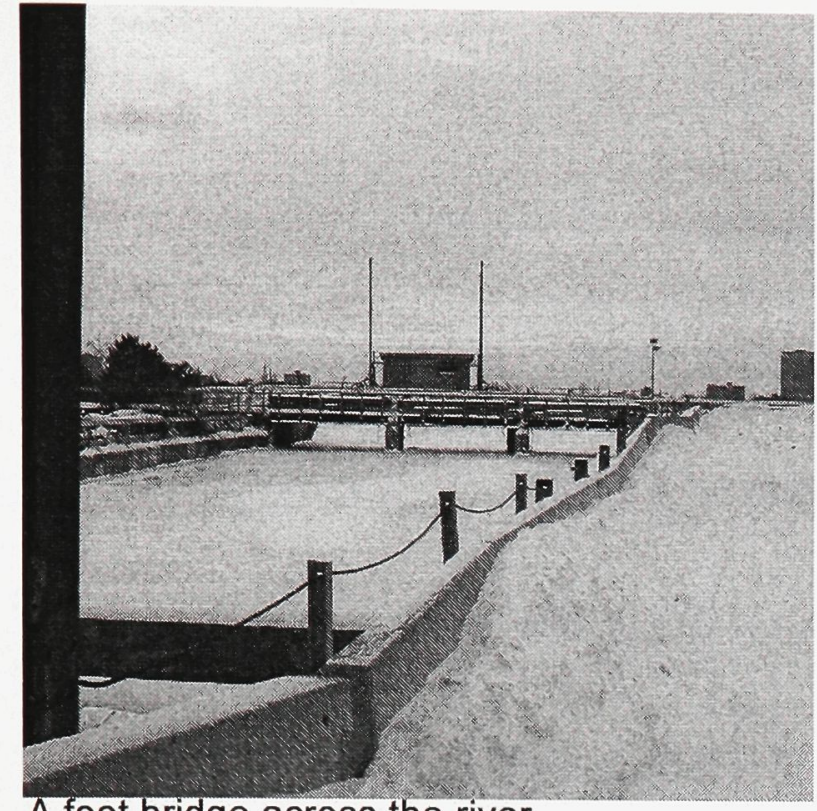

A foot bridge across the river connects to the New War Museum

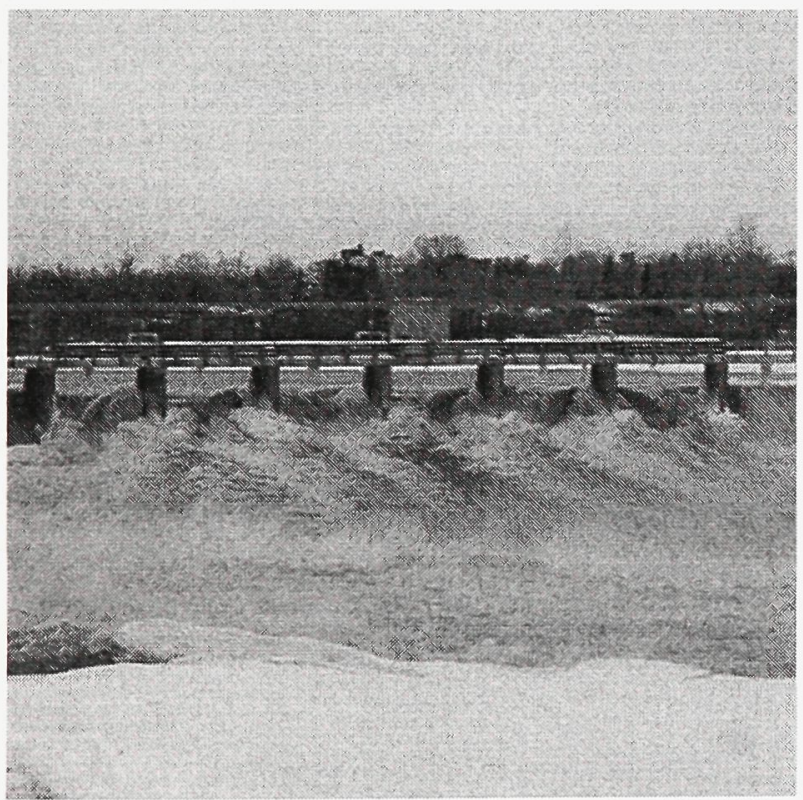

Ring Dam construction and Falls site (1910)

Fig. 7 Views from the Site

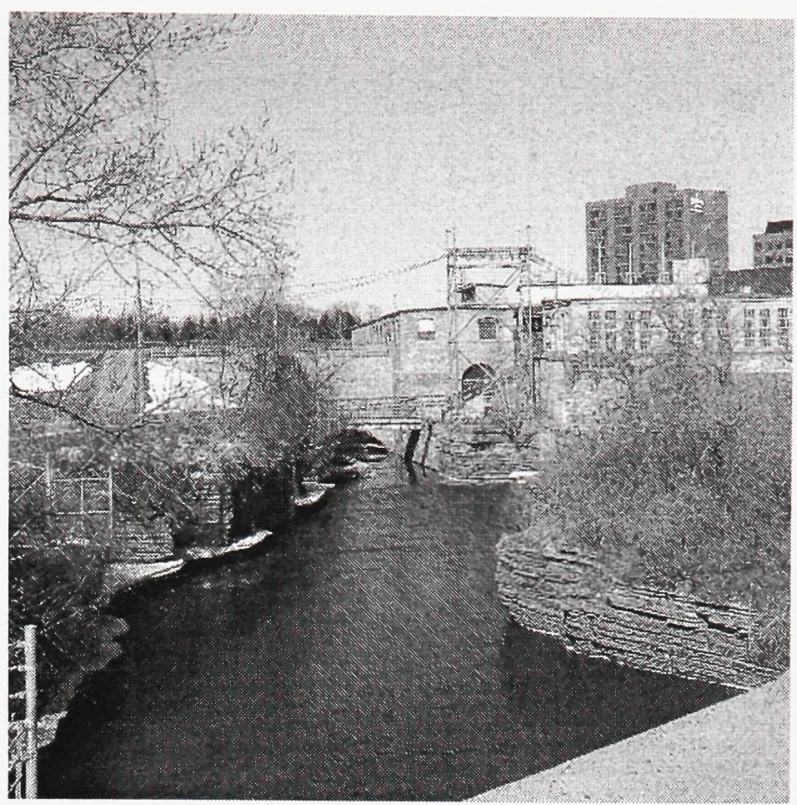

Devil's Hole site

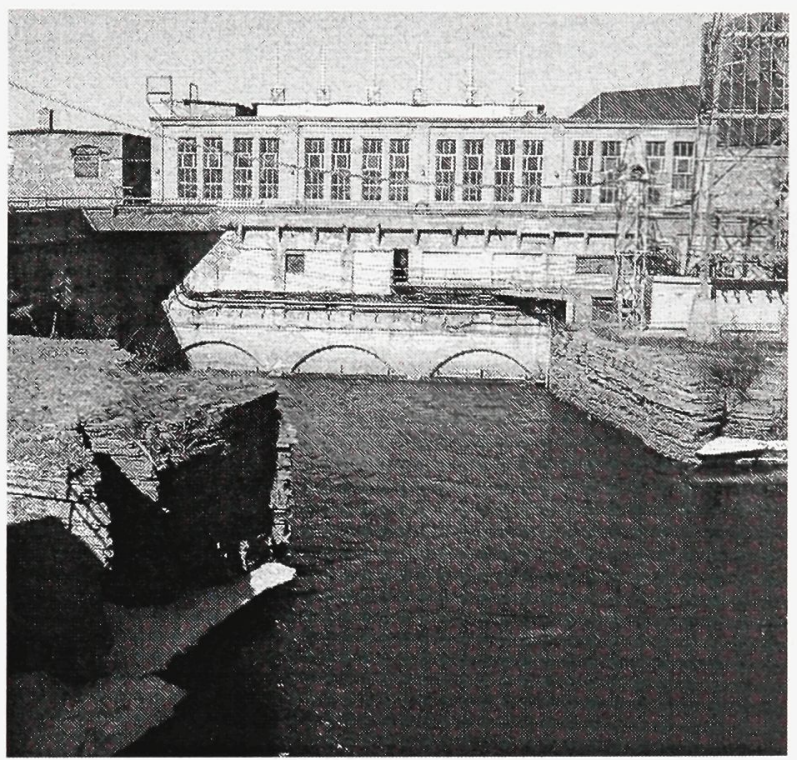

Eddy Paper Machine Building (1890)

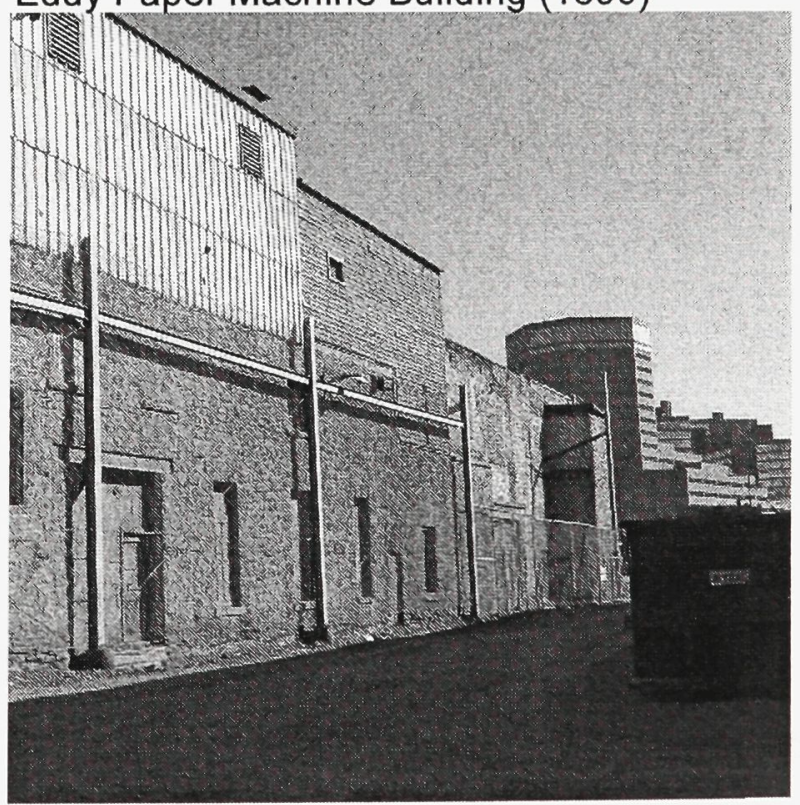


- The site presents a combination of dry and aquatic landscapes which, together, produce a unique and a memorable set of experiences. These microclimates will be experienced by the public as they travel among the various components and facilities on the site. The dense grove of trees in the Amelia-Victoria valley (“The Grove") provides a delightful, secluded space on the Islands. As stated in Thomson Brandt Study, "the abandoned log flume running the length of this grove is an added discovery element which suggests development as another water-oriented experience." 32 This grove (including the portion on the other side of the bridge, adjacent to Devil's Hole) was not affected by the new facilities and can be incorporated into a system of public spaces through the site.

- The Chaudiere falls connects to the Hydro-Quebec Power House - which was constructed in 1912. It is working example of how dams can be used to leverage hydraulic pressure to produce electricity and is an excellent example of a potentially positive

32 National Capital Commission. Thomson Brandt Study. 1992. 
relationship between science, technology and the natural environment. The plant will be opened for public and linked with a series of outdoor exhibit areas including Devil's Hole to display the utilization of river and grey water management. Their character and historical value, together with new walkways around and through them down to water level, would make them an extremely popular attraction.

- The site offers spectacular views of the Chaudiere falls and the Ottawa River. The Ring Dam on top of the Falls, constructed in 1910 to regulate the water level, was a key element in the historical development of this industrial complex. ${ }^{33}$ By locating the bulk of the new facilities at the south and eastern edges of Chaudiere Island, I was able to incorporate the ring dam into the site as an edge to the main exterior plaza. The circular shape of the ring, in turn, is echoed in the shape of the amphitheatre in the plaza. 
- The channel separating Chaudiere and Victoria islands (Lost Channel) comprises a variety of natural and industrial landscapes -- the enclosed nature of which stands in contrast with the more open waters upriver. A pedestrian bridge across Lost Channel was proposed to connect the new facilities with the new War Museum.

- Parliament Hill rises over the site in the distance. The new facilities will open exceptional unobstructed views of the Parliament Hill and of significant features on both sides of the River.

- As mentioned above, site planning took note of the historical significance of the existing heritage industrial buildings on both islands and on the northern shore of the river. It should be noted that many of my decisions about what elements to preserve and how to re-use then were informed by the suggestions from the Thomson Brandt study.

- The site is accessible by rail on the northern bank of the river at Gatineau. This is significant given the large number of trains in 
the Museum's collection.

My approach to the planning of the site was simple: to take full advantage of the generous setting in order to engage man, architecture and the natural environment in both a literal and symbolic dialogue.

Given the extensive and demanding program and the site characteristics, I divided the museum into separate programmatic components: the entrance pavilion and planetarium on Amelia Island, the main museum on Chaudiere Island, and a third element for archives and exhibition storage on the northern shore of Ottawa River. The existing heritage buildings adjacent to the Entrance Pavilion are also available to house some of the museum's collection of trains. This building is also programmed to accommodate an environmental conservation training centre.

The Entrance Pavilion houses many of the features people expect in an institution -- cloakrooms, ticket booths, a restaurant, gift shop and a cafeteria - in addition to a planetarium. Visitors travel the 400 meters between the Entrance Pavilion and the main museum on an elevated train, enjoying an overview of the site, views of the Falls, the Parliament, and the 
collision of natural, built and aquatic elements that characterize the site.

This train docks in the Main Museum Building on Chaudiere Island where visitors are received into the Great Hall. This main facility is organized in an "L" shape facing the falls for which it creates a forecourt. This arrangement also gave rise to the idea of a circulation path through the Great Hall and other exhibition galleries along the river at the base of the building masses to lend structure to the visitor's experience.

At its southern edge, the new CSTM connects to the new War Museum via a foot bridge across the river. A ramp leads up to a roof garden on top of one of the exhibition halls, offering access to the site and a view of the Chaudiere Falls without having to enter the building. This roof garden becomes a controlled demonstration area, exploiting a variety of kinds of vegetation to explore and explain bio-remediation processes.

The Archives and Exhibition Storage Building is located on the northern bank of Ottawa River, opposite the Entrance Pavilion. It was important to locate the archives along the existing rail line so that trains and other large artifacts could easily be moved along the tracks. The bulk of visitor parking is located adjacent to the Archives facility, with a 
pedestrian link under Booth Street to the Entrance Pavilion. 


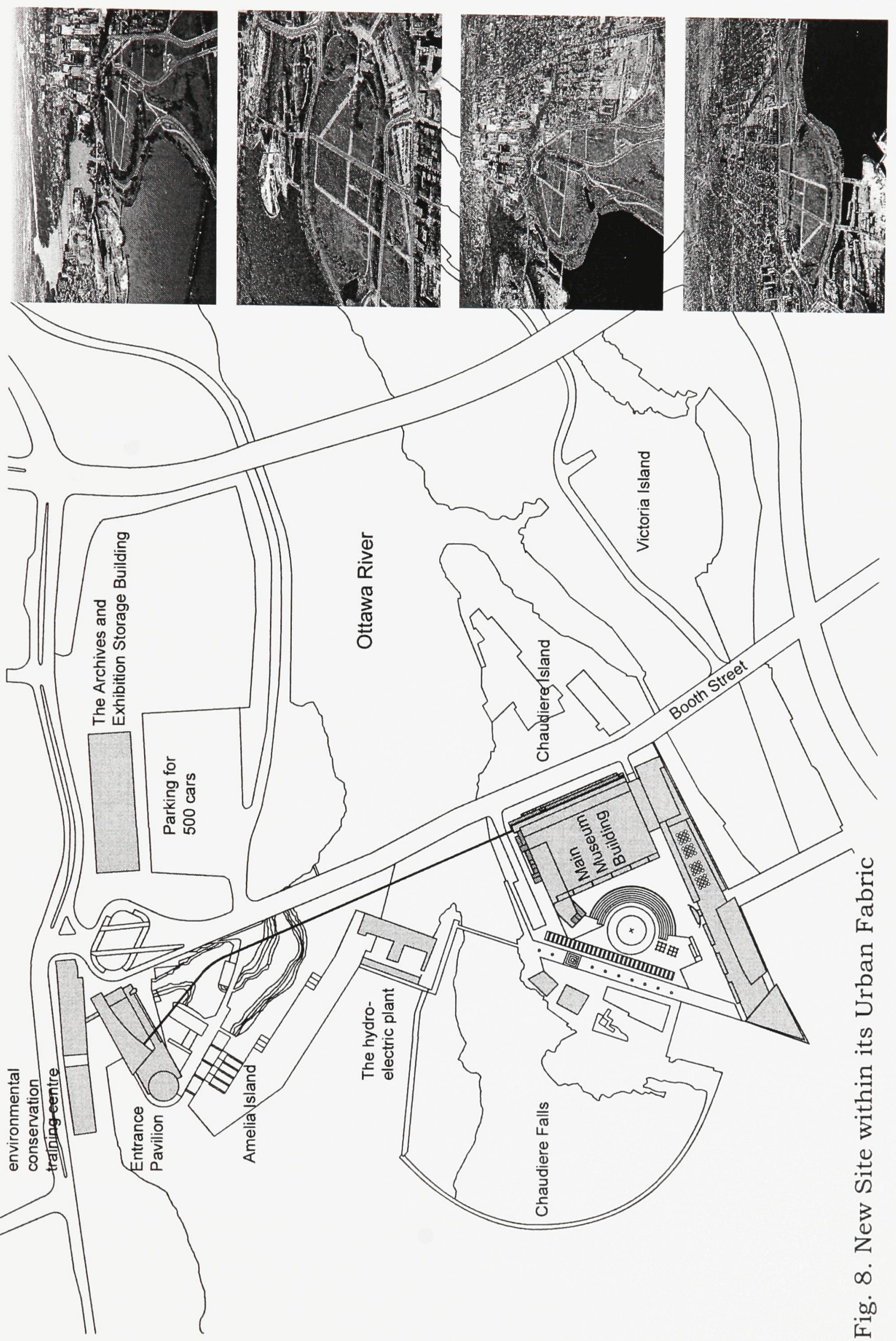




\section{2-5. The Building Program}

The existing Canada Science and Technology Museum is housed in four distinct buildings as follows:

\section{2-5-1. Main building}

The building houses $10,570 \mathrm{~m}^{2}$ of exhibit area, a $390 \mathrm{~m}^{2}$ auditorium, a $460 \mathrm{~m}^{2}$ education department, $890 \mathrm{~m}^{2}$ of offices, and $2170 \mathrm{~m}^{2}$ of workshops.

\section{2-5-2. Library building}

Located southwest of the main building, it contains the main library, some automotive artifact storage, and the main agricultural artifact storage space. It provides $3360 \mathrm{~m}^{2}$ of artifact storage, $700 \mathrm{~m}^{2}$ of office space, and $135 \mathrm{~m}^{2}$ of workshop space. 


\section{2-5-3. Collection Storage and Corporate Offices}

Located south of the main building this facility contains the corporate and staff offices, and general artifacts storage. It provides 7333 $\mathrm{m}^{2}$ of artifact storage, $1750 \mathrm{~m}^{2}$ office and $1075 \mathrm{~m}^{2}$ of corporate storage

\section{2-5-4. Corporate Storage}

Located southeast of the main building the storage facility contains $6484 \mathrm{~m} 2$ of artifact storage and $1500 \mathrm{~m}^{2}$ of conservation labs.

\section{2-5-5. List of Long-Term Exhibitions Areas ${ }^{34}$}

The following descriptions of the museum's long-term exhibitions have been paraphrase from descriptions on the museum's web site.

\section{INNOVATION CANADA}

This major exhibition introduces visitors to great Canadians

34 Canada Science and Technology Museum. 20 July 2004.

$<$ http://www.sciencetech.technomuses.ca/english/whatson/ongoing_exhibits. $\mathrm{cfm}>$ 
including, Wilder G. Penfield, the man who mapped the human brain; George Klein, who developed not only a suturing system for reconnecting arteries, but a battery-powered wheelchair and the STEM satellite antenna; and Elsie MacGill, the first Canadian woman to receive a degree in electrical engineering. Over 100 artifacts are on display, including Bombardier's B7 snowmobile, a Newt suit, a Deep Rover deep sea vehicle, the Theratron Cobalt- 60 bomb, and a replica of the hockey goalie mask worn by Jacques Plante.

\section{NORTEL NETWORKS CONNEXIONS - The Plugged-in World of Communications}

A major exhibition on communications, it is the largest exhibition of its kind in Canada, illustrating the history of electric and electronic communications in Canada. A collection of artifacts shows how our modes of communications have evolved through the 19th and 20th centuries and will continue to evolve in the future. Visitors are invited to explore the evolution of communications through the telegraph, telephone, radio communications, radio and $T V$ broadcasting, and to discover the lives of Canadian inventors such as Alexander Graham Bell and Reginald Fessenden.

\section{DIGITAL NETWORKS}

Informative and interactive, this area introduces visitors to the science and processes by which messages are formatted for travel through a digital network. With slides, videos, interactive displays and games, as well as numerous artifacts, this exhibit offers "an exceptional visitor experience. "

\section{MORE THAN A MACHINE - The Motor Vehicle in Canada, $1900-1930$}

This exhibition includes odd combination-vehicles developed in the early 20th century: a steam buggy (the Locomobile), a 1908 electric car, a 1914 Indian motorcycle, a 1920 Ward electric truck, a 1921 double-decker bus, and the elegant Buick-McLaughlin used by the Prince of Wales in 1927. 


\section{CANADA IN SPACE: DESTINATION EARTH}

Including the aurora borealis, rockets, Apollo 7, the Canadarm, and Roberta Bondar, this exhibit covers the exploration of space. Visitors discover the story of Canada's involvement in space as the third space-faring nation in the world, exploring various space tools such as Radarsat, MSAT, the Canadarm, and some of the Canadian astronauts.

\section{LOVE, LEISURE AND LAUNDRY - Why housework won't go} away

Looking at consumer good and material culture, this exhibit documents the ways in which the gradual introduction of new technologies into the home changed the ways we perform housework. Visitors explore the impact electricity and other services on routine tasks, from the turn of the century to today. From a demonstration of an early washing machine and to a discussion of how electricity was sold to farmers, visitors explore the consequences that these changes brought to present family life and what the future home might look like. The focus of this long-term exhibition is on the evolution of domestic appliances and their impact on gender roles in the home, in particular on the role of women.

\section{CANADIAN SCIENCE AND ENGINEERING HALL OF FAME}

This audio gallery, inside the Innovation Canada exhibit, honours Canadians who have made outstanding contributions to science and engineering over a long period of time. The Hall of Fame is to celebrate Canadian achievements and promotes careers in science, engineering and technology.

\section{LOCOMOTIVE HALL}

The Locomotive Hall contains four huge steam locomotives, some of which allow access to the cabs, a caboose, a business car, and an exhibit of Canadian railway bridges. Sound effects give the feeling of live locomotives. The engines are meticulously restored, with polished rods and with lighted number boards and class lights. You can also wander through a photo 
gallery of the Canadian railroad bridges that carried these magnificent machines. 


\section{2-6. The New Museum Building}

\section{2-6-1. New program}

The program component areas in net square meter for the Science and Technology Museum are as follows:

A) General area requirement

1.0 Entrance Pavilion.................................................. 5100

2.0 Exhibition spaces............................................ 14550

3.0 Research Program facilitie .................................... 1500

4.0 Office facilities ............................................... 1650

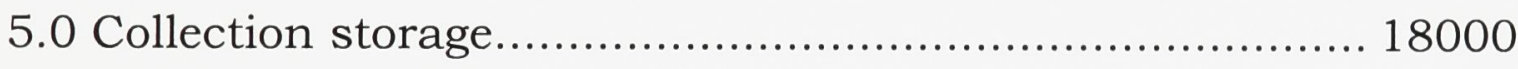

6.0 Maintenance and Building services .......................... 3500

7.0 The Archive Building .......................................... 5000

Allowance for building services and circulation ................. 12000

- Building services include an electrical equipment room, mechanical equipment room, communications equipment room, and environmental control room. 
- Services are divided among the various zones to provide uniform distribution of systems, and are accessible to provide routine maintenance and repair without interrupting the day-to-day operations of the Museum.

Total area requirement $61300 \mathrm{~m} 2$

A cohesive set of design strategies have been applied to the architecture, site, and program-related aspects of the project to stimulate visitors, and enhance the capabilities, as well as the flexibility, of the Museum. The ultimate goal is the expression of the new CSTM as a landmark institution and a symbol of civic engagement, promoting the role of technology in Canadian history, culture and identity.

The project uses specific spaces and key programmatic components to explore the essence and effects of technology. The site, spaces, architecture and exhibitions work together to heighten our appreciation and understanding of science and technology, leading to new interpretations of their roles in our lives and in our cultural identity. 
B) Detailed area requirement

\begin{tabular}{|r|l|r|}
\hline & C O M P O N E N T & sqm \\
\hline $\mathbf{1 . 0}$ & Entrance hall/Foyer & $\mathbf{5 1 0 0}$ \\
1.1 & Entrance hall/Foyer & 1800 \\
1.2 & Visitors Amenity & 500 \\
1.3 & Ticket and info- booths, porter & 150 \\
1.4 & Souvenir shop, shop supplies storeroom & 90 \\
1.5 & Restaurant \& Cafeteria & 270 \\
1.6 & Public toilets & 140 \\
1.7 & Community Library & 300 \\
1.8 & Administrative Services & 600 \\
1.9 & Train departure and arrival & 500 \\
1.10 & Planetarium & 750 \\
\hline $\mathbf{2 . 0}$ & Exhibition Spaces & $\mathbf{1 4 5 5 0}$ \\
2.1 & Great Hall & 6500 \\
2.2 & River Hall & 2500 \\
2.3 & Visitor's Orientation and train reception & 500 \\
2.4 & Innovation Canada & 700 \\
2.5 & More Than a Machine- The Motor Vehicle in & 2000 \\
2.6 & Canada In Space: Destination Earth & 900 \\
2.7 & Nortel Networks Connexions & 750 \\
2.8 & Man and Nature & 400 \\
2.9 & Love, Leisure and Laundry & 900 \\
2.10 & Auditorium and Presentation Theater & 1200 \\
\hline $\mathbf{3 . 0}$ & Research Program Facilities & $\mathbf{1 5 0 0}$ \\
3.1 & Research Program offices & 300 \\
3.2 & Research Library & 800 \\
3.3 & Lecture / activity rooms & 400 \\
\hline
\end{tabular}




\begin{tabular}{|r|l|r|}
\hline $\mathbf{4 . 0}$ & Offices and Staff Facilities & $\mathbf{1 6 5 0}$ \\
4.1 & Main office & 25 \\
4.2 & Offices & 800 \\
4.3 & Meeting room/ Break room & 50 \\
4.4 & Reference library/study & 300 \\
4.5 & Photograph archive & 150 \\
4.6 & Storeroom/photocopying & 100 \\
4.7 & Reference archive & 150 \\
4.8 & Staff dressing rooms, washrooms and toilets & 50 \\
\hline $\mathbf{5 . 0}$ & Collection storage & $\mathbf{8 0 0 0}$ \\
5.1 & Workshop storeroom & \\
5.2 & Photographers studio and documentation & \\
5.3 & Exhibition Management & \\
5.4 & Conservation's workshop & \\
5.5 & Storeroom for exhibition structures & \\
5.6 & Space for shipping and treatment of art works & \\
5.7 & Storeroom for permanent collections & \\
5.8 & Storeroom for temporary exhibitions & \\
5.9 & Storeroom for publications & \\
\hline $\mathbf{6 . 0}$ & Maintenance and Building services & \\
\hline $\mathbf{7 . 0}$ & Plant rooms (electrical substation and emergency & \\
& installation/ ventilation and air treatment plant/ & \\
\hline & boilers and heating plants/ water storage tanks) & \\
\hline
\end{tabular}




\section{2-6-2. Entrance Pavilion}

The organic shape of the Entrance Pavilion relates to its kinetic surroundings and expresses the dynamic profile of the institution. Visitors move through a double-height entrance lobby with a curved ceiling. This generous lobby accommodates all features necessary for visitor orientation: information, ticket booths and cloakrooms. A bar- restaurant is located just off the lobby, permitting casual visitors to enjoy the natural landscape. The gift shop, also accessible without paying an entrance fee, would offer a wide choice of books, magazines, toys and educational games, and souvenirs. Both of these facilities would contribute to the street life in Gatineau, being accessible through the Heritage Buildings on Laurier St. in Gatineau.

Museum visitors will use an escalator to move up to a mezzanine lobby, where the entrance of the Planetarium is located. The Planetarium will expand the museum's program in the direction of space exploration, presenting astronomy-themed shows in the "star-theatre".

Visitors will have the choice to attend the show(s) before or after 
visiting the main facility on Chaudiere Island. Exhibitions in this facility are accessed via an elevated monorail from the mezzanine level of the Entrance Pavilion. Train travel between the pavilion and the main facility treats visitors to an overview of the site and to spectacular views up and down the river.

As mentioned, the Entrance Pavilion is also connected with the adjacent heritage buildings along Laurier St. to the north. These buildings will house a centre for environmental conservation education and a portion of the Museum's extensive collection of trains.

Like the museum facility as a whole, the entrance space will support events, activities, and public discussions related to the museum's mandate. The unique location of the pavilion (and its autonomy from the main exhibition galleries) will allow it to function, eliminating some of the conventional obstacles to using museum facilities for special events.

\section{2-6-3. Planetarium}

The proposed planetarium will expand the museum's program in 
the direction of space exploration, and create a distinct identity for the new facilities. It would increase public awareness and attendance and, like the Entrance Pavilion itself, can be used independently of the museum as a whole. The Rose Center in the American Museum of Natural History provides us with an example of a prototype for such a facility. The Rose Center encompasses a completely rebuilt Hayden Planetarium and new exhibition halls that explore the vast range of sizes in the cosmos and the dynamic features of planet Earth. The design includes a large-scale curtain wall, manufactured of "water white" glass, and a unique interior space. The facility was designed as an educational resource, with the aim of informing and inspiring the public in a way that serves science. ${ }^{35}$

\section{2-6-4. The Exhibition Area}

The design of the exhibition areas is generally divided into two main components: open public spaces and self-contained galleries. Key architectural statements anchor both ends of the exhibition sequence.

35 American Museum of Natural History. 18 Sept. 2004. <http:/ /www.amnh.org/exhibitions/permanent/rose> 
Visitors arrive in the "Great Hall" and the sequence terminates in the "River Hall." The River Hall acts both as a turning point (for visitors to move back though the gallery sequence on the lower level) and an anteroom/reception area associated with the auditorium. Galleries are located along the path connecting the major spaces. In contrast to the public halls, the interior design of the galleries is intentionally neutral and light is highly controlled to allow the curatorial staff maximum flexibility to mount exhibitions and display artifacts.

The design strategies applied to the public spaces include an exploration of structural systems (steel in the Great Hall and wood in the River Hall), the use of natural light (direct, indirect, and reflected), and an effort to link public interior spaces to the site and particular views.

\section{2-6-5. The Research Facilities}

The public program for research will also provide a centre for studies in Science and Technology, intended for scholars undertaking advanced research in the history and impact of science and technology. 
The centre will be at the heart of the Great Hall, at the upper level of the east wing of the Great Hall. This location will allow scholars to communicate with the public will support dialogue, discussion, and shared understanding --reinforcing the museum's mandate.

\section{2-6-6.The Archive}

The collections will be accessible to make the "back of the house" visible and to allow visitors to view the internal workings of the museum.

The archive will offer a multi-layered approach with emphasis on programs integrated with exhibitions; increased demonstration activities; much more accessible collections, and a behind the scenes approach to different areas of interest. Visitors will proceed from the general to the specific through an introductory overview, thematic exhibitions and collection-inspired exhibitions that focus on the collections and provide a very high level of access to the objects. From there they will move on to accessible storage.

Artifacts will move from the archive facility to the exhibition 
galleries along Booth Street. A service access to the galleries is available directly from Booth Street, so that large artifacts can be easily placed in the display areas upon arrival. 


\section{2-7. The site as a successful urban community}

The new location of Science and Technology Museum will bring a sense of community in the islands - as well as integrating the islands into the community at large. The museum will play the dual role of interpreting the past and inspiring responsible action for the future.

As a culture institution, the museum will function as a meeting place, a place of interaction. The planning of the site encourages such meetings to take many forms, scales and events. The planning concept of separating and distributing programmatic components allows them to function separately, for various kinds and scales of events. The location of the site between the two provinces with a good mix of uses "to be established" on Victoria Island and historical buildings on the site will serve and foster this intention. I believe it is the appropriate program for this site.

The introduction of such a large program to the site will no doubt generate debate.

While it may be considered controversial to impose such a 
large-scale building program on a site so rich with historically significant artifacts, we need to be reminded that the history of the site is industrial in nature. Accordingly, I believe that no matter how contemporary its sensibility, the high-tech nature of the new, landmark architecture, the programmatic theme of design and technology, and the sustainable approach of the new facilities will complement rather than compromise the site and existing infrastructure. Moreover, a number of significant examples in the last few decades illustrate how contemporary architecture (particularly hi-tech architecture) can complement historical fabric: the Pompidou Center in the centre of historic Paris, the Guggenheim Museum in Bilbao, etc. These works demonstrate how architecture can reinforce by contrast rather than by imitation. 


\section{2-8. Design Concept}

After experiencing the building's dramatic exterior, visitors arriving by train are greeted by a dramatic atrium space (the Great Hall) that serves as both the focus of circulation and the symbolic focus of the entire museum.

As mentioned, the 15 meter high space is intended to function as an agora, accommodating various cultures, people, events and activities. It also connects directly to the main outdoor space -- visible through the glass, west-facing facade - which becomes an extension of the Great Hall.

The space is anchored by a series of elements, principle among which is a circular structure of natural stone, and a soothing waterfall fed by rainwater. The pool that collects the water is in the shape of a maple leaf, whose jagged edges are softened by the play of water and the constantly-changing light that pervades the atrium space. The rainwater resource is retained and recycled, both for aesthetic and functional purposes. The architectural elements are important to ground a space that both extends outward (across the plaza to include the falls and the 
Ottawa River beyond), and will accommodate large artifacts from the Museum's collection.

The long-term exhibition galleries are located in a long, narrow bar along the southern edge of Chaudiere Island - along Lost Channel. The space is divided into separate galleries and will accommodate a number of transportation and telecommunication exhibits. The galleries are connected by ramps and stairs which overlook the "River Hall".

River Hall is located close to the auditorium. The space features an arch-shaped roof with a unique wooden frame structure. The roof frames are composed of curved support members supported on reinforced concrete columns. Seen from the outside, the gently curving roof is designed to evoke the roofs of traditional architecture in Canada, and the Hall appears to be "docked" to the museum. The exposed structure on the inside recalls the skeletal structures of vessels and the churches built by boat builders in the Maritimes. The space will receive visitors into its dimly-lit and mysterious interior, enchanting them with the play of light reflecting off the surface of the river.

The museum can be described as a land of curiosity. The complex 
as a whole is a blurred series of thresholds - between the architecture and the site, between the islands and the river, between the enclosed amphitheatre and the views of the falls. Visitors proceed through the exhibitions, following the gentle form of the island and delight in a series of galleries that are, at the same time, a sequence of experiences leading to the auditorium at the end of the site -another key place of dialogue, learning and engagement. Together the museum and the site are conceived as an experimental space exploring "eco-technology" that incorporates renewable energy (from the Quebec-hydro plant) and promotes natural regeneration principles and energy and life circulation principles.

The Museum of Science and Technology will arouse curiosity and induce visitors to go inside to observe the marvels contained in the body of what I hope would be a masterful piece of architecture. It will raise public awareness of the inadequacy of various attitudes toward technology, and help them to grasp technology's inextricable relationship to society and the built environment, and what needs to be done to help change the way people think about how technology affects them. 
The planning and design concept of New Museum of Science and Technology will integrate with its surrounding and demonstrate applications of sustainable strategies to achieve successful environmental solutions by:

- Maintaining the natural landscape of areas that are not affected by the new facilities, particularly the existing river shore.

- Introducing a thematic garden on top of the southern edge as a controlled demonstration area, exploiting a variety of kinds of vegetation to explore and explain the practice of growing plants with little soil: "Hydroponics". The roof will be blend into the appearance of the surrounding natural landscape and affirm this ecological relation between man and the natural environment and the building.

- Utilize public transportation as means to reach the museum.

- Introducing technologies associated with renewable energies by utilization of the hydro-electrical plant on Amelia Island to supplying its hydraulic power to produce electricity for the Museum. 
- Preservation of water as a fundamental resource by the use of river water and the re-use of slightly "grey" water for outdoor watering, for cleaning, and for fountains and water features. A number of ponds will be distributed across the site and linked (through canals and falls) to the river to illustrate the use of water as a natural resource and contribute to the growing body of knowledge concerning wetlands and shorelines.

- Installation of low use water consumption equipment.

- Intensive use of wood in the River Hall as one of the fundamental objects of sustainable principles of using renewable material.

- Use of natural light by using large openings to the external spaces and views with introducing technological capabilities to control desired light of the spaces.

- Orientation of the exhibition galleries to East-West, permitting the most important surfaces to be exposed to the South sun and the natural lighting surfaces from the North in important quantities.

- The use of materials with thermal mass that store heat during 
winter and stay cool during the summer with consideration to required energy for manufacturing.

Other design strategies utilizing a lower environmental impact will apply to the electrical and mechanical systems. 


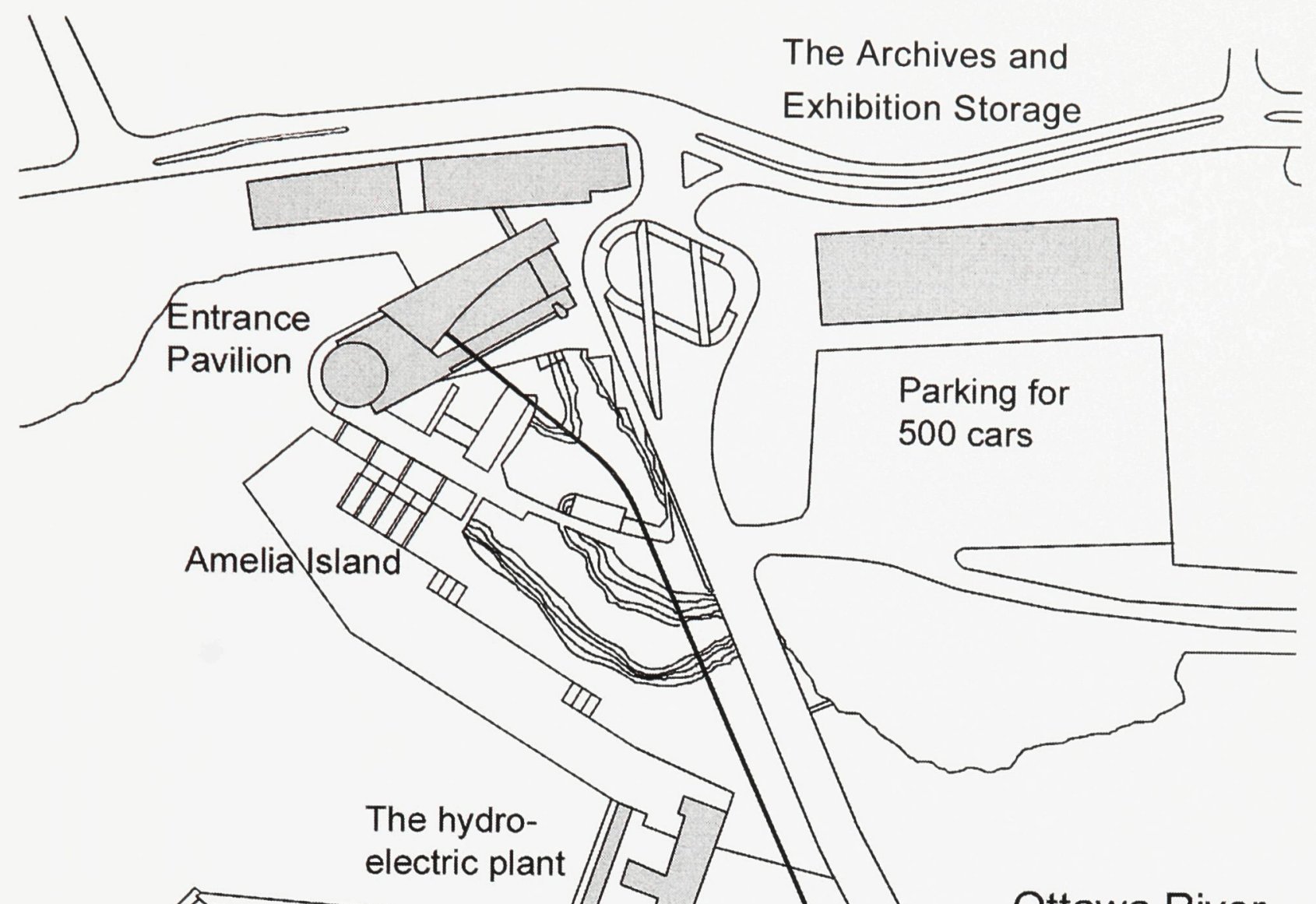

\section{Ottawa River}

Fig. 9. Site Layout 


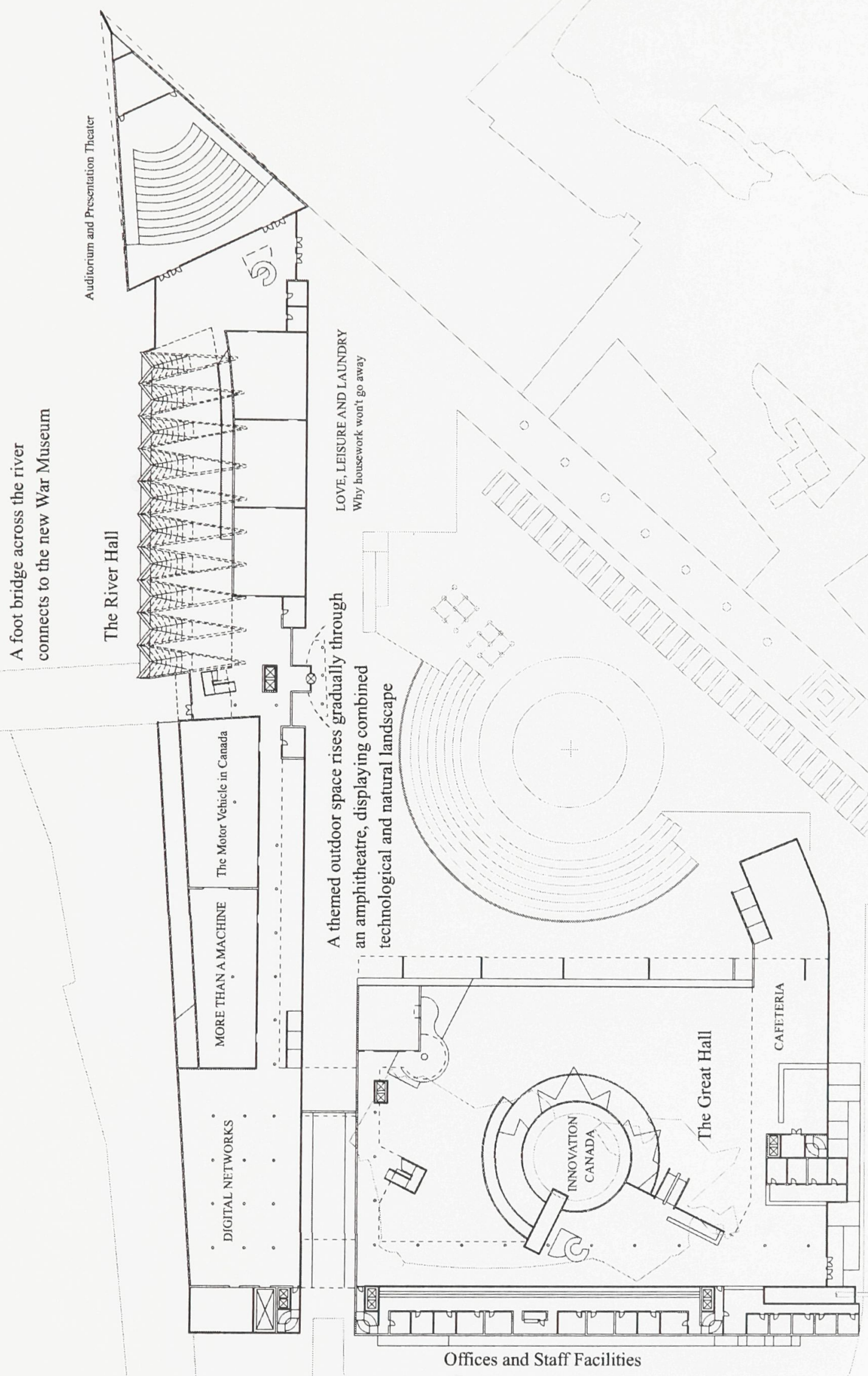

Fig. 10. Ground Floor Plan 


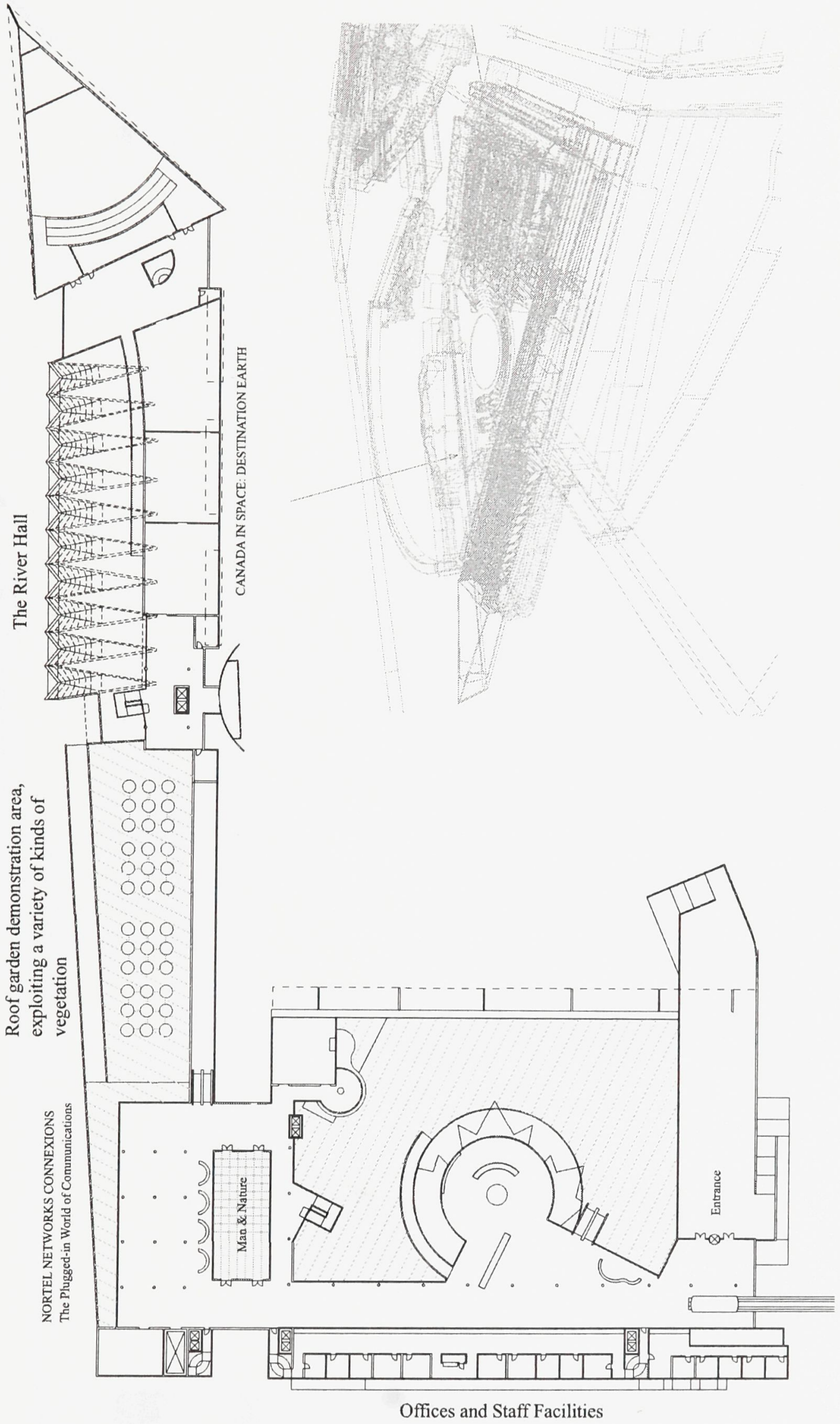

Fig. 11. First Floor Plan 


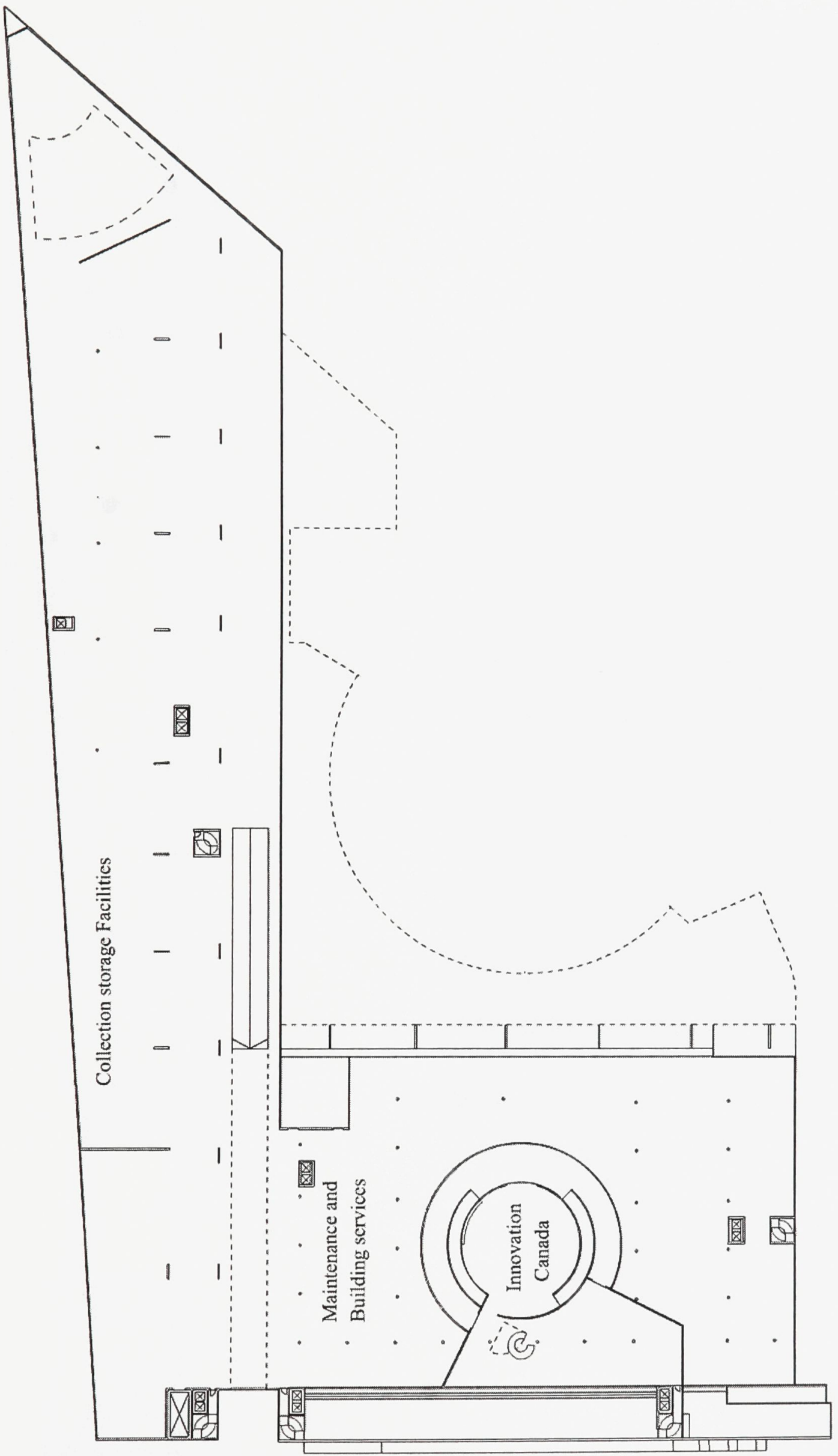

Fig. 12. Basement Layout 

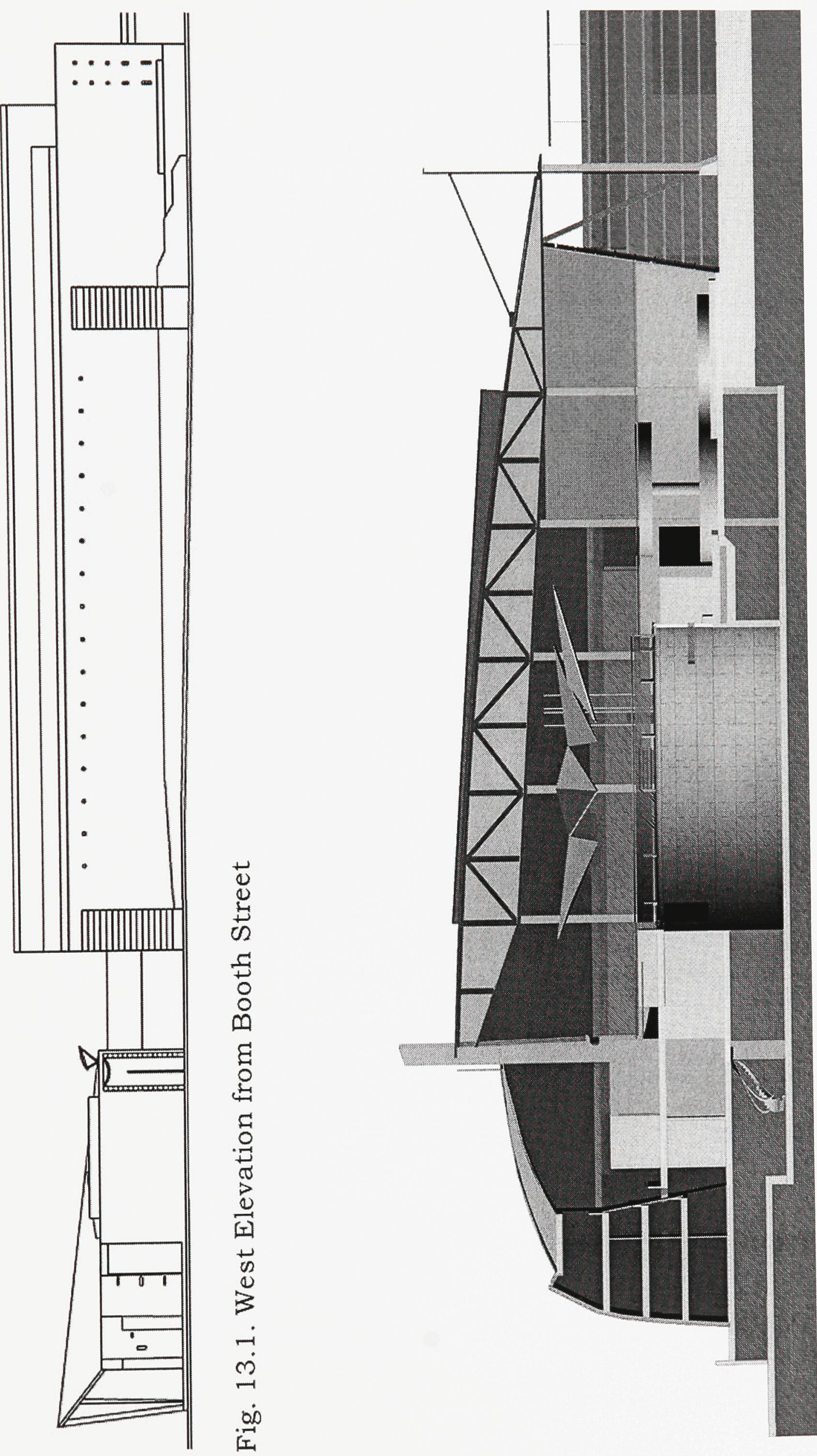

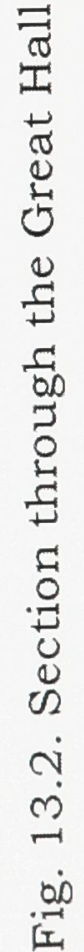




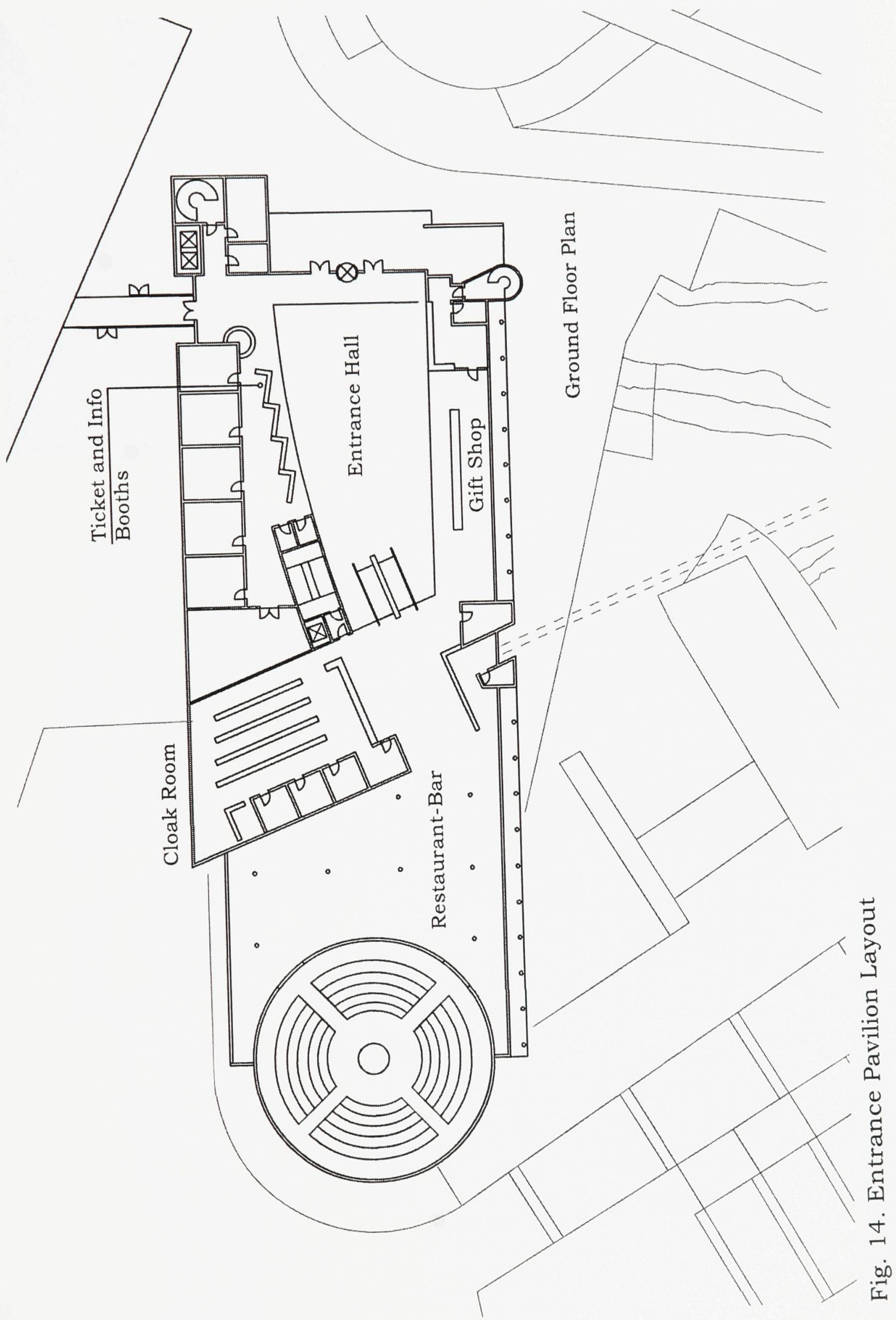



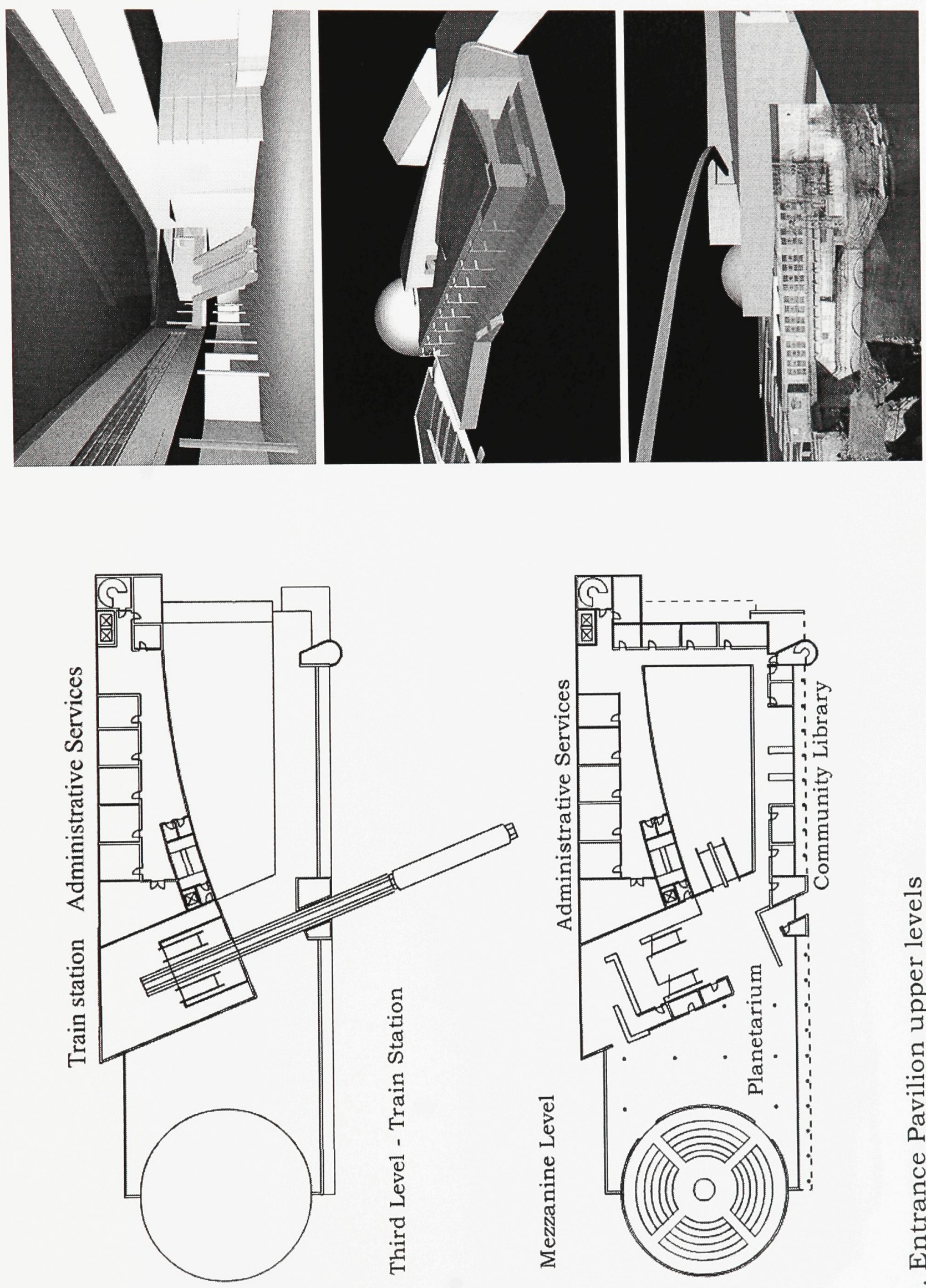

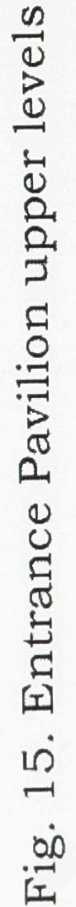




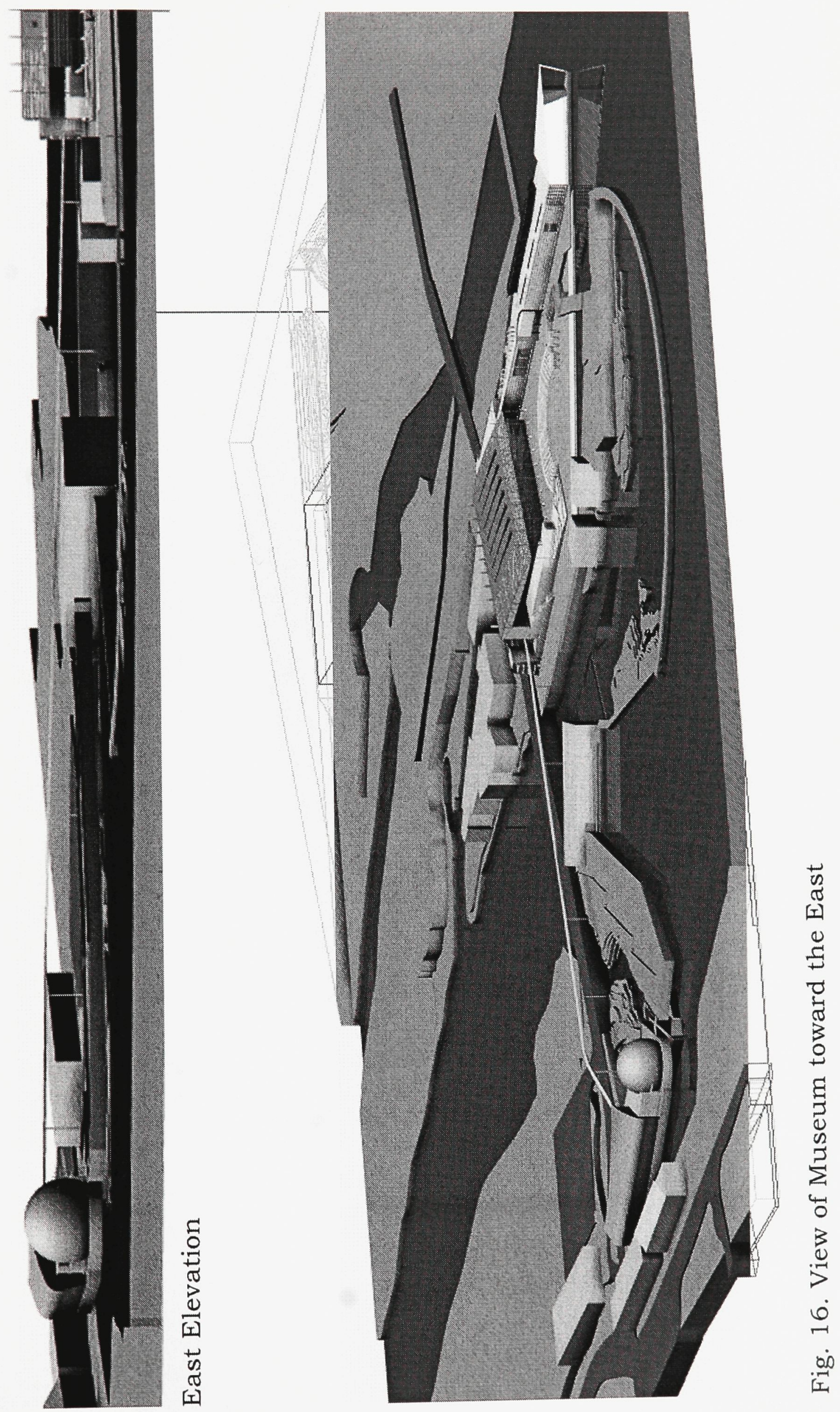



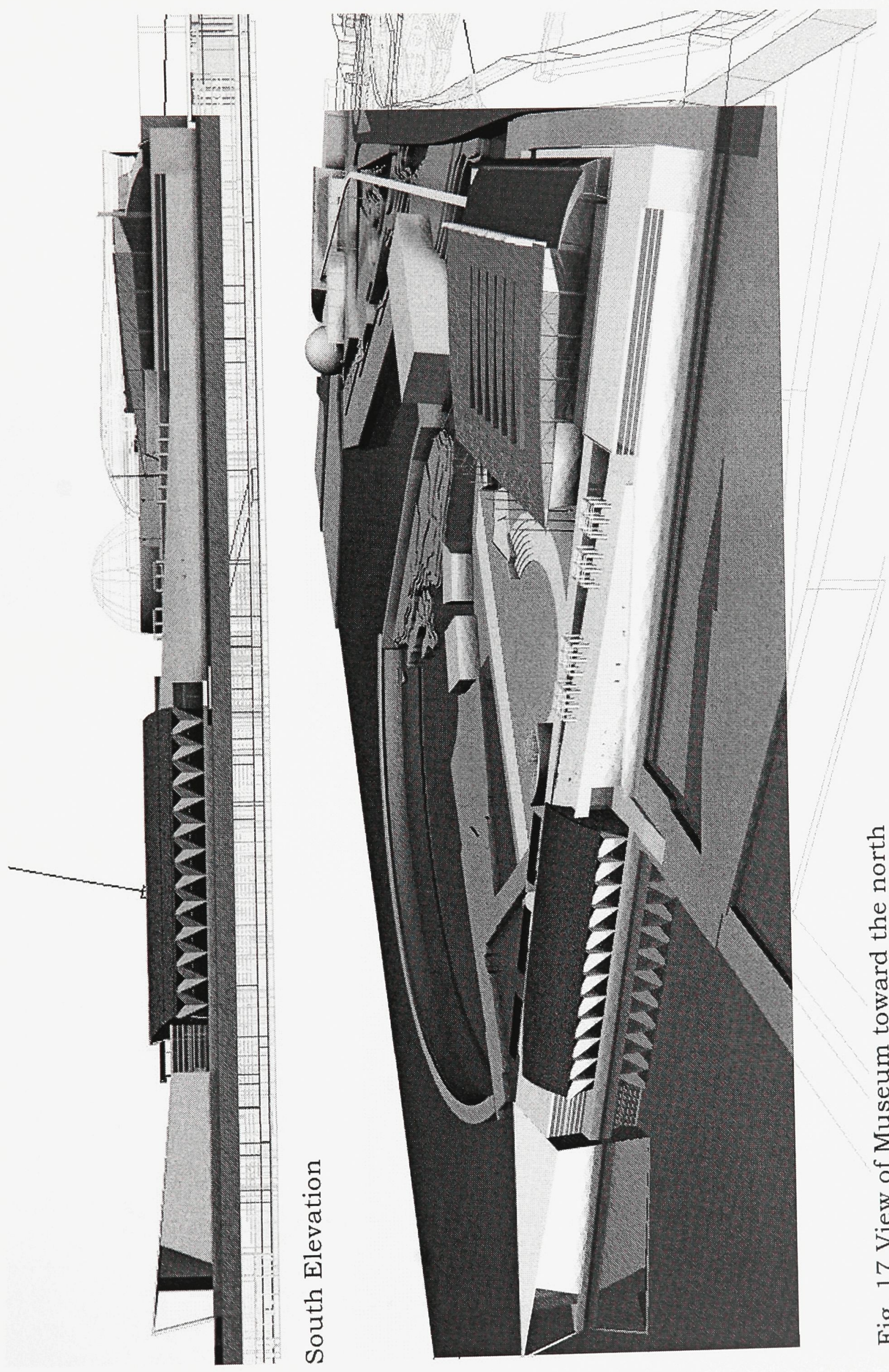

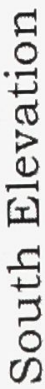
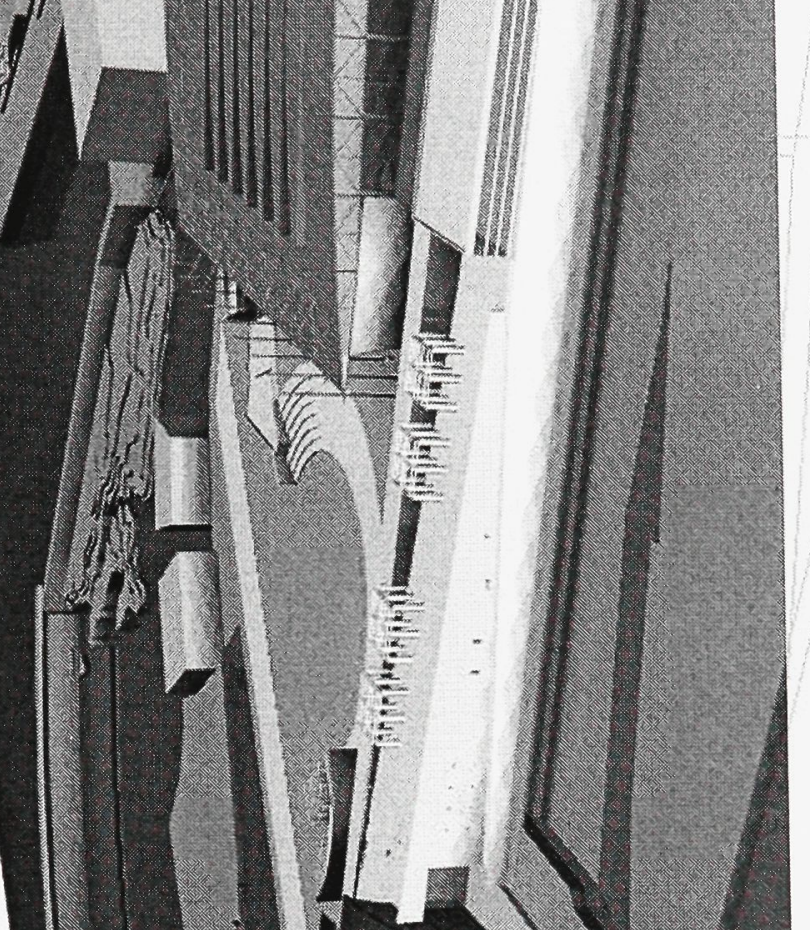

궁

운

范

E

3

章

$\sum_{4}$

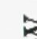

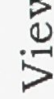

I

崩 
Fig. 18 External Views- 1

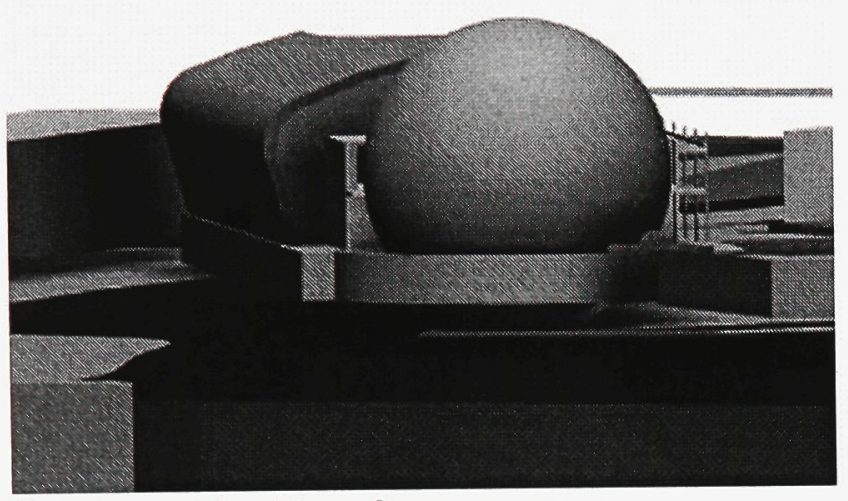

Entrance Pavilion from east

Plaza to include the falls and the Ottawa River beyond
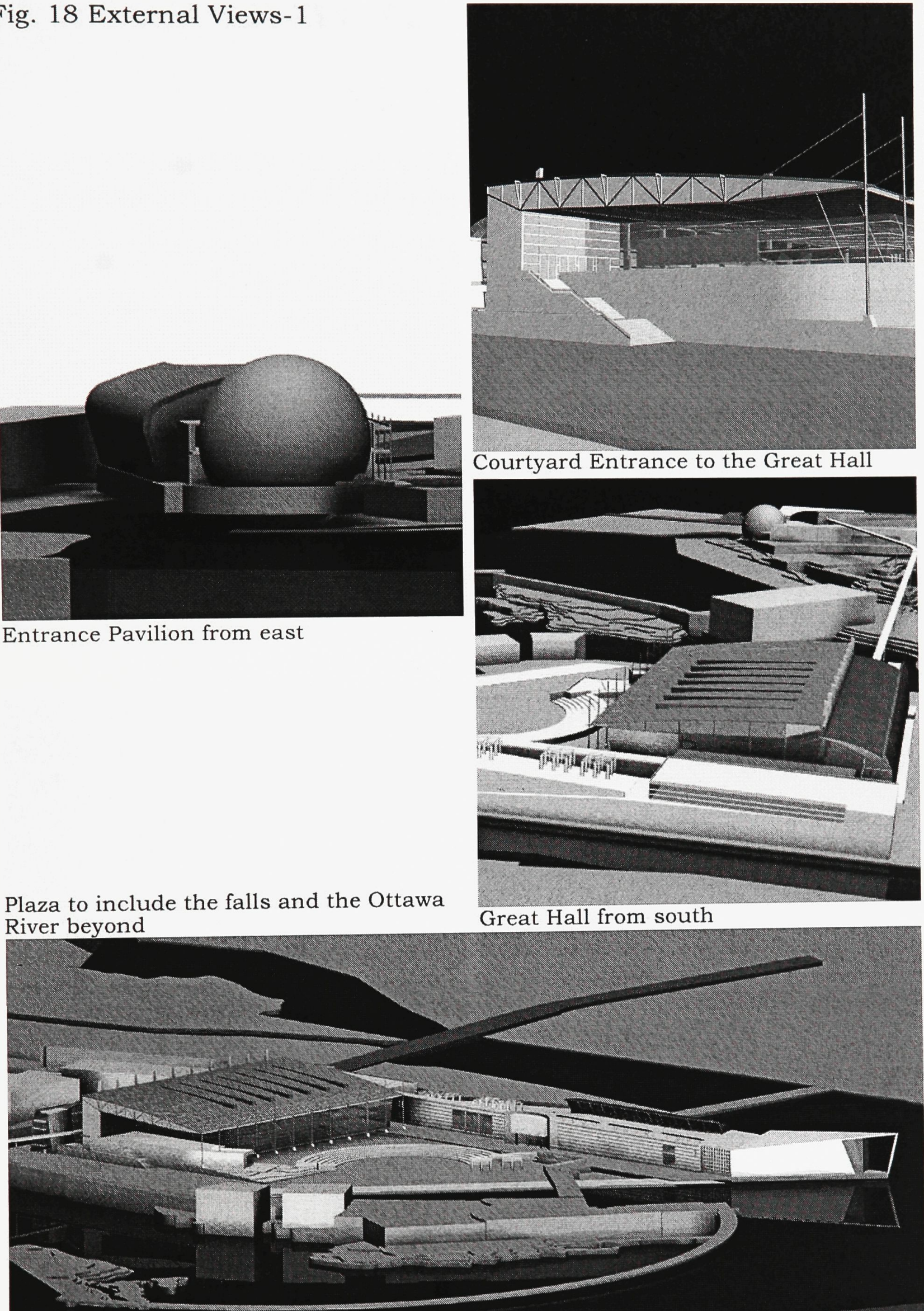


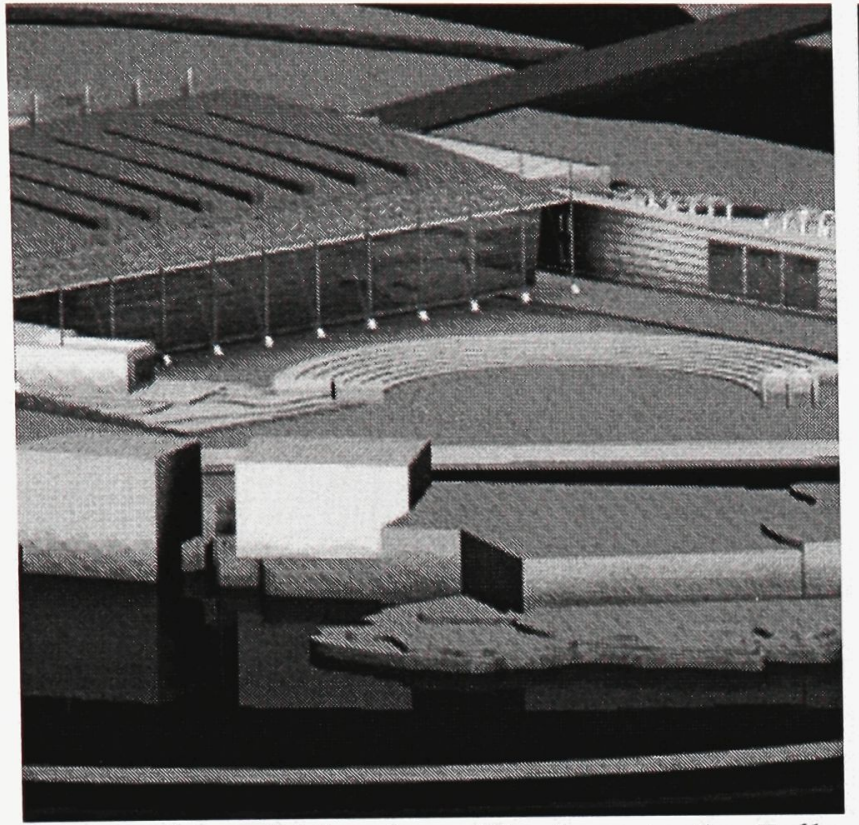

Enclosed Amphitheatre with views to the Falls

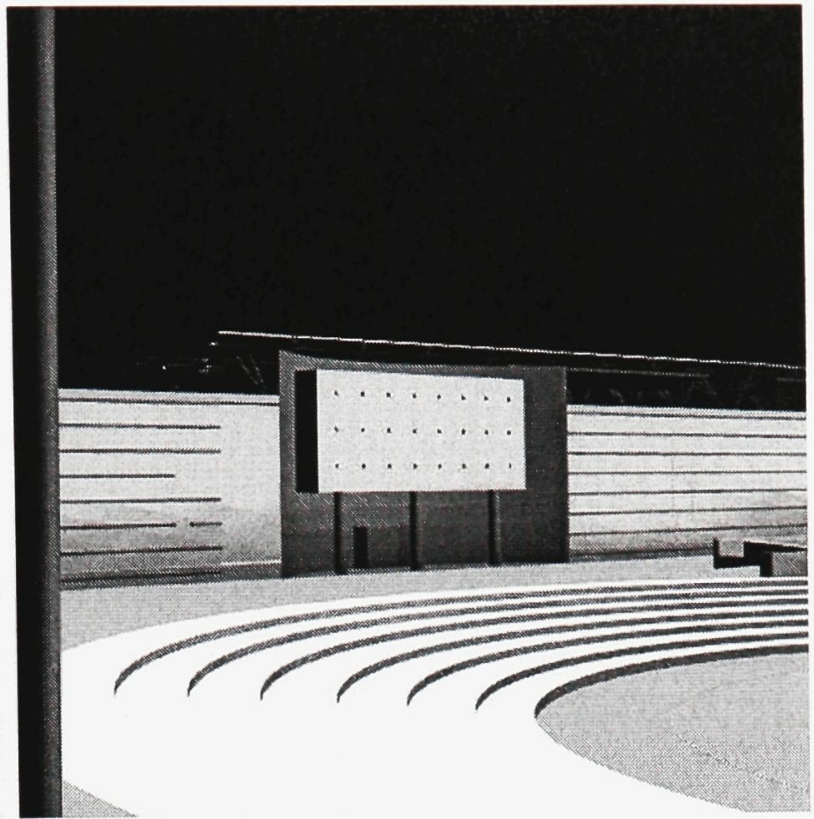

Amphitheatre

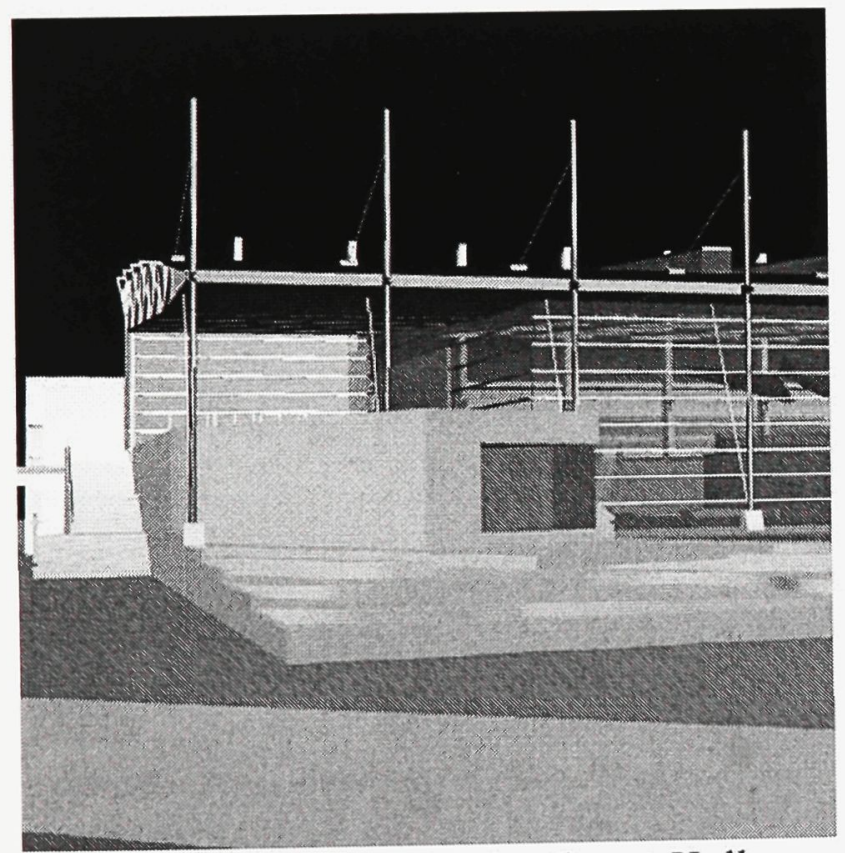

Courtyard Entrance to the Great Hall

Fig. 19 External views -2

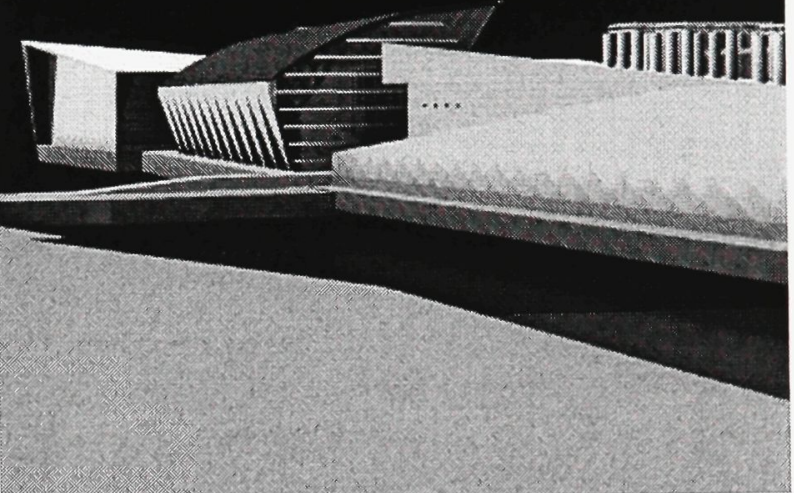

River Hall and Auditorium from south

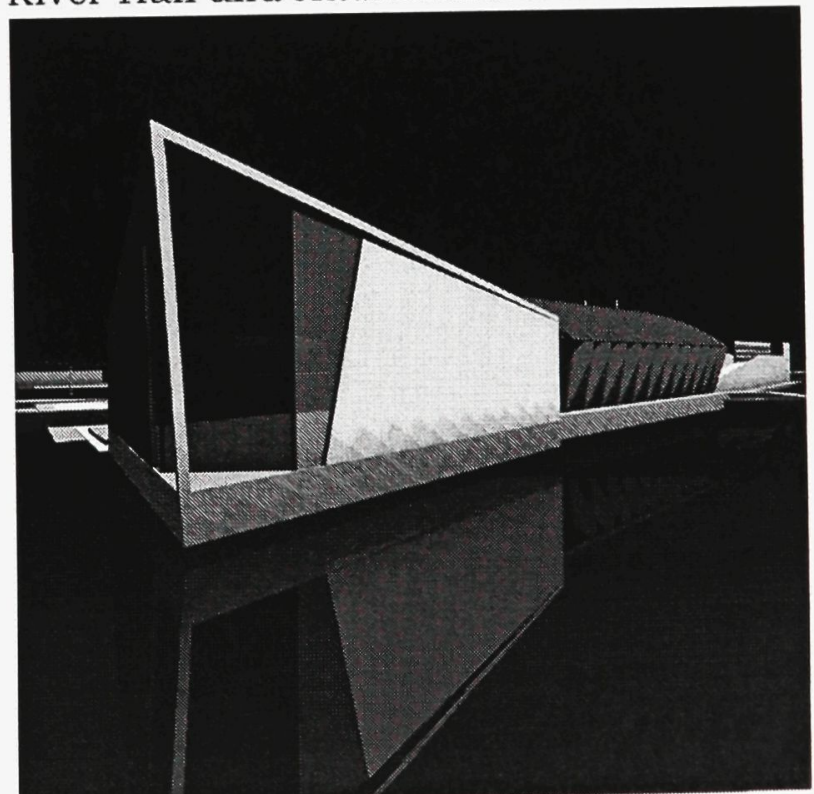




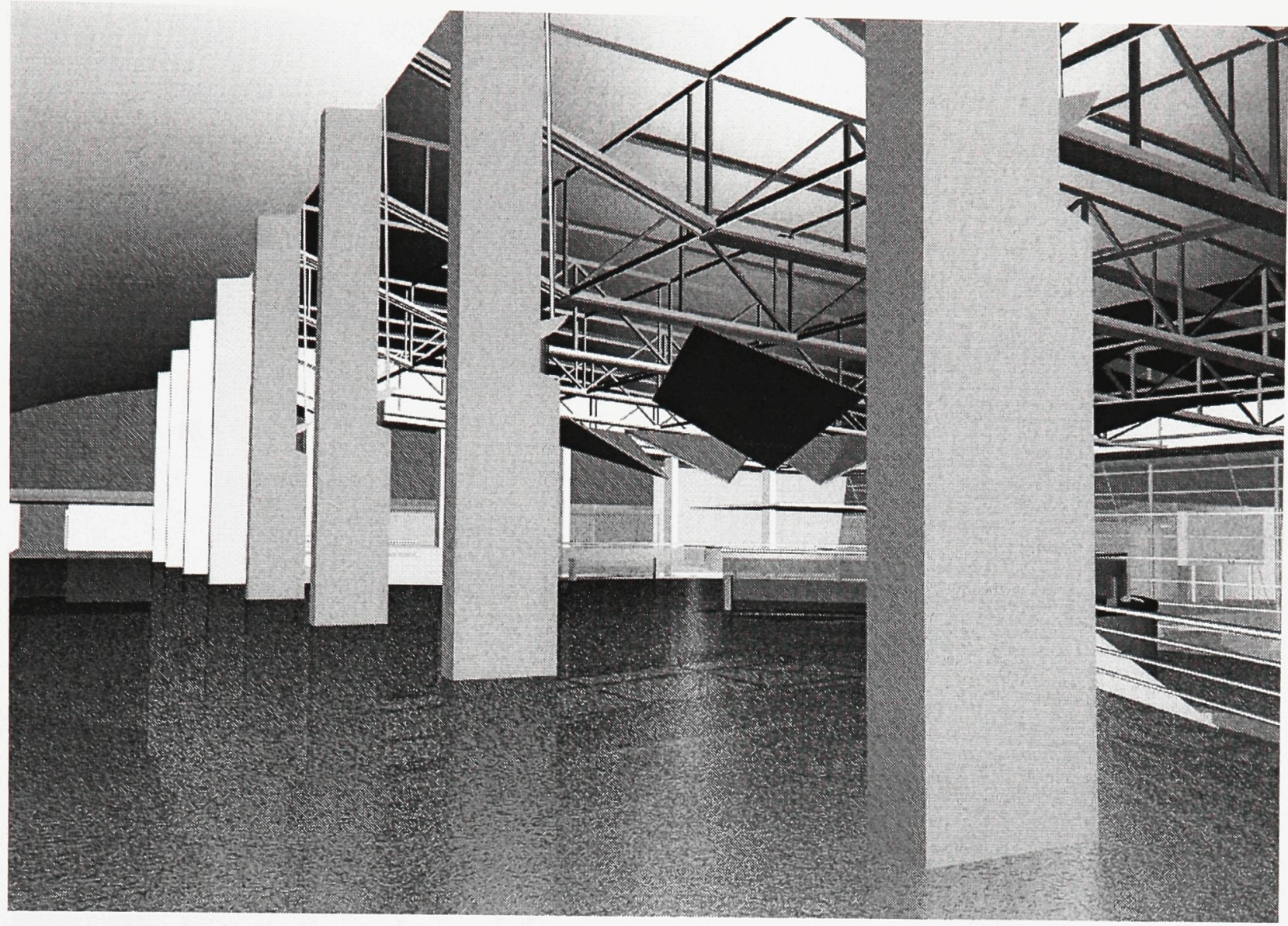

View from Train level

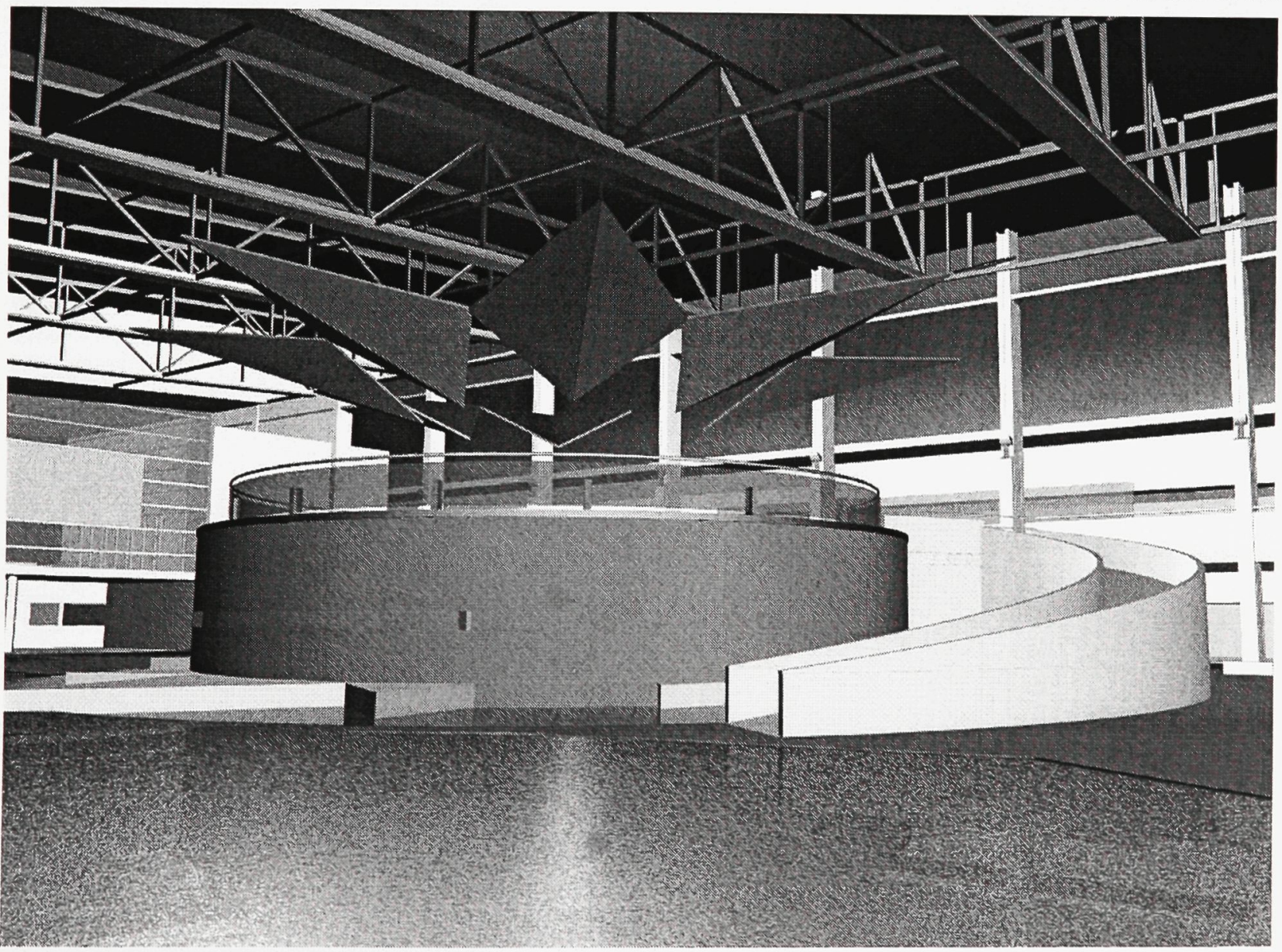

Fig. 20 Inside the Great Hall -1

View from Ground Level 


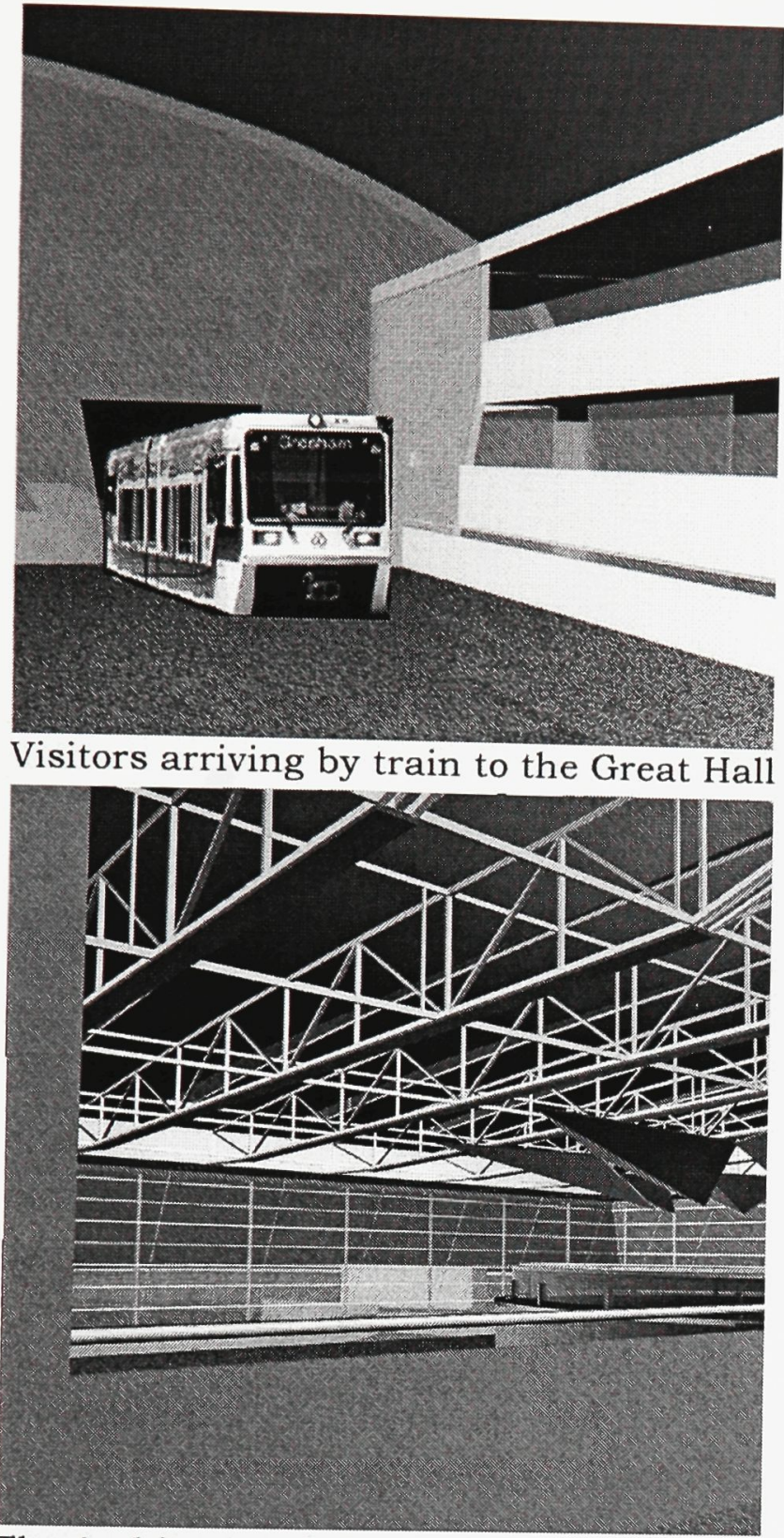

The Architectural elements forming space

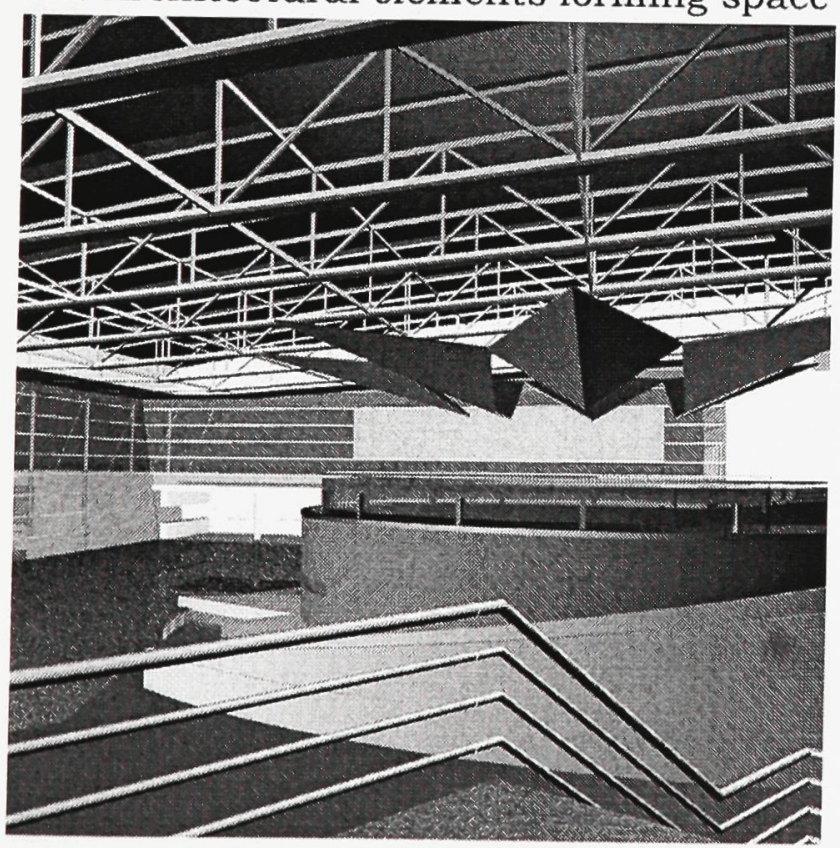

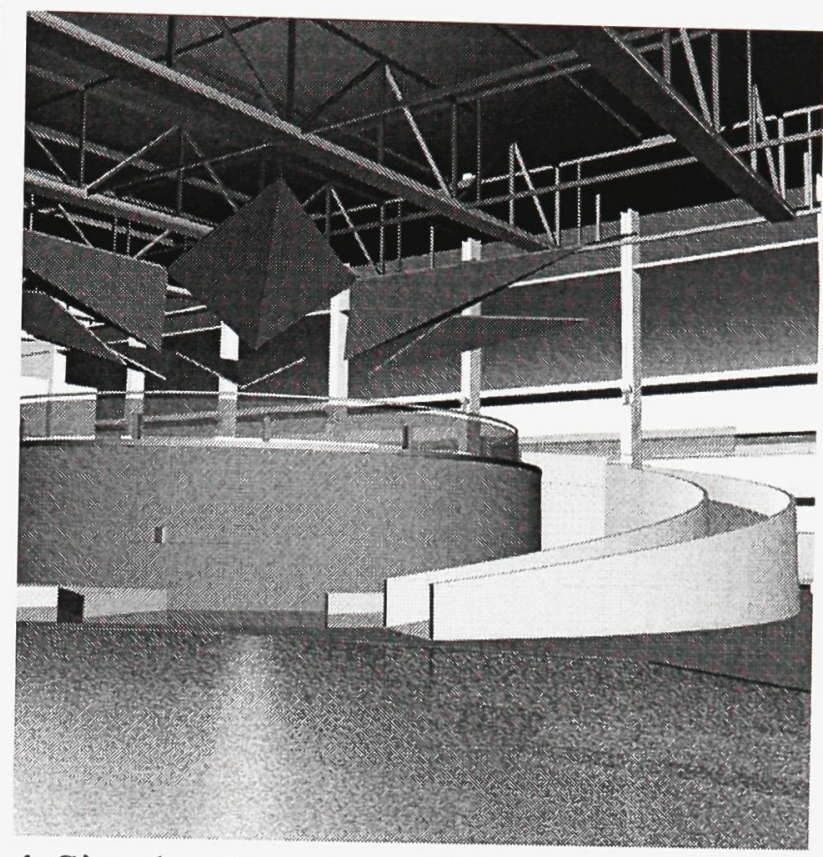

A Circular Structure of Natural Stone, and a soothing waterfall fed by rainwater 
The Wooden Structure of The River Hall
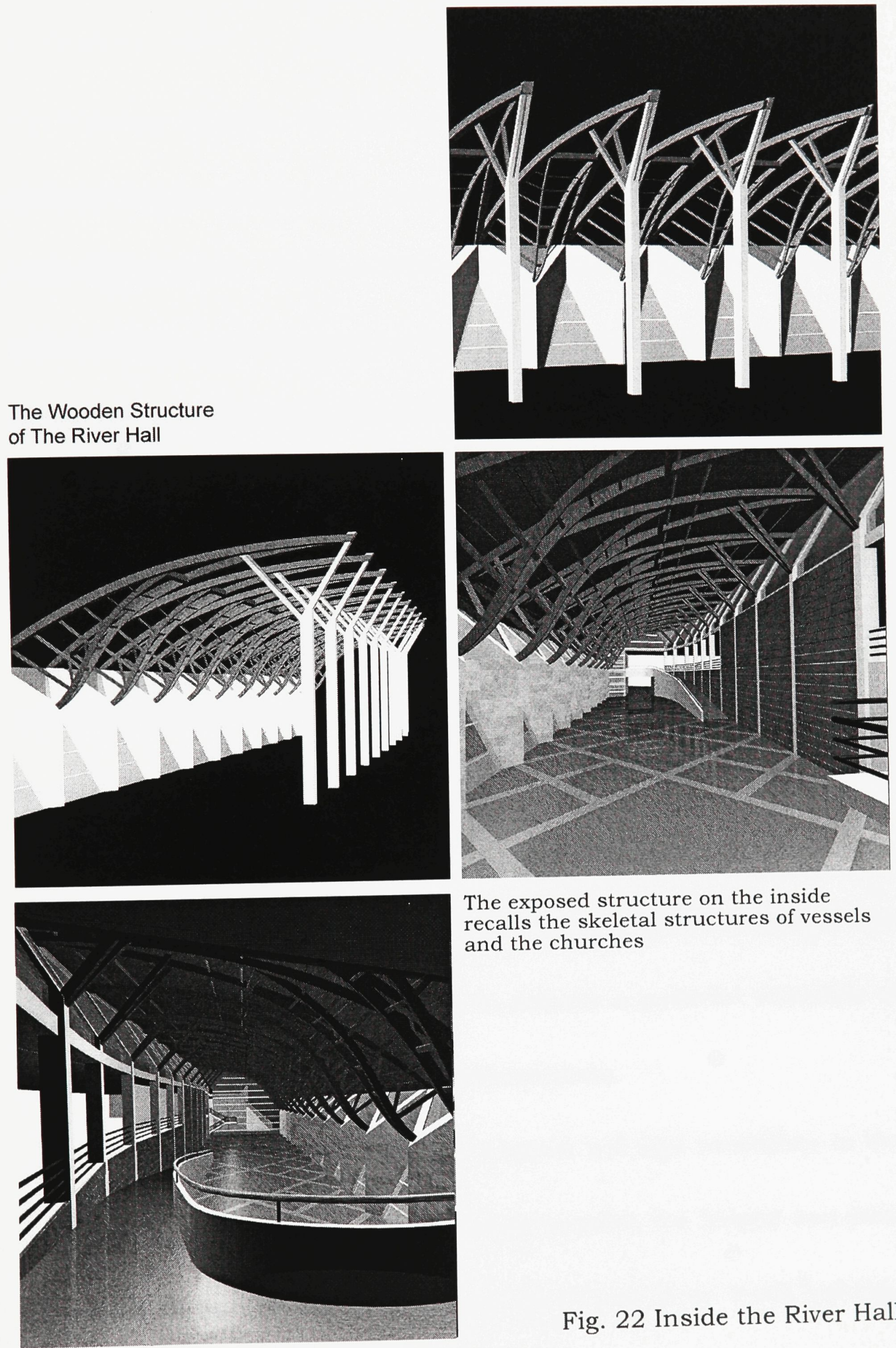

The exposed structure on the inside recalls the skeletal structures of vessels and the churches

Fig. 22 Inside the River Hall 


\section{Conclusion}

A new Museum for Science and Technology at the core of the National Capital Region will promote Canada's strong scientific and technological legacy. More so than other national museums (Civilization, National Gallery, and Museum of War) it will raise public awareness and encourage responsible action with respect to the ways in which science and technology interact with the natural and cultural environments.

The Museum's current facility, in conjunction with its location far from other tourist attractions, impedes it from effectively fulfilling this potential. In response, I have chosen a new site with a rich natural environment and a significant historical industrial infrastructure. To help promote the responsible use of natural and cultural resources I took full advantage of the features of the site to create a dynamic dialogue that merges interior and exterior spaces to achieve a powerful ensemble of architecture, landscape and urban infrastructure.

The Museum's proposed new location will also contribute to the current plan to strengthen the exchange between the federal and local aspects of the core area on both sides of the Ottawa River. It will highlight 
the scenic nature of Chaudiere Falls; encourage public access and pedestrian movement to the River to and from other cultural establishments, and open new views to the downtown and Parliament Hill.

The design strategy incorporated public spaces into the architecture, site and program such that the Museum's exhibition program can extend beyond its collection to define the whole character of the place. In addition to these spaces, controlled galleries and exhibition areas will be available to the curatorial staff for long-term and rotating exhibits.

At its new location the Museum of Science and Technology will be able to broaden its mission to further stimulate and inspire its visitors.

Rather than building a monument I am proposing an integrated environment to promote environmental responsibility and awareness that we are part of a larger living system. If the Twentieth Century has ended with many contradictions, new theories on technology imply cultural shifts and changes in our lifestyle in deference to our communities and environment. Among other manifestation of this change, architecture will be challenged to be more strongly connected to the natural environment and to employ sustainable strategies in support of the environment and the 
conservation of natural resources.

Thus the relationship between technology, culture and the natural environment will become an explicit new theme of the Museum of Science and Technology - supported by its site and the architecture of the new facilities. It is, therefore, not just LEED certification and/or the use of innovative technologies for heating and cooling that define innovation, but the way the museum complex (site, buildings, collection and exhibition program) inspires us to value sustainable communities, re-define our future and reconsider Canada's position in the world.

While the design of a new facility is a large-scale project worthy of an extensive design team, I used the thesis to set out general planning principles and to identify key spaces for further development. It is hoped that the work, in its current state of development will be sufficient to inspire, guide and accelerate the process by which a new Canada Science and Technology Museum will be realized in the core of the National Capital to the benefit of all Canadians. 

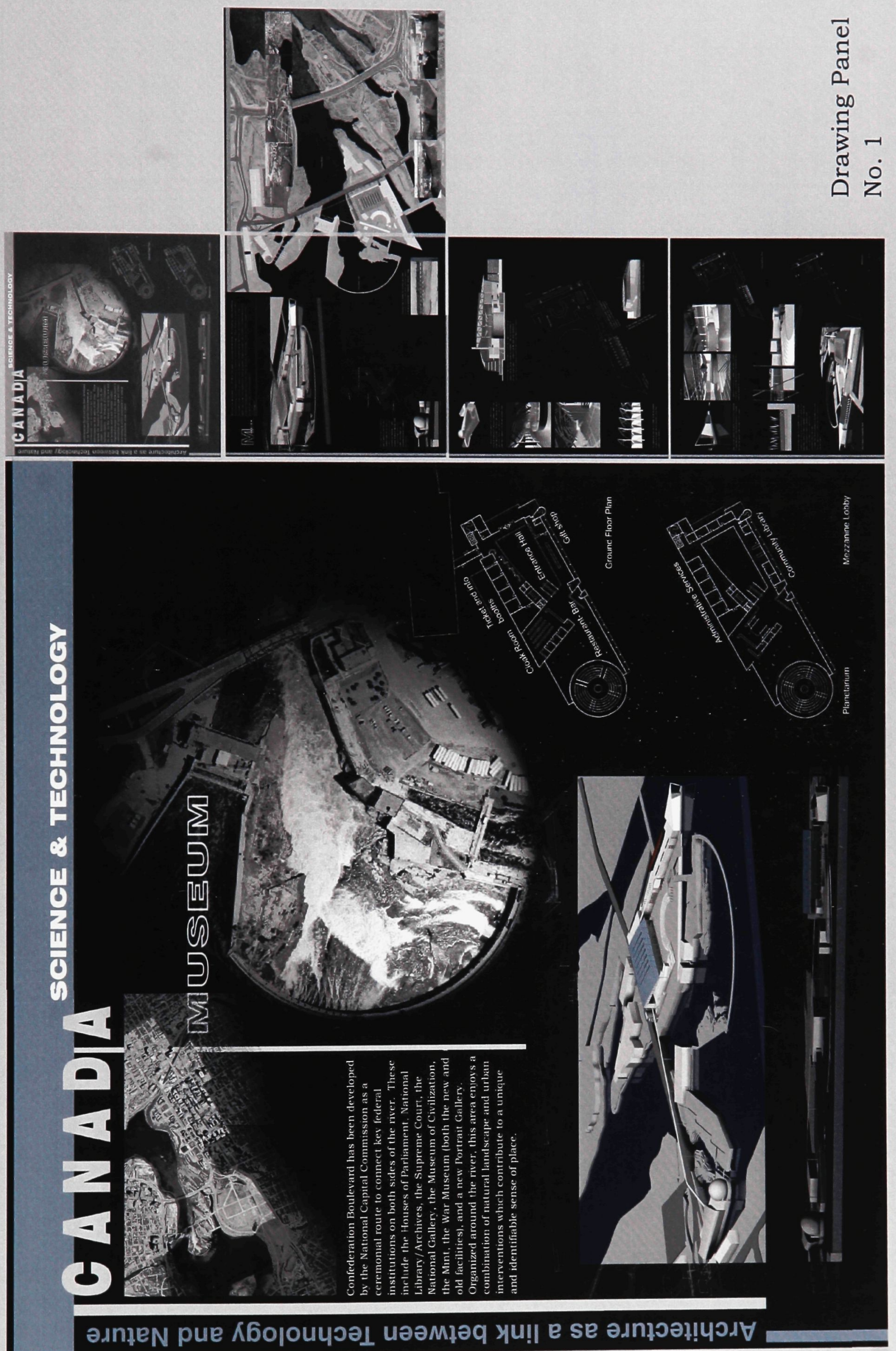

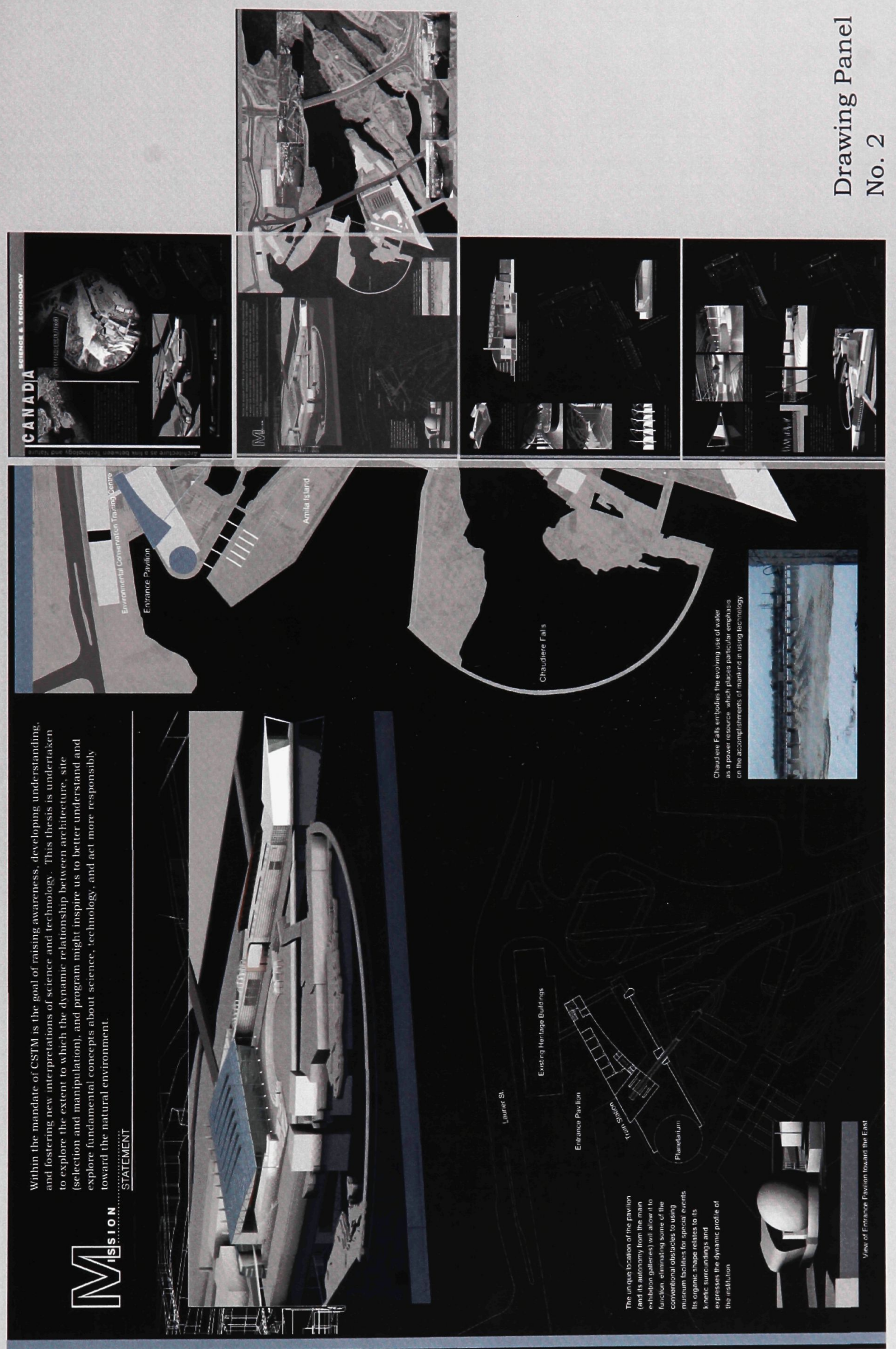

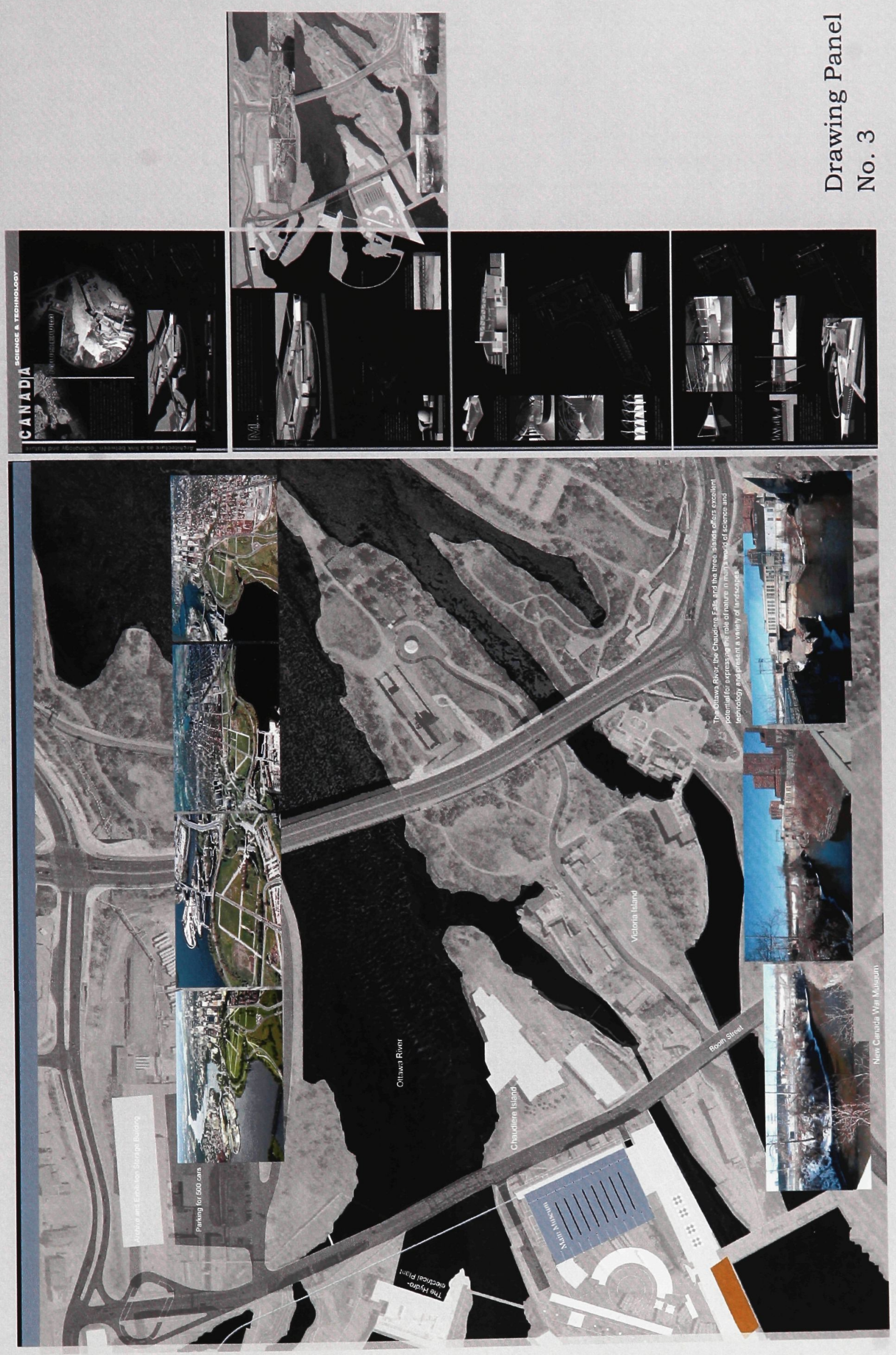

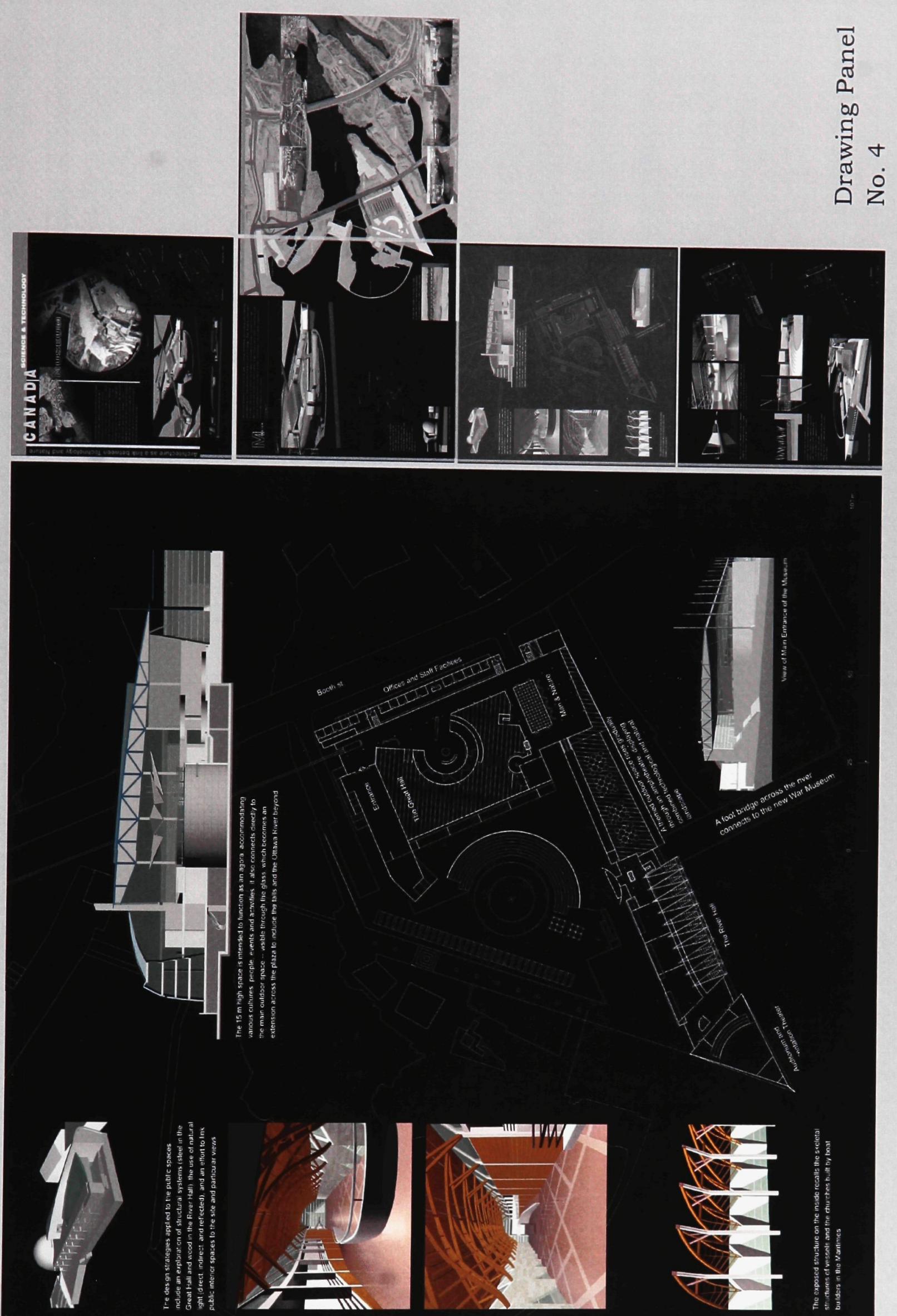

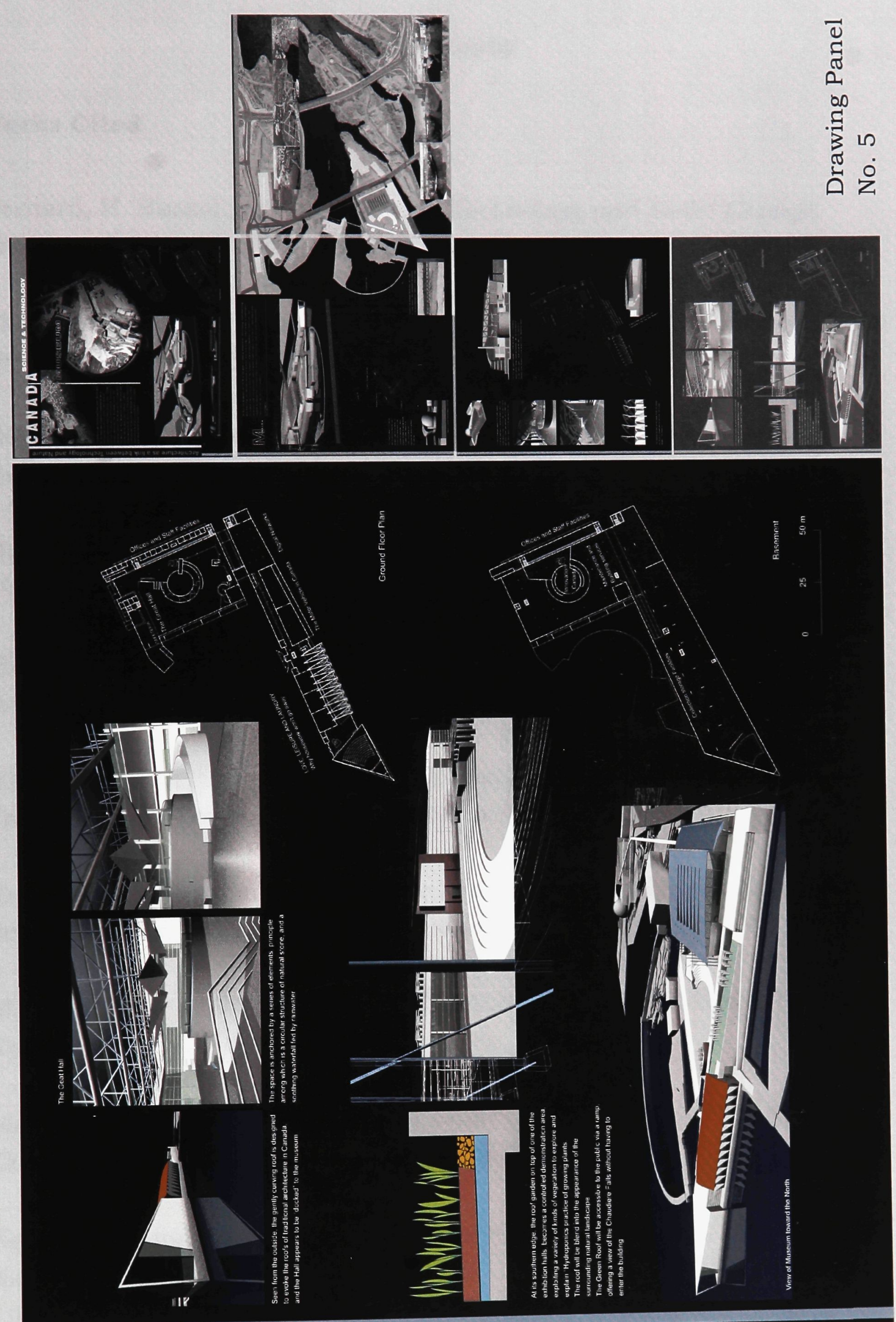


\section{Bibliography}

\section{Works Cited}

Bernard, H. Russell, and Pelto Pertti. Technology and Social Change. Prospect Heights, Ill.: Waveland Press, 1987.

The Ontario Science Centre. First Ten Years: A History of It's Founding. The Ontario Science Centre, 1979.

Goyder, John. Technology and Society: A Canadian Perspective. Peterborough, Ont.: Broadview Press, 1997.

Grant, George. Technology and Justice. Toronto: House of Anansi Press, 1986.

Hagan, Susannah. Taking Shape: A New Contract Between Architecture and Nature. Oxford; Boston: Architectural Press, 2001.

Heidegger, Martin. The Question Concerning Technology and Other Essays. Trans. William Lovitt. New York; London: Harper and Row, 1977.

Kurokawa, Kisho. Each One a Hero: The Philosophy of Symbiosis. Trans. Jeffrey Hunter. Tokyo; New York: Kodansha International, 1997.

Mahgoub, Yasser. Planning for Sustainable Development. International Conference on Urbanization and Housing, 1997.

Matthews, Geoff. Museums and Art Galleries: A Design and Development Guide. Oxford; Boston: Butterworth Architecture, 1991.

National Capital Commission. Chaudiere Historical Documentation. 1982. National Capital Commission. Core Area: Concept of Canada's Capital. 1998. 
National Capital Commission. Thomson Brandt Study. 1992.

Provencher Roy + Associés Architects. The Arcop Group. Feasibility and Functional Studies. Canada Science and Technology Museum, 2003.

The Oxford English Reference Dictionary. Oxford: Oxford University Press, 2002.

United Nations Economic Commission for Europe. Guidelines on Sustainable Human Settlements Planning and Management. New York and Geneva: United Nations Publications, 1996.

U.S. Green Building Council. LEED Reference Guide Version 2.1. Washington, DC: U.S. Green Building Council, 2002.

Van Der Ryn, Sim and Cowan, Stuart. Ecological Design. Washington, D.C.: Island Press, 1995. 


\section{Works Consulted}

Baudrillard, Jean. The Vital Illusion. New York: Columbia University Press, 2000.

Erickson, Arthur. The Architecture of Arthur Erickson. Vancouver: Douglas \& McIntyre, 1988.

Goyder, John. Technology + Society: A Canadian Perspective. Peterborough, Ont.: Broadview Press, 1997.

Harbison, Robert. Eccentric Spaces. New York: Knopf, 1977.

Pérez-Gómez, Alberto. Architecture and the Crisis of Modern Science.

Cambridge, Mass.: MIT Press, 1983.

Porter, William. "Technology, Form and Culture in Architecture:

Misconception and Myth, " in Architectural Education in the Islamic World. Ed. Ahmet Evin. Singapore: Concept Media/Aga Khan Award for Architecture, 1986.

Postman, Neil. Technopoly: The Surrender of Culture to Technology. New York: Knopf, 1992.

Toffler, Alvin. The Third Wave. Toronto: Bantam, 1981.

Watkins, Bruce O. Technology and Human Values: Collision and Solution. Ann Arbor, Mich.: Ann Arbor Science Publishers, 1977.

Virilio, Paul. The Art of Motor. Trans. Julie Rose. Minneapolis: University of Minnesota Press, 1995. 


\section{Web Sites}

American Museum of Natural History. 18 Sept. 2004.

<http://www.amnh.org/exhibitions/permanent/rose>

Canada Science and Technology Museum. 20 July 2004.

<http://www.sciencetech.technomuses.ca/english/whatson/ongoing_ex hibits.cfm>

The Green Engineer. Christopher, Schaffner. 9 Sept. 2004.

$<$ http://www.greenengineer.com/Leed.htm>

The Wikimedia Foundation Inc. Encyclopedia. Canada. 10 Aug. 2004

<http://www.campusprogram.com/reference/en/wikipedia/c/ca/canad a.html>

The Wikimedia Foundation Inc. Encyclopedia. The Smithsonian Institution. 15 Sept. 2004 <http://en.wikipedia.org/wiki/Smithsonian_Institution>

The www Virtual Library. History of Canada's Capital Region. 15 Sept. 2004.<http://www.canadascapital.gc.ca/about_canadas/ncr/history/hi story2_e.html\#Highway> 


\section{Appendices}

Appendix A: Leed project checklist

Source :

U.S. Green Building Council. LEED Reference Guide Version 2.1. Washington, DC: U.S. Green Building Council, 2002 


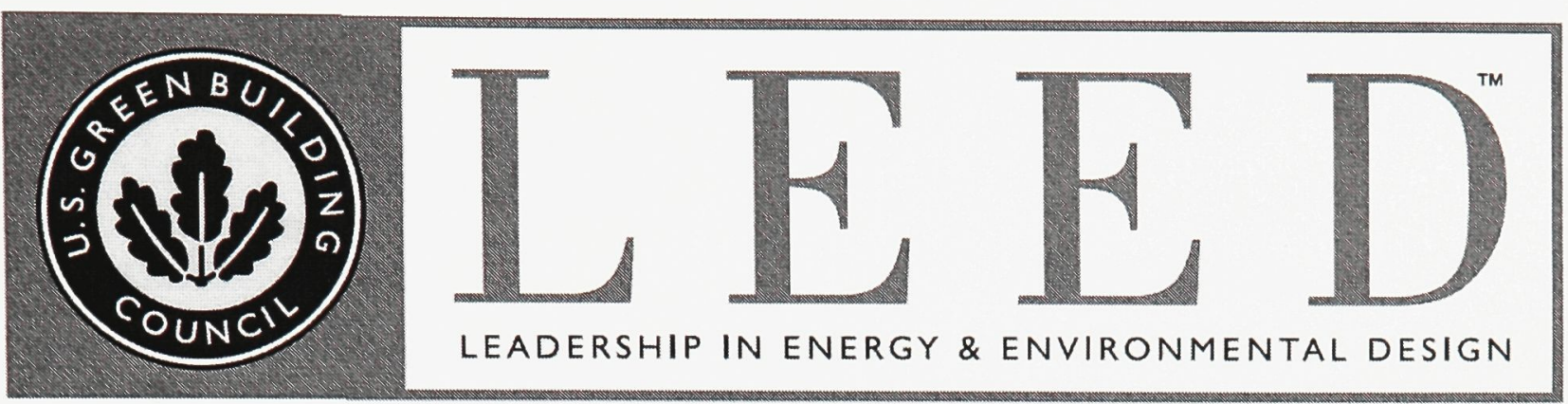

Green Building Rating System For New Construction \& Major Renovations $($ LEED-NC)
Version 2.1

November 2002 


\section{Project Checklist}

\section{Sustainable Sites}

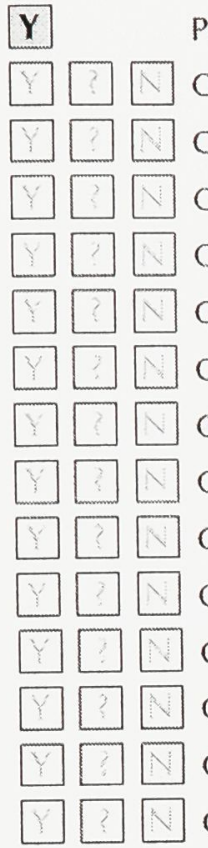

Prereq 1

Credit 1

Credit 2

Credit 3

Credit 4.1

Credit 4.2

Credit 4.3

Credit 4.4

Credit 5.1

Credit 5.2

Credit 6.1

Credit 6.2

Credit 7.1

Credit 7.2

Credit 8
Erosion \& Sedimentation Control

14 Possible Points

Site Selection

Urban Redevelopment

Brownfield Redevelopment

Alternative Transportation, Public Transportation Access

Alternative Transportation, Bicycle Storage \& Changing Rooms

Alternative Transportation, Alternative Fuel Vehicles

Alternative Transportation, Parking Capacity

Reduced Site Disturbance, Protect or Restore Open Space

Reduced Site Disturbance, Development Footprint

Stormwater Management, Rate and Quantity

Stormwater Management, Treatment

Heat Island Effect, Non-Roof

Heat Island Effect, Roof

Light Pollution Reduction

Required

\section{Water Efficiency}

5 Possible Points

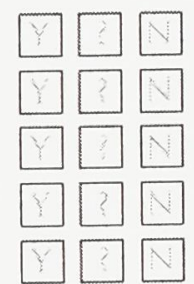

Credit 1.1 Water Efficient Landscaping, Reduce by $50 \%$

Water Efficient Landscaping No Potable Use or No Irrigation

Credit 2 Innovative Wastewater Technologies

Credit 3.1 Water Use Reduction, 20\% Reduction 1

Credit 3.2 Water Use Reduction, 30\% Reduction

\section{Energy \& Atmosphere}

17 Possible Points

\begin{tabular}{|c|c|c|c|}
\hline $\mathrm{Y}$ & Prereq 1 & Fundamental Building Systems Commissioning & Required \\
\hline $\mathrm{Y}$ & Prereq 2 & Minimum Energy Performance & Required \\
\hline $\mathbf{Y}$ & Prereq 3 & CFC Reduction in HVAC\&R Equipment & Required \\
\hline$Y$ & Credit 1 & Optimize Energy Performance & $1-10$ \\
\hline \begin{tabular}{|r} 
\\
\end{tabular} & Credit 2.1 & Renewable Energy, 5\% & 1 \\
\hline & Credit 2.2 & Renewable Energy, $10 \%$ & 1 \\
\hline$Y$ & Credit 2.3 & Renewable Energy, 20\% & 1 \\
\hline & Credit 3 & Additional Commissioning & 1 \\
\hline Y & Credit 4 & Ozone Depletion & 1 \\
\hline & Credit 5 & Measurement \& Verification & 1 \\
\hline & Credit 6 & Green Power & 1 \\
\hline
\end{tabular}


Prereq 1 Storage \& Collection of Recyclables

Required

Credit 1.1 Building Reuse, Maintain 75\% of Existing Shell

Credit 1.2 Building Reuse, Maintain $100 \%$ of Shell

Credit 1.3 Building Reuse, Maintain 100\% Shell \& 50\% Non-Shell

Credit 2.1 Construction Waste Management, Divert 50\%

Credit 2.2 Construction Waste Management, Divert 75\%

Credit 3.1 Resource Reuse, Specify 5\%

Credit 3.2 Resource Reuse, Specify 10\%

Credit 4.1 Recycled Content, Specify $5 \%$ (p.c. + 1/2 p.i.)

Credit 4.2 Recycled Content, Specify $10 \%$ (p.c. $+1 / 2$ p.i.)

Credit 5.1 Local/Regional Materials, $20 \%$ Manufactured Locally

Credit 5.2 Local/Regional Materials, of 20\% in MRc5.1, 50\% Harvested Locally 1

Credit 6

Credit 7

Rapidly Renewable Materials

Certified Wood

\section{Indoor Environmental Quality}

15 Possible Points

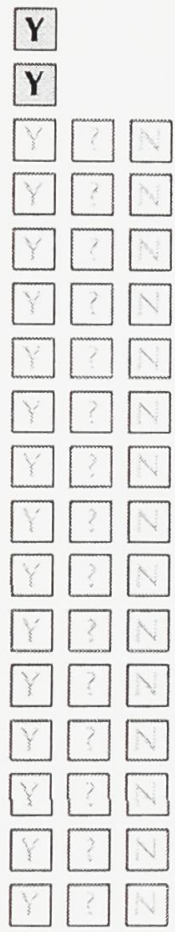

Prereq 1 Minimum IAQ Performance

Required

Prereq 2 Environmental Tobacco Smoke (ETS) Control

Required

Credit 1

Carbon Dioxide $\left(\mathrm{CO}_{2}\right)$ Monitoring

Credit 2 Ventilation Effectiveness

Credit 3.1 Construction IAQ Management Plan, During Construction

Credit 3.2 Construction IAQ Management Plan, Before Occupancy

Credit 4.1 Low-Emitting Materials, Adhesives \& Sealants

Credit 4.2 Low-Emitting Materials, Paints

Credit 4.3 Low-Emitting Materials, Carpet

Credit 4.4 Low-Emitting Materials, Composite Wood

Credit 5 Indoor Chemical \& Pollutant Source Control

Credit 6.1 Controllability of Systems, Perimeter

Credit 6.2 Controllability of Systems, Non-Perimeter

Credit 7.1 Thermal Comfort, Comply with ASHRAE 55-1992

Credit 7.2 Thermal Comfort, Permanent Monitoring System

Credit 8.1 Daylight \& Views, Daylight $75 \%$ of Spaces

Credit 8.2 Daylight \& Views, Views for $90 \%$ of Spaces

\section{Innovation \& Design Process}

5 Possible Points

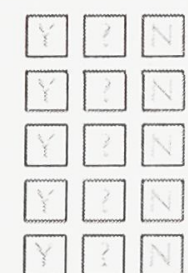

Credit 1.1 Innovation in Design

Credit 1.2 Innovation in Design

Credit 1.3 Innovation in Design

Credit 1.4 Innovation in Design

Credit 2 LEED ${ }^{T M}$ Accredited Professional

Project Totals

69 Possible Points 
Appendix B: History of the Ottawa-Hull Chaudiere Industrial District

Source:

National Capital Commission, 1967 
The explorers, missionaries, fur traders and first settlers who passed up the Ottawa River knew the waterfall where Bytown came to be built as a great interruption where the water poured in four channels between islands. The next to the northernmost of these channels was - and still is - by far the widest, and here the major part of the river's flow tumbles over a jagged edged limestone shelf into a basin that had been named by Champlain the Chaudiere this cataract was the Chaudiere falls.

Chaudiere Island is one of three islands that block Ottawa River near the falls, Amelia and Victoria, from north to south. Just south of Victoria Island the mainland jutted downriver in a blunt point. Here had landed the disbanded soldiers who had arrived in 1818 to take up lands and establish the Richmond settlement to the south, and the point came to be known as Richmond Landing.

The Uncontrolled major channel of the Chaudiere was too fierce for the establishment of mills. Philemon Wright had built his industries on the north shore. The quieter southerly channels were largely under the control of captain John Lebreton and Judge Levius Sherwood, who would not permit mills to be establish there for some time. However, Daniel Mc-Lachlin was able to build a stone grist mill on government land by the southerly channel.

The early industrial development in the Bytown area occurred at the Rideau falls, beginning about 1831. Sherwood finally relented in 1842, and permitted the stone flour and grist mill of Philip Thompson and the wooden sawmill of John Perkins to be built on the southerly channel at the Chaudiere.

Another early development at the Chaudiere concerned the transportation of raw materials downriver past the obstacle of the rough water.

The squared timbers of red and white pine for the English market that were brought down the Ottawa in great rafts had to be run at great risk past the Chaudliere. Lt-Colonel By in 1827 designed and had constructed a crude timber slide that permitted the passage of single sticks, this was on the, south shore.

Ruggles Wright two years later built a private slide on the north or lower Canada shore that was wide enough to allow groups of timbers, made 
up into small units of about twenty pieces to pass. George Buchanan built a new, wide slide on the southerly channel in 1836, replacing By's earlier channel. The government of the United Province of Canada made a number of improvements at the Chaudiere Falls in 1854. One of these was the creation of a new slide, taking the business of timber transportation at this cataract out of the hands of private enterprise. This slide remained in action until 1908, when the last raft, a sentimental gesture on the part of John R. Booth on the occasion of the Quebec Tercentenary, passed down the river. The old channel still exists, but almost all of the timber works and other construction have long since gone.

The major work done by the government at the Chaudiere was the installation of wing dams and the building of flumes, to permit the hitherto untamed main cataract to be harnessed. Following on the heels of this development happened what has been called the American invasion, citizens of the States coming to Ottawa, not yet named the capital, to establish sawmills of the Chaudiere to cut Ottawa pine for the American market. Among these were Levi Young, J.J. Harris, H.F. Bronson, W. G. Perley and C.B. Pattee. Nathaniel S, Blasdell established his foundry and machine shop, where sawmill machinery and axes were made, at the Chaudiere Falls.

At first the sawmills were small, and their output was not great. As the demand grew, however, and new equipment became available, the production increased. From 1886 until the turn of the century the huge amount of some 300 million board feet of lumber was cut annually in the Ottawa area, and much of it was piled about the Chaudiere for a year to dry. Here it was loaded into canal and river barges. John R. Booth, from Waterloo, Quebec, became one of the great lumber entrepreneurs of the falls. The old mill which he acquired on Chaudiere island, that of A.H. Baldwin, has been preserved by Booth's successors. The E.B. Eddy Company; it lies at a much lower level than the present buildings. The Booth mill operated until the 1920 s, operations then gravitating toward the making of paper.

The reason for the Baldwin mill lying at such at low level is the fact that the Chaudiere was completely dammed in 1908, by the great crescent structure which stands across the falls today, raising the level of the water serving the mills there. This necessitated the building of a number of concrete 
retaining walls, or bulkheads. The old timber slide was protected for a time by the creation of a lock, but its opening was eventually sealed by a dam.

Beginning in 1885 a new use for the hydraulic power at the Chaudliere was found: the generation of electricity. In 1891 Thomas Ahearn and Warren Soper ran the first cars on the Ottawa electric street railway, using Power from their generators at the Chaudiere Falls. When they found that ice in zero weather would stop or slow the turbine, under certain conditions, thus interfering with the movement of public transportation, they built a steam generating plant for standby services. This high brick structure still stands on Middle Street, Victoria Island.

Lumber mills owners at the Chaudiere dumped a great deal of fill in the river, extending Richmond Landing over one hundred yards to the east-ward, to make an area where lumber could be piled. With the advent of the petroleum age, oil storage tanks were built on the point, served by river barges. The building of the oil pipeline from Montreal to the capital led to the establishment of an oil tank-farm to the south of the city; the tanks at Richmond Landing were removed in 1966.

The electro-chemical industry was once represented at the Chaudiere; the largest structure there today is a monument to the industrial genius of Thomas Leopold (Carbide) Willson. About 1894 he established a large factory on Victoria Island, a stone building which stands today. Electric power was used to ---- limestone and coal in the manufacture of calcium carbide. The latter chemical, in the presence of water, releases acetylene, once popular for illumination. Until not many years ago some railways cars were still illuminated with acetylene. It has also been used in navigation buoys. The carbide factory was one of the few buildings to survive the fire of 1900. It still stands. The hydro-electric plant is still in operation, forming part of the Ottawa Hydro-electric system. Another generating station on the Ontario side, that on Amelia Island is also part of the Ottawa system. The generators in these plants are of an old design.

In 1961 the national capital commission prepared elaborate plans for the exploitation of many historical structures and sites in the Capital Region. For the Chaudiere area the proposals were complex, involving development 
of the Richmond Landing peninsula, the possible reconstruction of the timber slide, preservation of the Thompson Mill, of which the stone shell remained, the development of a lookout on the downstream and Victoria island and the possible development of a display interpreting industrial history of the area in the Carbide Mill building. In addition, the picturesque aspect of the area was to be developed, particularly the north side of Victoria Island where there is a striking cleft spanned by an early flume. 